Rogério Cesar Serapião Silva

\title{
PROTEÇÃO DIFERENCIAL DE GERADORES SÍNCRONOS: $O$ uso de redes neurais artificiais para identificação e correção da saturação dos transformadores de corrente
}

Dissertação de Mestrado apresentada à Escola de Engenharia de São Carlos da Universidade de São Paulo, como parte dos requisitos para obtenção do título de Mestre em Ciências, Programa de Engenharia Elétrica.

Área de Concentração: Sistemas Elétricos de Potência.

Orientador: Prof. Tit. Denis Vinicius Coury

São Carlos

2012 

Ficha catalográfica preparada pela Seção de Tratamento da Informação do Serviço de Biblioteca - EESC/USP

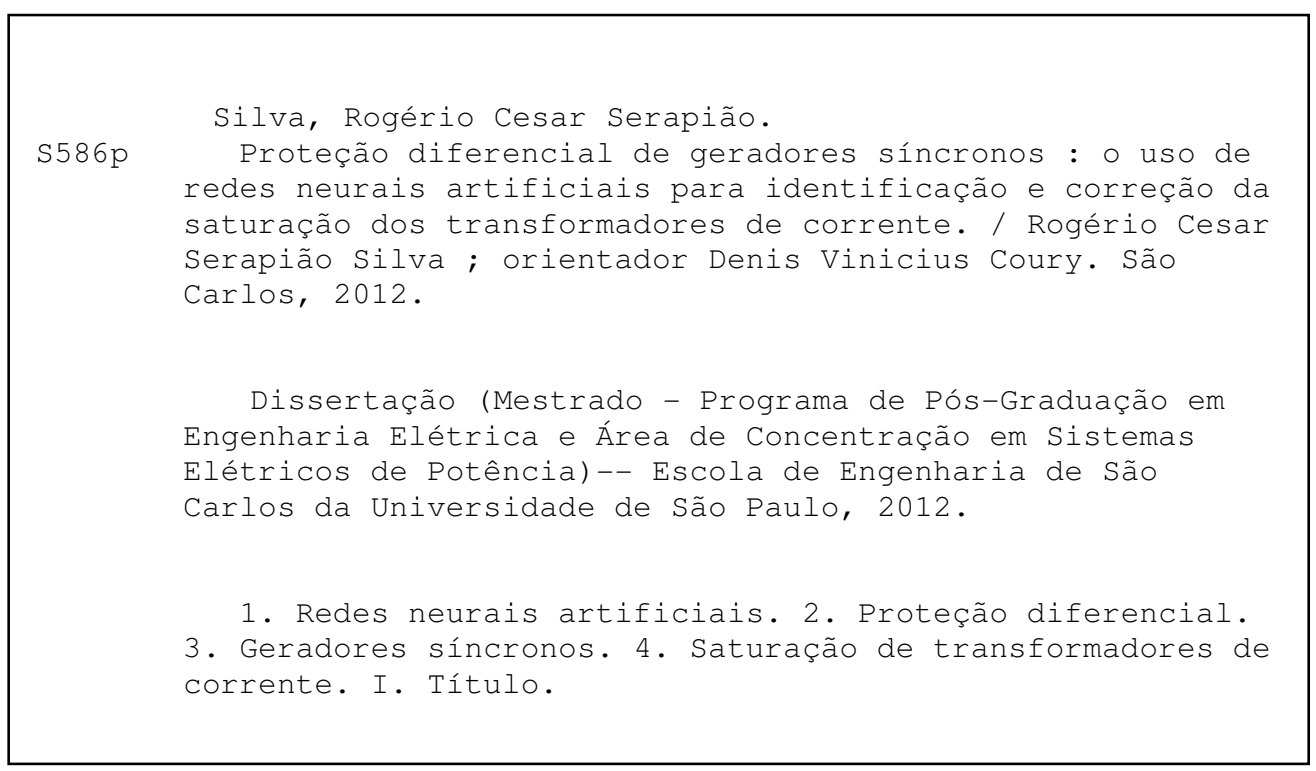




\section{FOLHA DE JULGAMENTO}

\section{Candidato: Engenheiro ROGÉRIO CESAR SERAPIÃO SILVA.}

Título da dissertação: "Proteção diferencial de geradores síncronos: o uso de redes neurais artificiais para identificação e correção da saturação dos transformadores de corrente".

Data da defesa: 09/03/2012

\section{Comissão Julgadora:}

Prof. Titular Denis Vinicius Coury (Orientador)

(Escola de Engenharia de São Carlos/EESC)

Prof. Dr. Ricardo Caneloi dos Santos

(Universidade Federal do ABC)

Prof. Dr. Mário Oleskovicz

(Escola de Engenharia de São Carlos/EESC)

\section{Resultado:}

APROVADO

Aprovado

Coordenador do Programa de Pós-Graduação em Engenharia Elétrica:

Prof. Titular Denis Vinicius Coury

Presidente da Comissão de Pós-Graduação:

Prof. Associado Paulo Cesar Lima Segantine 


\section{Agradecimentos}

Este trabalho de pesquisa teve a colaboração de diversas pessoas a quem gostaria de agradecer mesmo correndo o risco de esquecer algumas delas.

Agradecimentos especiais devem ser feitos a minha esposa Selma e filhas Karen e Carolina, pela compreensão e por todo apoio dado em momentos difíceis e que forneceram suporte em todas as fases de estudo pelas quais passei.

Ao meu pai por me ensinar a ter muita força e garra, mesmo quando nada funciona, e por sempre ter me instigado a ir além. À minha mãe, pelo carinho e por sempre estar ao meu lado quando mais precisei.

Ainda devo agradecer, de forma geral, a todas estas pessoas, pois, contribuíram para a formação do bem mais precioso que possuo, meu conhecimento, em especial aos meus Gerentes da CPFL, Wilson Geraldo Gonçalves de Aguiar (in memorian), Walter Henrique Bernardelli, Pedro Paulo Derrico, Aparecida Maria Rangel Ferreira, além de a todos os colegas de trabalho que sempre me apoiaram nos momentos difíceis.

Seguindo uma linha cronológica, gostaria de agradecer aos amigos que fiz na graduação e que continuam ao meu lado. Dentre estas pessoas, devo ressaltar o Eng. Carlos Alberto Tadeu dos Reis Santos, que me ajudou muito no aprendizado de projeto elétrico e, também, por sempre tentar me mostrar que os problemas podem ser visualizados por ângulos diferentes.

Aos professores de graduação da FEB/Barretos, instituição na qual tive o privilégio de adquirir toda base de conhecimentos acadêmicos. Em especial, ao professor Ms. Nazin Chubaci, pelo auxílio dado desde o período da graduação até hoje. Ao professor Walter Henrique Bernardelli pelos grandiosos ensinamentos.

Aos amigos de graduação, Eng. Reginaldo Leopoldino, Eng. Marcio Aparecido da Silva, Eng. Fabio Cesar Remiro pelos seis anos bem vividos e que, mesmo distantes, ainda mantêm contato.

Agradeço, também, aos amigos da CPFL Eng. Alexandre José Pires, Eng. Marcos Cezar Vilela, Eng. Paulo José China e à Eng ${ }^{\mathrm{a}}$ Cíntia Beatriz.

Agradeço, ainda, aos amigos da USP, Eng. Ricardo de Souza Fernandes e ao Eng. Renato Machado Monaro, pelo companheirismo e amizade e pela grandiosa ajuda neste trabalho de pesquisa. 
Ao Prof. Dr. Mário Oleskovicz, por estar sempre ao meu lado, auxiliando na elaboração dos temas realizados nos seminários referentes às disciplinas Qualidade da Energia Elétrica e Proteção de Sistemas Elétricos de Potência.

Ao Prof. Dr. Denis Vinicius Coury que, desde o começo, sempre deu liberdade para pesquisar assuntos que fossem de meu interesse, pela grandiosa contribuição para a conclusão deste trabalho e pela confiança depositada neste estudo. Agradeço, ainda, pela orientação acadêmica e pelos ensinamentos trabalhados nas disciplinas.

Ao Eng. Murilo da Silva, pela grandiosa ajuda neste trabalho de pesquisa.

Aos colegas dos demais laboratórios: Eng. Daniel Falconi, Eng. Silvio Albuquerque, Eng. Adriano e muitos outros.

Aos funcionários da Universidade de São Paulo (USP/EESC/SEL), em especial, as secretárias de Pós-Graduação, Marisa Fortulan e Rosane Aranda.

À Escola de Engenharia de São Carlos (EESC/USP) que acolheu este trabalho, por meio da destinação de espaço físico e apoio administrativo, traduzindo assim, a grandiosidade da instituição e sua visão de futuro. 
"O vento sopra onde quer, ouves a sua voz, mas não sabes de onde vem, nem prá onde vai; assim é todo aquele que é nascido do Espírito". Amém."

João 3,8 


\section{RESUMO}

SILVA, R. C. S. (2012). Proteção Diferencial de Geradores Síncronos: o uso de redes neurais artificiais para identificação e correção da saturação dos transformadores de corrente. 109 f. Dissertação (Mestrado) - Escola de Engenharia de São Carlos, Universidade de São Paulo, 2012.

Este trabalho tem como objetivo apresentar um algoritmo de proteção diferencial de geradores baseado em Redes Neurais Artificiais (RNAs), que seja robusto e confiável em situações onde os algoritmos padrões podem apresentar dificuldades, como no caso, da saturação de TCs. O algoritmo desenvolvido é constituído por dois módulos principais: a) um módulo de detecção da saturação dos transformadores de corrente (TCs) empregados na proteção diferencial de geradores e; b) um módulo de correção das formas de onda distorcidas devido à saturação dos TCs. Os módulos utilizam RNAs para detectar e corrigir situações onde haja saturação dos TCs, a fim de evitar a má operação da proteção diferencial. $O$ algoritmo foi desenvolvido em ambiente Matlab e validado com base nos dados da modelagem e simulações de um sistema elétrico utilizando o software Alternative Transients Program (ATP).

Palavras Chave: Proteção diferencial. Redes neurais artificiais. Geradores síncronos. Saturação dos transformadores de corrente. 


\begin{abstract}
SILVA, R. C. S. (2012). Differential protection for synchronous generators: the use of artificial neural networks for identification and correction of the saturation of current transformers. 109 f. Dissertação (Mestrado) - Escola de Engenharia de São Carlos, Universidade de São Paulo, 2012.
\end{abstract}

This work has as objective to present an algorithm for differential protection of generators based on Artificial Neural Networks (ANN), which is robust and reliable in situations where standard algorithms fail, as in the case of Current Transformer (CT) saturation. The algorithm developed consists of two main modules: a) a module to detect saturation of CTs used in differential protection of generators and; b) module to correct distorted waveforms due to CT saturation. The modules use ANNs to detect and correct situations where there is saturation of CTs in order to avoid misoperation of the differential protection. The algorithm was developed using Matlab software and validated based on data modeling and simulations of a power system using the Alternative Transients Program (ATP) software.

Keywords: Differential protection. Artificial neural networks. Power generator. Current transformer saturation. 


\section{LISTA DE ABREVIATURAS E SIGLAS}

\begin{tabular}{|c|c|}
\hline$A / D$ & Analógico/Digital \\
\hline$A N N$ & Artificial Neural Network \\
\hline ATP & Alternative Transients Program \\
\hline$B P A$ & Bonneville Power Administration \\
\hline EMTP & Electromagnetic Transient Program \\
\hline$E P R I$ & Eletric Power Research Institute \\
\hline MLP & Multi Layer Perceptron \\
\hline RNA & Rede Neural Artificial \\
\hline IEC & International Electrotechnical Commission \\
\hline IEEE & Institute of Electrical and Electronics Engineers \\
\hline$R B F$ & Radial Basis Function \\
\hline TC & Transformador de Corrente \\
\hline EQM & Erro Quadrático Médio \\
\hline LEC & Leuven EMTP Center \\
\hline SEP & Sistema Elétrico de Potência \\
\hline CPFL & Companhia Paulista de Força e Luz \\
\hline SEs & Subestações \\
\hline $\mathrm{TP}$ & Transformador de Potencial \\
\hline $\mathrm{TI}$ & Transformador de Instrumento \\
\hline RTC & Relação de Transformação do TC \\
\hline RTE & Relação de Transformação do Equipamento \\
\hline ANSI & American National Standart Institute \\
\hline$A S A$ & American National Association \\
\hline ABNT & Associação Brasileira de Normas Técnicas \\
\hline
\end{tabular}


$A C$

$D C$

RMS

TDNN

ANEEL

CEMIG

LT

GT

LSEE
Alternated Current

Direct Current

Root Mean Square

Time Delay Neural Networks

Agência Nacional de Energia Elétrica

Companhia Energética de Minas Gerais

Linha de Transmissão

Gerador-Transformador

Laboratório de Sistemas de Energia Elétrica 


\section{LISTA DE FIGURAS}

Figura 1.1 - Sistema elétrico de potência ………….........................................

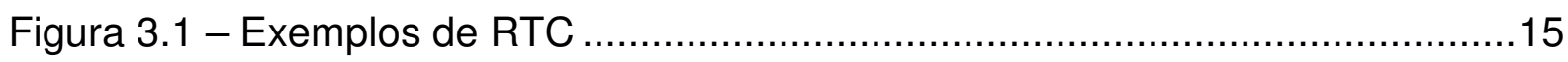

Figura 3.2 - Relação única x relação múltipla........................................................15

Figura 3.3 - Curva de excitação do TC ............................................................17

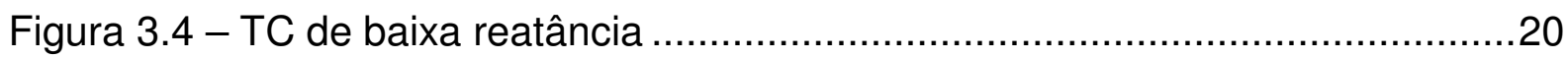

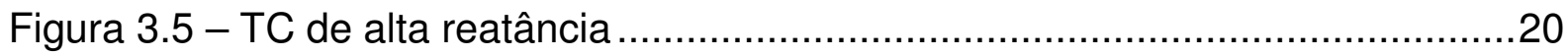

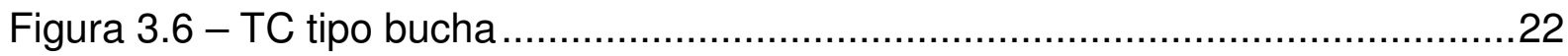

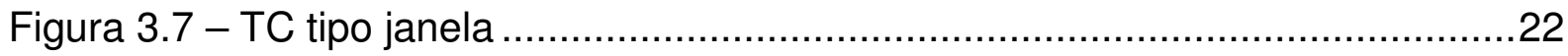

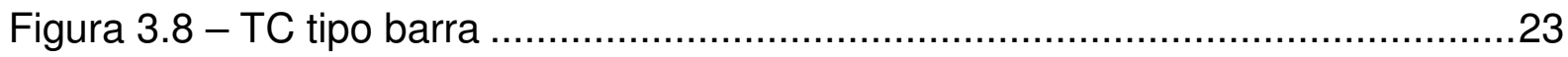

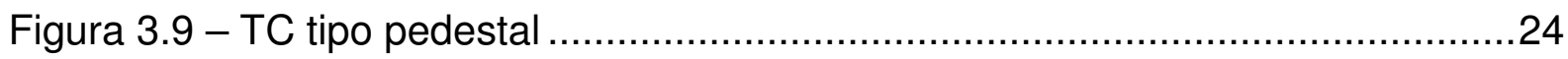

Figura 3.10 - Corrente e fluxo do TC em saturação …………………................27

Figura 3.11 - B (Fluxo Magnético) H (Força Magnética) com histerese ...................28

Figura 3.12 - B (Fluxo Magnético) H (Força Magnética) sem histerese ...................29

Figura 3.13 - Corrente e fluxo do TC com pequena saturação CA ………………...30

Figura 3.14 - Corrente e fluxo do TC com moderada saturação CA..........................31

Figura 3.15 - Fluxo do núcleo com as componentes CA e CC ..............................32

Figura 3.16 - Saída do TC com saturação CC....................................................32

Figura 4.1 - Máquina síncrona operando como gerador.........................................38

Figura 4.2 - Principais sub-sistemas de um relé computadorizado ..........................44

Figura 4.3 - Proteção diferencial dos enrolamentos da máquina síncrona ................45

Figura 4.4 - Proteção diferencial tipo autobalanço ................................................46

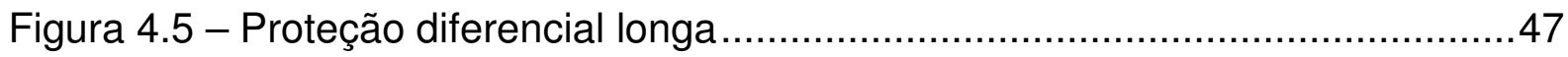

Figura 4.6 - Falta externa ao relé diferencial .....................................................48

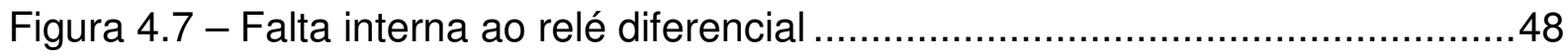

Figura 4.8 - Proteção diferencial percentual ........................................................49 
Figura 4.9 - Curva de ajuste para proteção diferencial percentual.......................... 50

Figura 4.10 - Circuito equivalente do transformador de corrente ........................... 51

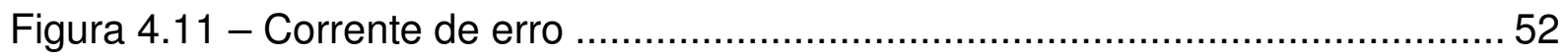

Figura 4.12 - Proteção de um gerador síncrono e transformador elevador de uma usina hidrelétrica .............................................................................. 54

Figura 5.1 - Representação do neurônio artificial modelado por McCulloch e Pitts comparado a um neurônio biológico. ........................................................ 57

Figura 5.2 - Representação da função de ativação do tipo degrau bipolar.............. 60

Figura 5.3 - Representação da função de ativação do tipo degrau.......................... 61

Figura 5.4 - Ilustração da função de ativação do tipo linear.................................... 61

Figura 5.5 - Representação gráfica da função de ativação do tipo tangente

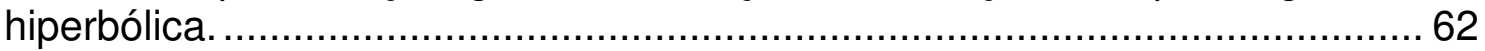

Figura 5.6 - Ilustração da função de ativação do tipo logística (sigmóide)................ 62

Figura 5.7 - Representação gráfica da função de ativação do tipo rampa................ 63

Figura 5.8 - Ilustração da função de ativação de base radial (gaussiana)............... 63

Figura 5.9 - Arquitetura de uma rede neural do tipo MLP .................................... 64

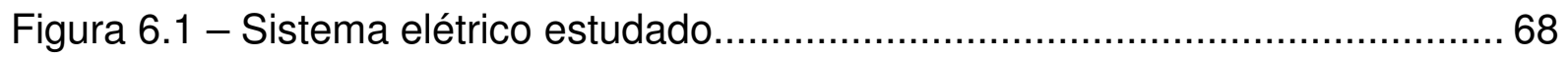

Figura 6.2 - Sistema elétrico real simulando uma falta interna ao gerador. .............. 70

Figura 6.3 - Sistema elétrico simulado no ATP simulando uma falta interna ao

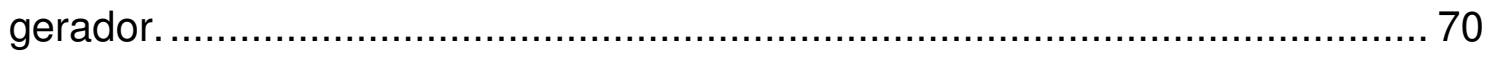

Figura 6.4 - Sistema elétrico real simulando uma falta externa ao gerador. ............. 71

Figura 6.5 - Sistema elétrico simulado no ATP simulando uma falta externa ao

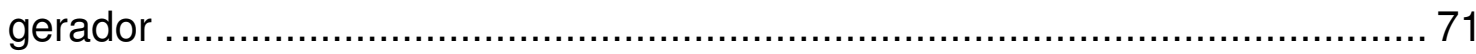

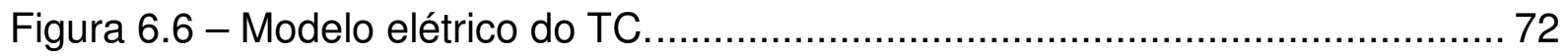

Figura 6.7 - Curva de magnetização do TC. ………………………………..... 73

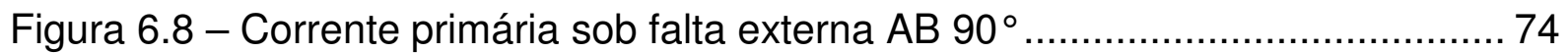

Figura 6.9 - Corrente secundária sob falta externa $A B 180^{\circ} \mathrm{com}$ saturação do

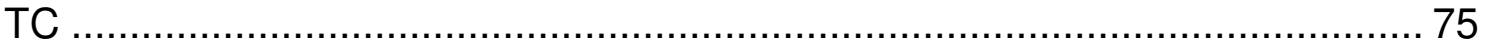

Figura 7.1 - Arquitetura da rede neural detectora ............................................. 79

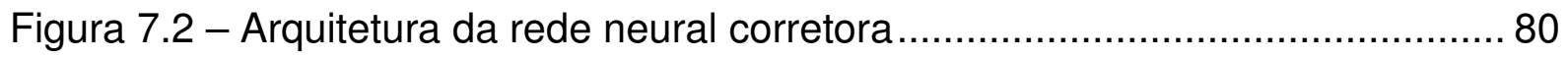


Figura 7.3 - Fluxograma do algoritmo do rele diferencial ................................82

Figura 7.4 - Exemplo do janelamento do sinal.......................................... 83

Figura 7.5 - Curva de ajuste para proteção diferencial .....................................86

Figura 7.6 - Resposta da rede neural detectora falta externa $A B\left(180^{\circ} \ldots \ldots \ldots \ldots \ldots \ldots . . . . .17\right.$

Figura 7.7 - Resposta da rede neural detectora falta externa $A B 360^{\circ} \ldots \ldots \ldots \ldots \ldots \ldots . . . . . . .88$

Figura 7.8 - Resposta da rede neural detectora falta interna ABC $180^{\circ} \ldots \ldots \ldots \ldots \ldots . . . . . . .89$

Figura 7.9 - Resposta da rede neural corretora falta externa fase $A B\left(80^{\circ} \ldots \ldots \ldots . . .91\right.$

Figura 7.10 - Resposta da rede neural corretora falta externa AT $270^{\circ} \ldots \ldots \ldots \ldots \ldots . . . . . . .92$

Figura 7.11 - Resposta da rede neural corretora falta externa ABT $90^{\circ} \ldots \ldots \ldots \ldots \ldots . . . . . . .93$

Figura 7.12 - Saída do algoritmo de detecção e correção falta externa ABC $270^{\circ}$

Figura 7.13 - Saída do algoritmo de detecção e correção falta externa ABT 90 ....94

Figura 7.14 - Saída do algoritmo de detecção e correção falta interna ABC $180^{\circ}$. 


\section{LISTA DE TABELAS}

Tabela 3.1 - Cargas nominais definidas pela Norma ABNT (NBR 6856/1992) ........ 18

Tabela 3.2 - Valores obtidos ao se aplicar tensão nos terminais secundários do TC

Tabela 3.3 - Exemplos de especificação de TCs ………….................................. 21

Tabela 4.1 - Indicações-base para proteção de geradores (critérios de potência e de tipo da turbina).

Tabela 4.2 - Levantamento estatístico e percentual de falhas dos equipamentos de uma usina hidrelétrica.

Tabela 7.1 - Resultado dos testes antes e após o uso da RNA 96 


\section{SUMÁRIO}

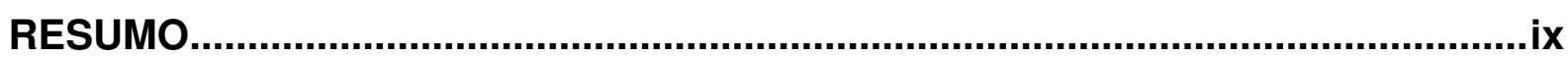

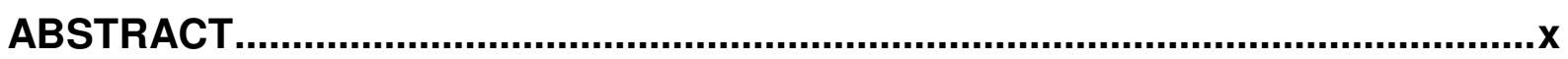

LISTA DE ABREVIATURAS E SIGLAS .........................................................

LISTA DE FIGURAS ................................................................................... xiii

LISTA DE TABELAS ...................................................................................... xvi

1 INTRODUÇÃO .............................................................................................

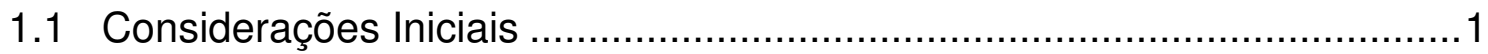

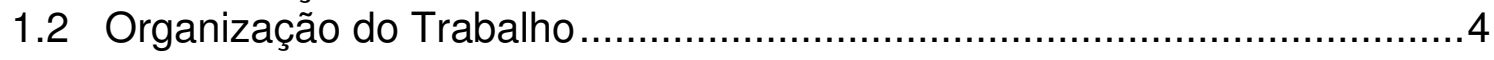

2 REVISÃO BIBLIOGRÁFICA.....................................................................

2.1 Reconstrução de Sinais Distorcidos e Detecção da Saturação dos TCs ....7

2.2 Proteção de Geradores utilizando ferramentas inteligentes ....................10

3 TRANSFORMADORES DE CORRENTE E A SATURAÇÃO ..........................13

3.1 Transformadores de Instrumentos .................................................... 13

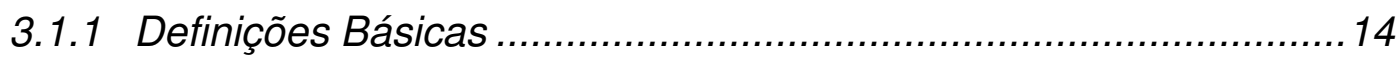

3.2 Transformadores de Corrente (TCs) ............................................. 14

3.2.1 Curva de Excitação e Classificação dos Transformadores de

Corrente .................................................................................... 16

3.2.2 TC de Medição x TC de Proteção .............................................19

3.2.3 Tipos de TCs mais utilizados..............................................21

3.3 A Saturação dos Transformadores de Corrente.....................................24

3.3.1 Transformadores de Corrente e Replicação de Correntes de Falta30

4 PROTEÇÃO DE GERADORES .................................................................35

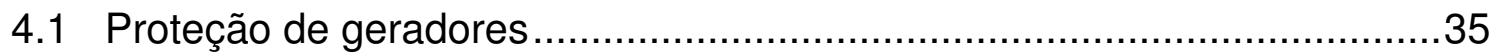

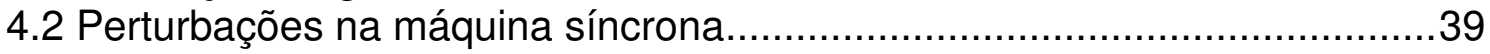

4.3 A Proteção do gerador síncrono...........................................................41

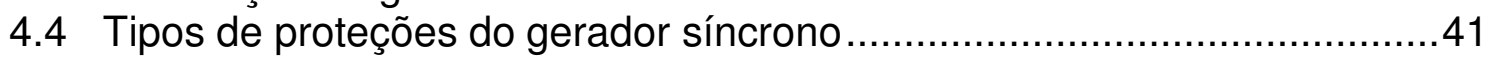

4.5 Proteção digital............................................................................... 42

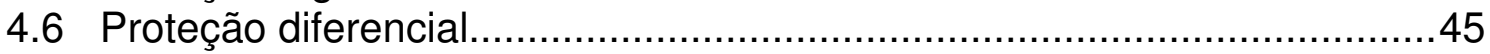

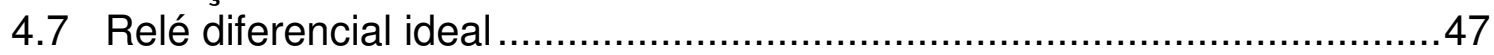

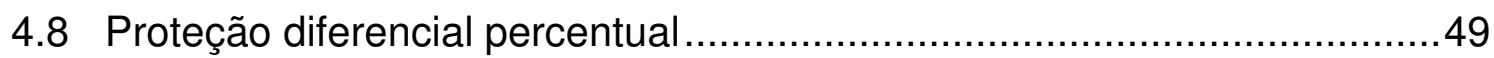

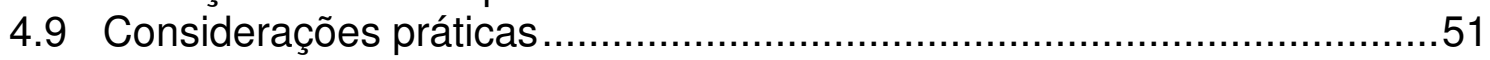

5 REDES NEURAIS ARTIFICIAIS............................................................56

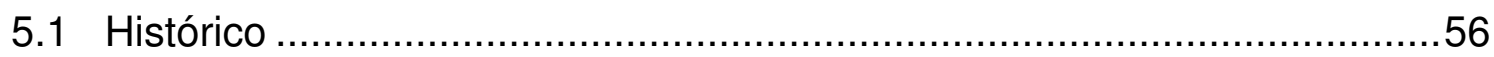

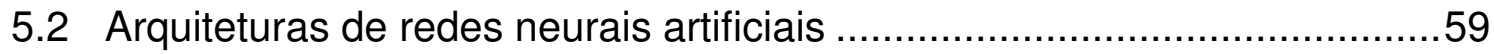

5.2.1 Perceptron de múltiplas camadas .........................................63

5.2.2 Treinamento Backpropagation..............................................6 65

5.2.3 Treinamento Levenberg-Marquardt ...................................6 65

6 O SISTEMA ELÉTRICO EM ANÁLISE ......................................................67

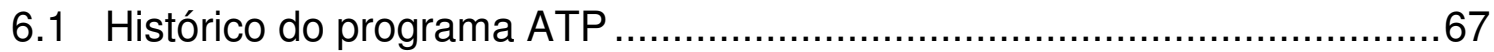

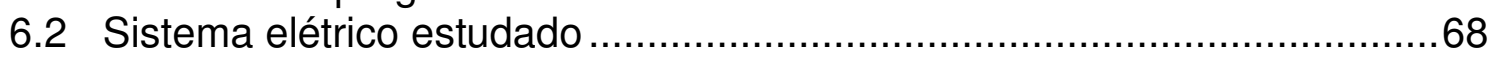


7 ALGORITMO APLICADO À PROTEÇÃO DIFERENCIAL DO GERADOR..... 77

7.1 Processo de definição, treinamento e avaliação das RNAs ..................... 77

7.1.1 Rede neural detectora........................................................ 78

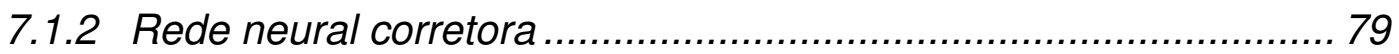

7.2 Fluxograma do algoritmo do rele diferencial ........................................ 81

7.2.1 Entrada de dados............................................................... 83

7.2.2 A detecção e a correção da saturação do TC ................................. 84

7.2.3 Rede neural detectora.......................................................... 84

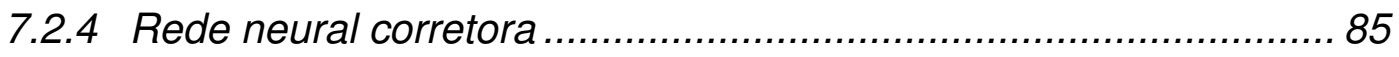

7.2.5 Cálculo da corrente diferencial................................................ 85

7.3 Resultados da aplicação de Redes Neurais na detecção e correção de sinais de TCs distorcidos pela saturação ............................................... 86

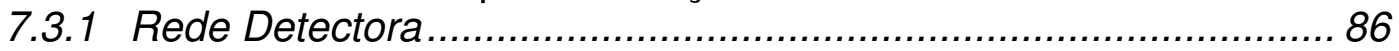

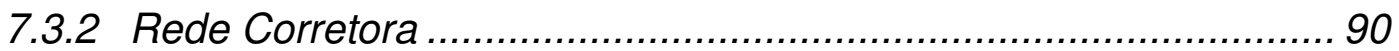

7.3.3 Algoritmo de Correção e Detecção ............................................. 93

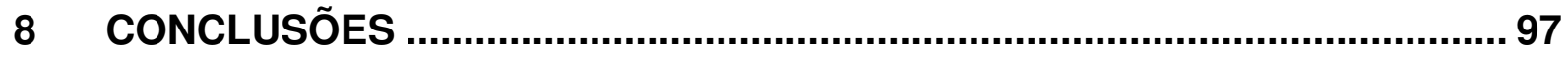

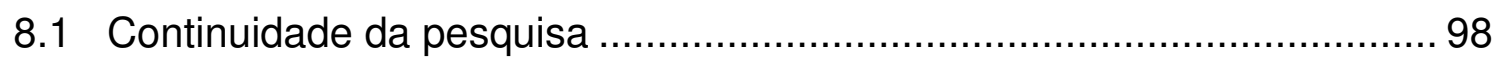

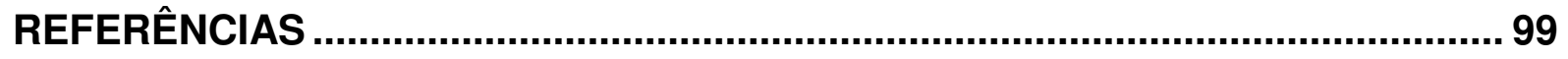

APÊNDICE A - Casos utilizados para treinamento e validação das RNAs .... 103

APÊNDICE B - Processo de treinamento da RNA detectora ............................. 105

APÊNDICE C - Processo de treinamento da RNA corretora .............................. 107 


\section{INTRODUÇÃO}

\subsection{Considerações Iniciais}

$\mathrm{Na}$ história da sociedade, a energia elétrica, desde a sua descoberta, sempre ocupou lugar de destaque, tendo em vista a dependência da qualidade de vida, do progresso econômico, da qualidade do produto e dos serviços relacionados à energia elétrica, que por sua vez dependem de como as empresas de eletricidade projetam, operam e mantêm o Sistema Elétrico de Potência (SEP).

A energia elétrica proporciona à sociedade, trabalho, produtividade e desenvolvimento, e aos seus cidadãos conforto, comodidade, bem-estar e praticidade, o que torna a sociedade moderna cada vez mais dependente de seu fornecimento e mais suscetível às falhas do sistema elétrico. Em contrapartida esta dependência dos usuários vem se traduzindo em exigências por melhor qualidade de serviço e produto.

A energia elétrica é uma das mais nobres formas de energia secundária. A sua facilidade de geração, transporte, distribuição e utilização, com as conseqüentes transformações em outras formas de energia, atribuem à eletricidade uma característica de universalização, disseminando o seu uso pela humanidade. No mundo de hoje, eletricidade, como o alimento e a moradia, é um direito humano básico. Eletricidade é a forma dominante de energia moderna para telecomunicações, tecnologia da informação, e produção de bens e serviços.

O crescimento da população mundial e da economia nos países em desenvolvimento implicam, necessariamente, no aumento do consumo de energia.

No entanto, a produção de energia deve seguir os conceitos de desenvolvimento sustentável e de responsabilidade ambiental.

O SEP possui três etapas muito importantes, onde podemos citar a geração, transmissão e distribuição, até a medição do cliente. Na geração temos a casa de máquinas onde a energia é gerada de 2 à $14 \mathrm{kV}$, depois é elevada essa tensão na subestação elevadora em tensões usuais de $34,5 \mathrm{kV}, 69 \mathrm{kV}, 138 \mathrm{kV}, 230 \mathrm{kV}, 440 \mathrm{kV}$, $500 \mathrm{kV}$ e $750 \mathrm{kV}$, onde após é transmitida até os grandes centros de consumo através das linhas de transmissão, tendo as suas tensões rebaixadas para as tensões 
usuais de $11,4 \mathrm{kV}, 13,2 \mathrm{kV}, 13,8 \mathrm{kV}$ e $23 \mathrm{kV}$ através da subestação abaixadora e novamente as tensões são rebaixadas através dos transformadores de distribuição para o consumo dos clientes residenciais, comerciais, industriais e rurais.

Por intermédio da Figura 1.1, podem ser verificadas, simbolicamente, todas as etapas do SEP que foram descritas anteriormente.

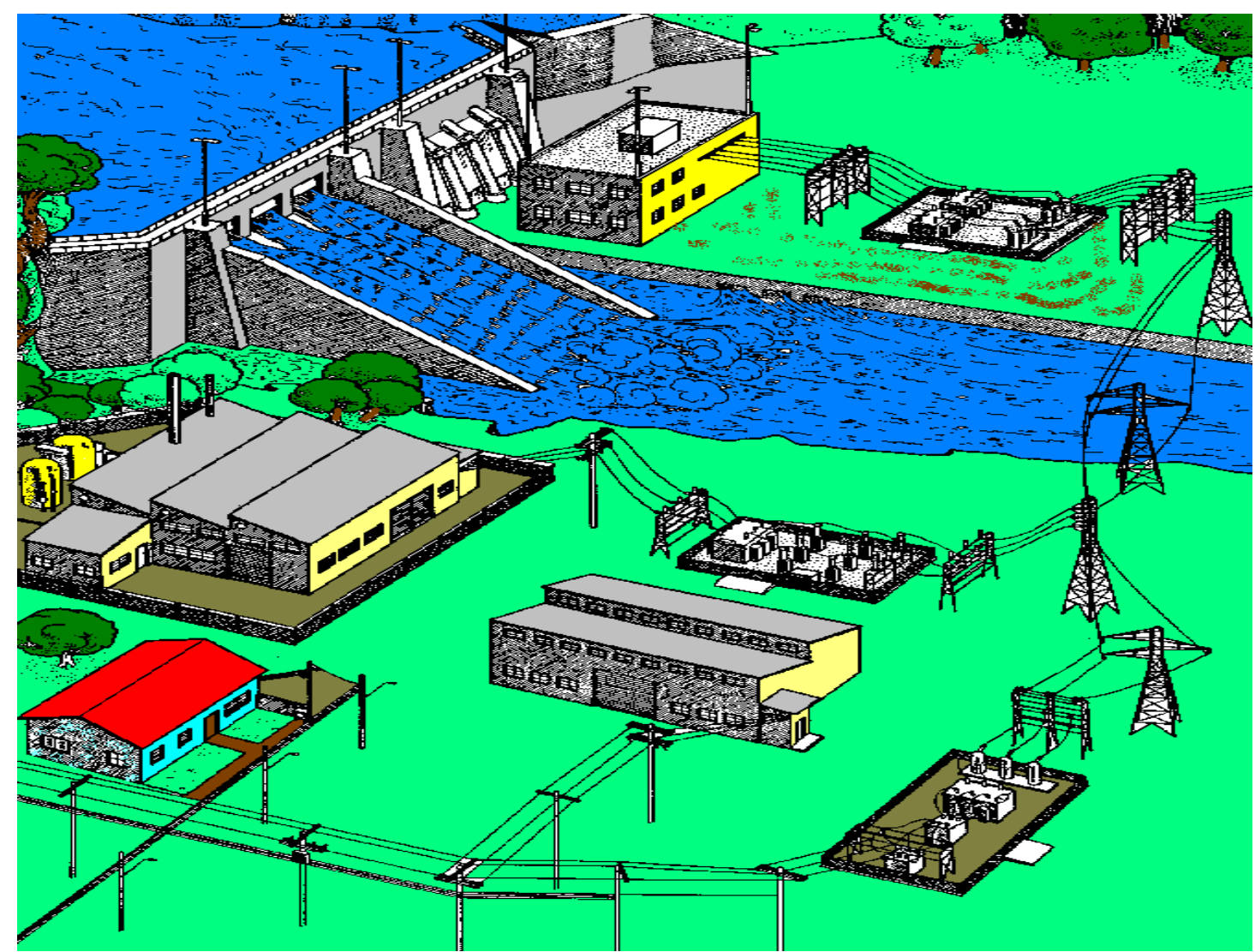

Figura 1.1 - Sistema elétrico de potência

Fonte:(Companhia Paulista de Força e Luz (CPFL), 2010)

Os SEPs são constituídos por uma diversidade de equipamentos, sendo que alguns deles possuem alto custo associado tanto para aquisição quanto para manutenção. Os geradores síncronos encaixam-se nessa categoria de equipamentos.

Geradores síncronos são de grande importância para o fornecimento de energia elétrica, assim, técnicas que realizem sua proteção encontram-se em constante desenvolvimento, pois esses geradores estão sujeitos a vários tipos de faltas. Como resultado dessas faltas, observa-se o aparecimento de altas correntes de curto circuito, necessitando, portanto, de proteção que consiga atuar 
rapidamente, isolando o gerador da rede elétrica quase que instantaneamente para que maiores danos sejam evitados.

Dentre as metodologias encontradas para a proteção de geradores síncronos, destacam-se os relés de proteção diferencial (eletromecânicos e digitais) - foco deste trabalho - responsável por comparar os valores das correntes da entrada e da saída para cada fase do estator, a fim de detectar faltas internas e, assim, realizar a proteção no momento de sua ocorrência.

Os SEPs tem crescido em complexidade e tamanho, devido à expansão da capacidade de geração e da interconexão do sistema, e consequentemente, observa-se o aumento dos níveis de curto-circuito.

O aumento da complexidade do sistema exige o refinamento da proteção de modo a garantir a confiabilidade e estabilidade do mesmo. Desta maneira os relés de proteção assumem cada vez mais importância no SEP, pois eles devem isolar as faltas com precisão o mais rápido possível (Coury et al., 2007).

Para tanto é necessária a reprodução precisa da corrente e/ ou tensão. A alimentação dos relés com os sinais de corrente faz-se por meio do uso dos TCs, os quais têm como função rebaixar a magnitude da corrente elétrica a níveis compatíveis com os relés. Entretanto, os TCs, devido as suas características construtivas, estão sujeitos à saturação em condições de correntes elevadas, o que se observa nos casos de faltas severas, levando à reprodução errônea da corrente medida.

Essa reprodução errônea da corrente medida, causada pela saturação dos TCs prejudica a proteção diferencial, sendo esse aspecto abordado e aprofundado no presente estudo.

Dado o contexto anterior, estabeleceu-se como objetivo deste trabalho, desenvolver um algoritmo baseado em RNA que auxilie no processo de proteção de geradores síncronos. O algoritmo apresentará como principais características: a) detecção da saturação dos TCs empregados na proteção diferencial dos geradores; b) correção das formas de ondas distorcidas devido à saturação dos TCs, pois tal saturação pode acarretar má operação da proteção. 


\subsection{Organização do Trabalho}

O trabalho em questão é estruturado da seguinte forma:

$\mathrm{Na}$ introdução, pontua-se a importância dos Sistemas Elétricos de Potência (SEP) e sua proteção dentro do contexto nacional. Neste capítulo, são delineados 0 escopo, a motivação e os objetivos deste trabalho.

No capítulo 2, encontra-se a síntese da pesquisa bibliográfica, com enfoque na área de proteção diferencial de geradores síncronos, envolvendo os mecanismos de prevenção contra problemas nos dispositivos do sistema, como os TCs. Outro aspecto importante abordado é a utilização de ferramentas inteligentes para melhorar o sistema de proteção, como a aplicação de Redes Neurais Artificiais (RNAs) para a reconstrução de sinais distorcidos provenientes da saturação dos TCs.

No Capítulo 3, são destacados os TCs de medição e proteção, abrangendo a diferença entre eles e os tipos de TCs existentes, a curva de excitação e a classificação dos TCs, exemplos de especificação de TCs, a saturação dos TCs e replicação das correntes de falta.

No Capítulo 4, são apresentados de forma sucinta os conceitos e filosofias sobre a proteção diferencial de geradores, partindo da proteção eletromecânica até a digital. São abordadas também considerações práticas sobre a proteção diferencial.

No Capítulo 5, enfoca-se o conceito geral das redes neurais artificiais (RNAs) e seu surgimento, ou seja, a história da arte sobre essa ferramenta inteligente, suas principais aplicações e sua importância. São abordadas também as arquiteturas de RNAs e as funções de ativação mais utilizadas.

No Capítulo 6, é descrito detalhadamente o sistema elétrico estudado e sua modelagem por meio do programa ATP, utilizado neste trabalho com a finalidade de gerar os dados para a etapa de treinamento, validação e teste da RNA. Neste capítulo, também é apresentada a metodologia empregada para a identificação e correção dos sinais provenientes de TCs saturados.

No Capítulo 7, aborda-se o algoritmo desenvolvido para a proteção diferencial do gerador síncrono e todas as etapas que o compõem. São apresentados os resultados experimentais alcançados pelo algoritmo e a eficiência 
da detecção e correção dos sinais de corrente provenientes de TCs saturados utilizando-se RNAs.

Finalmente, no Capítulo 8, são discutidos os resultados alcançados pelo algoritmo proposto e apresentadas as conclusões finais e propostas de trabalhos futuros. 


\section{REVISÃO BIBLIOGRÁFICA}

Neste capítulo, apresentam-se os aspectos-chave de estudos do período de 1990 a 2011, referente a trabalhos relacionados à proteção diferencial de geradores síncronos. Nesse sentido, encontra-se um número significativo de publicações em revistas especializadas, anais de conferências e artigos sobre o tema em pauta, envolvendo a proteção do gerador em si e os mecanismos de prevenção contra problemas nos dispositivos transdutores do sistema, como os TCs.

Outros dois aspectos importantes abordados por esses trabalhos são a tentativa de reconstrução dos sinais distorcidos pelos TCs, utilizando RNAs, e a análise de ferramentas inteligentes para melhorar o sistema de proteção, como a aplicação de RNAs em certas funções auxiliares, fornecendo maior rapidez, confiabilidade e precisão ao conjunto de dados.

\subsection{Reconstrução de Sinais Distorcidos e Detecção da Saturação dos TCs}

Alguns trabalhos têm sido realizados na tentativa da reconstrução de sinais distorcidos pelos TCs utilizando Redes Neurais Artificiais.

O trabalho apresentado pelos autores Mikrut e Witek (1989) e Hosemann e Steigerwald (1993) tratam do fenômeno da saturação dos TCs que foram reportados no passado e os critérios especiais adotados para a implementação das propostas. A maioria dos algoritmos propostos para este tipo de proteção usava critérios especiais para detectar a saturação. A utilização destes requeria um atraso na operação dos relés para evitar operações incorretas.

Hosemann e Steigerwald (1993), criaram um novo método digital para a detecção rápida e confiável da saturação de um único TC quando submetido a diversos tipos de falta. O princípio de funcionamento é independente do número de fases envolvidas no curto circuito e independente das propriedades magnéticas dos TCs. 
A metodologia baseia-se no uso das componentes modais positivas ( $\alpha$ ) e negativas ( $\beta$ ) para o cálculo da detecção da saturação do sinal. No estado sem saturação, suas trajetórias são círculos. O desvio desta trajetória padrão caracteriza o início da saturação do TC; o qual pode ser detectado em um tempo mínimo de 3 milissegundos (ms). O resultado de uma rápida detecção da saturação do TC leva a um ajuste da proteção diferencial com maior precisão e sensibilidade quando comparado aos dispositivos conhecidos. Isto garante uma operação confiável mesmo em caso de curto circuito com correntes de curto circuito menores. O novo detector de saturação modal é ideal para a proteção diferencial de linhas, bem como barramentos e arranjos de outros circuitos.

Segundo (Barnett e Chadwick (1993)), se a característica da saturação do TC é conhecida, uma estimativa da corrente do primário na situação em que o TC satura pode ser encontrada, assumindo-se carga resistiva. Porém, a maioria das correntes de falta não terá a característica simétrica necessária para essa estimativa simplificada. Dependendo da impedância da linha e do ângulo de falta, a corrente de falta terá um decaimento exponencial.

Kang, Park e Aggarwall (1997), mostraram algoritmos para estimar a corrente secundária correspondente à relação do TC sob saturação, usando a curva "fluxo versus corrente". Os resultados da implementação em hardware dos algoritmos usando um processador digital de sinais são apresentados. A principal vantagem dos métodos é que eles podem melhorar a sensibilidade dos relés para faltas internas de baixa amplitude, maximizar a estabilidade dos relés para faltas externas e reduzir a seção requerida para o núcleo do TC.

Jamali et al. (1997) trataram da componente CC da corrente de falta, que é a principal causa de saturação do TC. A corrente de excitação do TC saturado depende do aumento no fluxo do núcleo que distorce a corrente secundária. A forma de onda corrompida da corrente pode causar operação errônea do dispositivo de proteção. $O$ artigo apresentou um novo algoritmo para compensar e evitar 0 problema descrito, adicionando a corrente de excitação calculada à corrente secundária medida.

Yu et al. (1999) e Cummins et al. (2000) apresentaram o uso de RNAs para corrigir distorções na forma de onda secundária do TC. A rede neural é treinada para obter uma função de transferência inversa dos TCs toroidais com núcleo de ferro, os quais são amplamente utilizados nos sistemas de proteção. A RNA fornece uma boa 
estimativa da corrente primária para um transformador saturado. A rede neural foi desenvolvida dispondo do software Matrix Laboratory (MATLAB) e treinada usando simulações do software ATP. Para manipular grandes quantidades de correntes de falta, usou-se uma técnica com dois conjuntos de coeficientes de rede neural, os quais lidam com diferentes variações de corrente. O algoritmo da RNA em questão foi implementado em um processador digital de sinais (DSP). A velocidade e precisão fornecidas mostraram-se satisfatórias para aplicações em tempo real. Ressalta-se que, no método proposto em Cummins, Yu e Kojovic (2001), realizou-se apenas a correção da saturação por RNAs, sendo que o algoritmo diferencial completo do relé não foi testado. Em Yu et al. (1999) e Yu et al. (2001), os métodos foram utilizados somente com dados de faltas que continham o fenômeno da saturação.

Monaro et al. (2010) abordaram no seu trabalho uma maneira de detectar e corrigir a saturação de TCs empregando uma RNA especialista na detecção da saturação e outra RNA dedicada à correção da corrente saturada. Este arranjo direciona a corrente corrigida pela RNA corretora somente quando é necessário, ou seja, quando é detectada a saturação do TC, sendo esta uma vantagem da técnica proposta pois a correção do sinal de corrente é aplicada somente quando é detectado à saturação do TC. Outra vantagem do método proposto é a carga computacional reduzida, decorrente dos baixos níveis de processamento das RNAs previamente treinadas, viabilizando sua aplicação em relés de proteção microprocessados. 


\subsection{Proteção de Geradores utilizando ferramentas inteligentes}

Megahed e Malik (1999), apresentam uma rede neural tipo Feed-Forward com o algoritmo de backpropagation, para a proteção diferencial de geradores síncronos, conseguindo tempos de detecção da ordem de $4 \mathrm{~ms}$. A rede neural é alimentada com uma corrente de campo e sinais de corrente em todas as três fases terminais no lado do neutro do gerador.

Taalab et al. (1999) apresentaram um esquema mais simples de proteção diferencial usando uma rede do tipo Time-Delay Neural Network (TDNM). Essa rede neural utiliza seis entradas que consistem na diferença e na média das correntes de entrada e saída dos enrolamentos do gerador, em que se pode perceber que o tempo de detecção da falta, neste caso, subiu para quase metade de um ciclo.

Halinka e Szewczyk (2004) ampliaram o esquema de Taalab et al. (1999) para uma proteção integral por sobrecorrentes do grupo gerador-transformador como um todo e que abrange faltas monofásicas e trifásicas entre o gerador, transformador e linhas de transmissão. Os autores utilizam, igualmente, redes neurais do tipo TDNN, mas não incluem a proteção diferencial.

Lu Yuping, Lai e Guoqing (2004) propõem uma nova técnica para aplicação da RNA para proteger a unidade gerador-transformador. Esta técnica combina a teoria da proteção convencional de gerador, desenvolvida em várias décadas, com a técnica inteligente da RNA.

No algoritmo em questão são utilizadas seis formas diferentes de entradas para apresentar as correntes de operação e restrição. Segundo os autores, utilizando-se deste principio é possível reduzir os efeitos negativos presentes nos sinais causados pelos períodos transitórios ou saturação dos TCs. Esta combinação promove uma abordagem efetiva para o desenvolvimento dos relés de proteção de alta performance e alta confiabilidade. $O$ algoritmo utiliza uma rede neural do tipo Multilayer Perceptoron (MLP) com o algoritmo de backpropagation e saída com 5 (cinco) patamares com caracterização de 5 (cinco) distúrbios diferentes (faltas internas graves, leves, faltas de energia transitórias, estado de saturação e faltas externas do sistema). Os resultados demonstraram que esta nova abordagem melhora o desempenho do relé significativamente. A segurança e confiabilidade das RNAs são significativas se comparadas com a teoria de proteção convencional. 
Kasztenny e Finney (2005) apresentaram um novo projeto do relé diferencial de gerador, em particular a função diferencial do estator, que inclui casos extremos de saturação dos TCs devido a elevadas correntes CA ou duradouras correntes CC. O algoritmo funciona com $1 / 2$ ciclo, incluindo uma resposta global do hardware do relé. A análise da resposta de uma função diferencial tradicional sob saturação do TC é incluída para fornecer definição de orientações para a missão futura dos relés.

Villada et al. (2006) propõe um novo sistema de proteção diferencial de geradores síncronos baseados em redes neurais artificiais com filtros de resposta finita ao impulso (FIRANN), seguindo os postulados de Haykin (1994). Estes tipos de redes neurais apresentam vantagens sobre as redes do tipo TDNN, pois, como elas não exigem pré-processamento dos sinais de entrada, apresentam velocidades de resposta superiores. As redes FIRANN foram treinadas para detectar e classificar faltas internas. Os padrões de treinamento são gerados por meio da simulação de faltas internas utilizando o programa Alternative Transient Program (ATP). Embora o ATP não possa modelar diretamente as faltas internas de um gerador, propõe-se uma nova metodologia para trabalhar com assimetrias internas no modelo da máquina síncrona do ATP. Por fim são mostrados os resultados experimentais de um modelo de faltas internas, a estrutura da rede neural, o método de treinamento e os testes da rede.

Rigotto, Batista e Alves (2010) apresentaram um trabalho sobre uma experiência da CEMIG na aplicação de uma função de proteção diferencial digital de geradores (87G) com detecção de saturação de TCs, encontrada no mercado. Os autores descrevem a atuação indevida dessa função para eventos externos como curto-circuito e manobra de blocos de carga. São apresentados os critérios de ajuste dessas funções, seu principio de funcionamento e a solução dada para o problema. $\mathrm{Na}$ análise do desempenho da função diferencial digital, ficou evidente que a lógica de detecção de saturação não atuou corretamente para os eventos observados, devido às baixas correntes de restrição, inferiores ao ajuste. A primeira solução adotada foi reduzir o ajuste deste parâmetro de 1,2 pu para 1,0 pu, sendo este último o menor valor permitido pela função 87G.

Hunt (2010) apresenta um novo projeto para proteção de geradores de pequeno porte que são comumente instalados para fornecer energia de emergência ou de espera para as instalações essenciais, como hospitais, centros de dados, centros de comunicações, e similares. Estes geradores são tipicamente a diesel com 
potência de 1 à 3 MVA, e são normalmente destinados a uso em aplicações para as instalações no nível de tensão entre $4 \mathrm{kV}$ à $15 \mathrm{kV}$. Esse artigo destaca as questões em torno da proteção diferencial do estator para pequenos geradores, o uso de TCs com uma classe de precisão mais baixa, baixa relação de espiras e relação de grandes cargas. Cada um desses fatores aumenta a probabilidade de ocorrer à saturação dos TCs. A seleção dos TCs de baixa classe de precisão e grandes cargas pode estar sendo baseada na economia, com pouca consideração para 0 bom funcionamento do elemento diferencial. $O$ fabricante de relés tem tomado medidas no projeto de algoritmos para melhorar a segurança da proteção diferencial do estator em relação a componente $\mathrm{CC}$ presente durante à saturação dos TCs.

No próximo capítulo, abordam-se aspectos sobre os TCs e a saturação, em que se discriminam os tipos de TCs, curva de excitação, diferenças entre TC de medição e proteção, finalizando com a saturação de corrente em que se aponta a replicação da corrente de falta. 


\section{TRANSFORMADORES DE CORRENTE E A SATURAÇÃO}

O objetivo deste capítulo é descrever sobre os Transformadores de Instrumentos (TI) e suas definições, bem como a descrição da curva de excitação e, ainda, a classificação dos tipos de TCs de acordo com a norma American National Standards Institute (ANSI) padrão C57.13 (Requirements For Instrument Transformers, 1993), fazendo uma abordagem entre as diferenças dos TCs de medição e proteção, os tipos de TCs mais utilizados e como ocorre o fenômeno da saturação nesses equipamentos, finalizando com a abrangência da replicação das correntes de falta.

\subsection{Transformadores de Instrumentos}

Segundo Araújo et al. (2005), com o objetivo de redução das perdas, devido às suas grandes extensões, o sistema elétrico de potência exige o uso de correntes e tensões cada vez mais elevadas. Para que sejam controlados e protegidos, estes sistemas utilizam instrumentos de medição e proteção que necessitam receber informações destas grandezas. Como é inviável, economicamente, o uso de instrumentos que meçam diretamente as tensões e correntes de linha, utilizam-se os transformadores de instrumento que possuem os seguintes objetivos:

- Alimentar o sistema de proteção e medição com tensão e corrente reduzidas, mas proporcionais às grandezas dos circuitos de força;

- Proporcionar isolamento entre o circuito de alta tensão e os instrumentos e, conseqüentemente, segurança pessoal;

- Padronizar a fabricação dos instrumentos.

Para a transformação dos valores de corrente e tensão do sistema de potência, são utilizados, respectivamente:

- O Transformador de Corrente (TC);

- O Transformador de Potencial (TP). 


\subsubsection{Definições Básicas}

De acordo com Filho (2005) em Manual de equipamentos elétricos, podem ser apresentadas algumas definições sobre os componentes que constituem 0 Transformador de Instrumento ( $\mathrm{TI})$, conforme abaixo:

- Circuito Primário - circuito conectado ao enrolamento primário do TI, onde se tem o verdadeiro valor da grandeza a ser transformada (circuito de força, geralmente um cabo, um barramento, etc..);

- Circuito Secundário - circuito conectado ao enrolamento secundário do $\mathrm{TI}$, onde se tem o valor proporcional da grandeza do circuito primário, composto por fiações, blocos terminais e instrumentos (amperímetros, voltímetros, relés, etc.);

- Carga do TI - impedância total do circuito secundário;

- Erro de Relação - diferença entre a relação de transformação medida e relação de transformação nominal;

- Classe de Exatidão - valor máximo do erro de relação expresso em porcentagem.

\subsection{Transformadores de Corrente (TCs)}

Os TCs são equipamentos que permitem aos instrumentos de medição e proteção funcionarem de forma adequada sem que haja a necessidade de possuírem correntes nominais de acordo com a corrente de carga do circuito ao qual estão ligados.

O enrolamento primário dos TCs é normalmente constituído por um reduzido número de espiras (N1) podendo ser até mesmo o próprio condutor ao qual o TC está conectado. $O$ enrolamento secundário possui um número elevado de espiras (N2) e é projetado para uma corrente nominal padronizada (1 ou $5 \mathrm{~A}$, por exemplo), sendo que, $1 \mathrm{~A}$ refere-se ao padrão europeu e $5 \mathrm{~A}$ ao padrão norte-americano, sendo a corrente primária nominal estabelecida de acordo com a ordem de grandeza da corrente do circuito a que o TC está ligado. Dessa forma, as relações mais comuns encontradas no mercado são: 2000-5A, 1200-5A, 600-5A, 300-5A e 200-5A. 
A Figura 3.1 apresenta dois TCs com diferentes Relações de Transformadores de Corrente (RTCs).

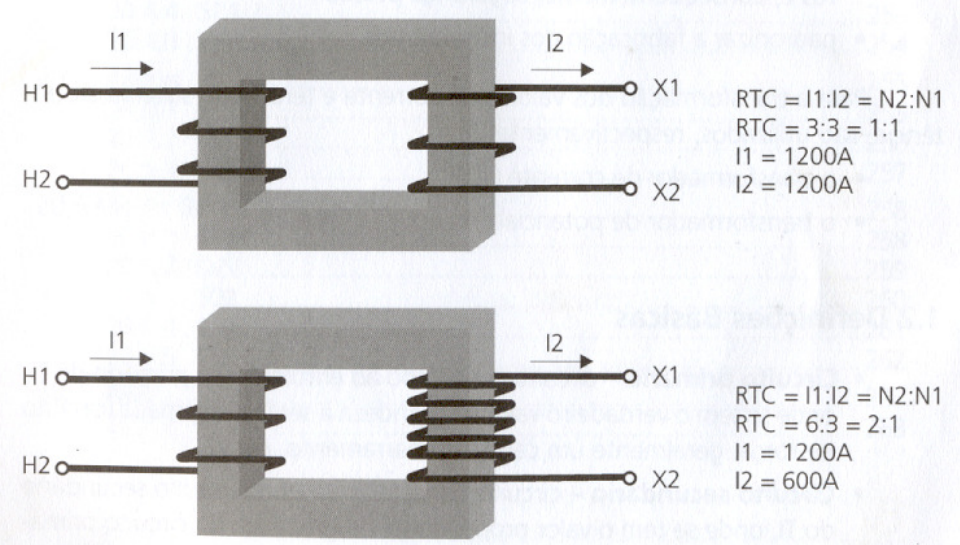

Figura 3.1 - Exemplos de RTC

Fonte:(Araújo et al., 2005)

Para permitir uma maior flexibilidade na utilização dos TCs, alguns fabricantes apresentam modelos com derivações no enrolamento secundário, possibilitando diferentes RTCs. A Figura 3.2 apresenta um quadro comparativo entre TCs com relação única e TCs com relação múltipla.

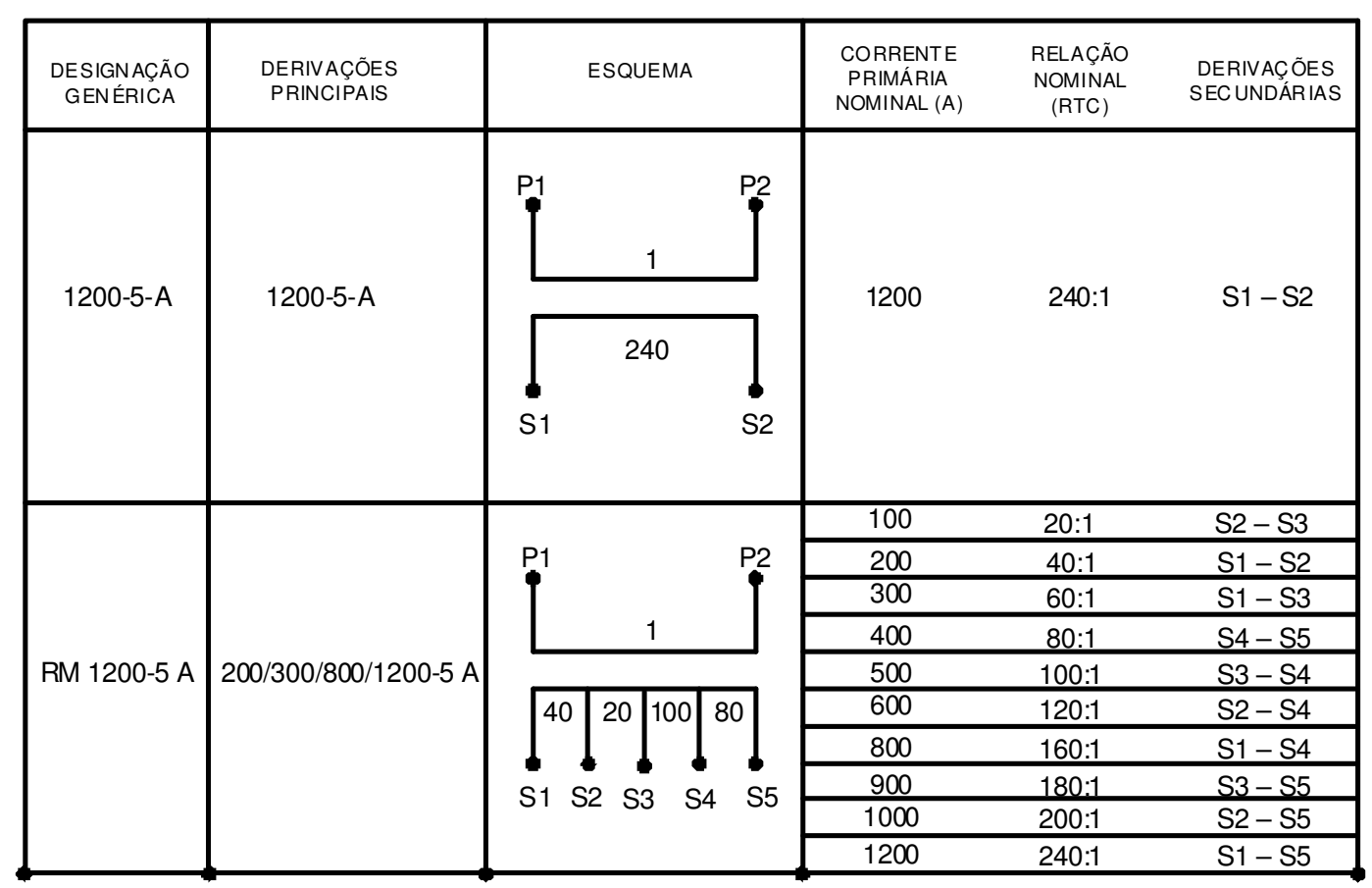

Figura 3.2 - Relação única x relação múltipla 


\subsubsection{Curva de Excitação e Classificação dos Transformadores de Corrente}

Conforme cita Zocholl (2004), o conceito da tensão em relação ao tempo considera que o núcleo magnético é uma chave da tensão em relação ao tempo. Este conceito admite que não existe corrente de magnetização se houver uma taxa de variação do fluxo e toda a corrente refletida fluir para a carga. Quando o fluxo de saturação for atingido e não houver mais mudança de fluxo, a chave fecha, desviando toda a corrente refletida da carga até que ocorra uma reversão da corrente e a integração torne-se negativa para reduzir o fluxo. Neste caso, a saturação ocorre em um ponto bem definido, indicado por um valor específico do fluxo e espiras.

Uma quantidade limitada de amperes-espiras é necessária para estabelecer o fluxo no núcleo do TC e pode ser expressa como a corrente de magnetização medida nos terminais secundários. A corrente de excitação, que é subtraída da corrente refletida, tem valores limitados para cada valor de tensão, conforme mostrado na Figura 3.3. Esta curva detalha a tensão em regime versus a corrente de excitação, onde a tensão eficaz é medida através de um voltímetro. A curva apresenta, na verdade, um gráfico do fluxo versus a corrente de magnetização, uma vez que a tensão média é a integral da tensão em relação ao tempo calculada durante o período da senóide.

A curva de excitação para um TC de bucha com relação de 2.000:5, C400, mostrada na Figura 3.3, representa uma medição do desempenho do TC que pode ser usado para determinar os fatores de correção da relação em diversos níveis de excitação para a condição de regime. Embora a curva de excitação tenha um valor do "ponto de joelho" ("knee point") bem definido, ela não tem um ponto discernível de saturação. Por este motivo, as características nominais de precisão para uso com relés são baseadas na correção da relação não ultrapassando $10 \%$, e as características nominais são determinadas pela classificação e pela tensão secundária. A tensão nominal secundária é a tensão que o TC vai suportar para uma carga padrão, com 20 vezes a corrente nominal, sem exceder a correção da relação de $10 \%$. 


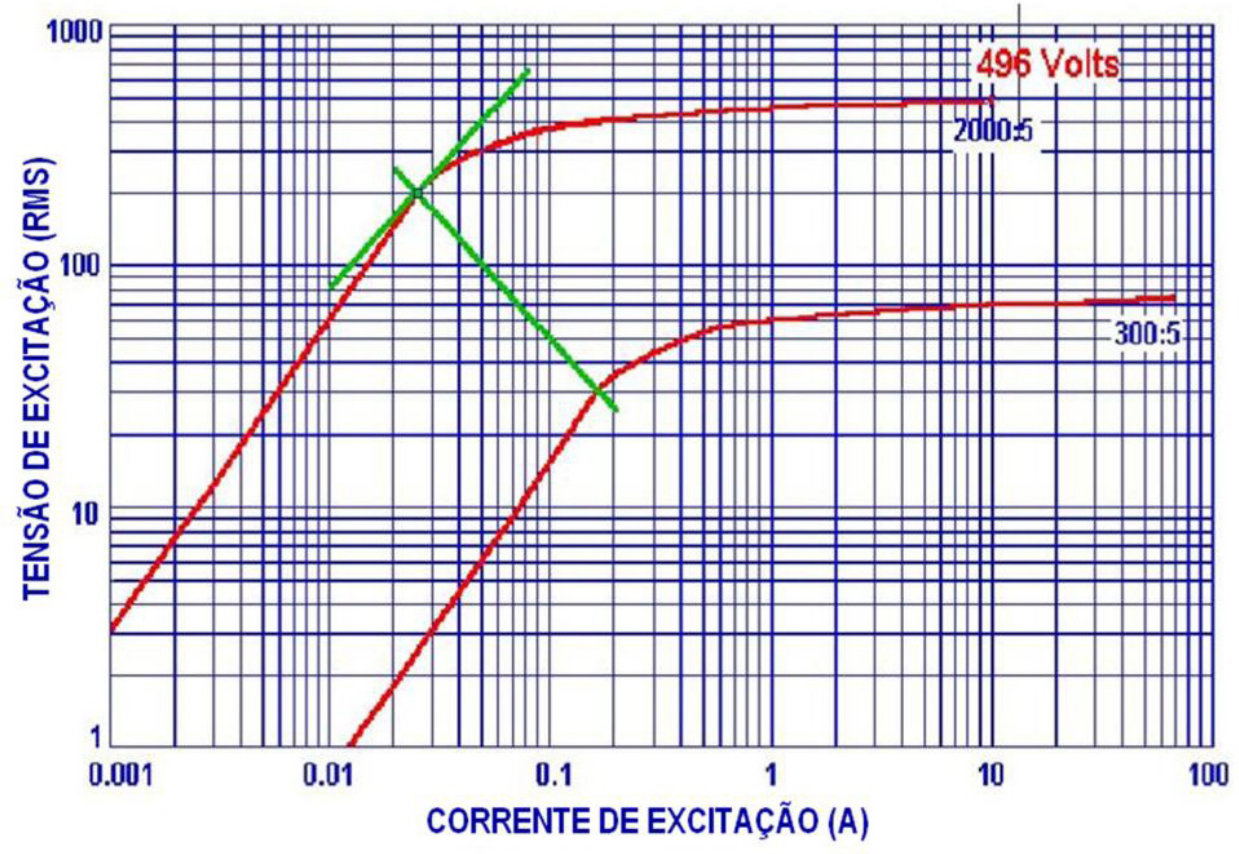

Figura 3.3 - Curva de excitação do TC

Fonte:(Zocholl, S. E., 2004)

Segundo Zocholl (2004) e Reimert (2006), a classificação e a tensão nominal no terminal secundário definem as características nominais de precisão segundo a norma American National Standards Institute (ANSI) padrão C57.13 (Requirements For Instrument Transformers, 1993) para o uso com relés de proteção. Os transformadores de corrente toroidais com um enrolamento distribuído possuem fluxo de dispersão desprezível no núcleo e recebem classificação "C", indicando que a relação pode ser calculada.

Os transformadores de corrente com um enrolamento secundário enrolado ("wound") e um fluxo de dispersão significativo no núcleo recebem a classificação "T", indicando que a relação tem de ser calculada através de teste.

As cargas padronizadas para os relés de proteção são de 1, 2, 4 e 8 ohms, todas com um ângulo de impedância de 60 graus. Conseqüentemente, para 20 vezes a corrente nominal secundária de 5 amperes, um TC com múltipla relação tem tensão nominal usando a relação máxima de espiras. Os valores nominais padronizados são 100, 200, 400 e 800 volts. Uma vez que os valores nominais do TC ocorrem para 100A de corrente secundária, a um fator de correção da relação de 
$10 \%$, a tensão nominal pode ser lida a partir da curva excitação para $10 \mathrm{~A}$ de corrente de excitação.

Em primeiro lugar, temos de subtrair a queda da tensão interna devida à resistência CC do enrolamento. Para o enrolamento com relação de 2.000:5 da Figura 3.3, a tensão lida na curva, para 10A, é de 496 volts. Neste caso, a tensão é menor do que o valor nominal 800 e maior do que 400. Portanto, a classificação nominal é C400, uma vez que o enrolamento de 400 espiras tem uma resistência CC menor do que 0,0024 ohm-por-espira para garantir uma queda de tensão interna menor do que 96 volts.

Para definir os requisitos de exatidão, as normas padronizaram determinados valores de impedância de cargas, denominadas cargas padrão ou cargas nominais.

A Tabela 3.1 apresenta cargas nominais definidas pela norma ABNT (NBR 6856/1992).

Tabela 3.1 - Cargas nominais definidas pela Norma ABNT (NBR 6856/1992)

\begin{tabular}{cccccc}
\hline Designção & $\begin{array}{c}\text { Potência } \\
\text { Aparente } \\
\text { (VA) }\end{array}$ & $\begin{array}{c}\text { Resistência } \\
(\boldsymbol{\Omega})\end{array}$ & $\begin{array}{c}\text { Reatância } \\
\text { Indutiva } \\
(\boldsymbol{\Omega})\end{array}$ & $\begin{array}{c}\text { Impedância } \\
(\boldsymbol{\Omega})\end{array}$ & $\begin{array}{c}\text { Tensão a } \\
\text { 20x5A } \\
\text { (Volts) }\end{array}$ \\
\hline $\mathrm{C} 25$ & 25 & 0,50 & 0,866 & 1,0 & 100 \\
\hline $\mathrm{C} 50$ & 50 & 1,00 & 1,732 & 2,0 & 200 \\
\hline $\mathrm{C} 100$ & 100 & 2,00 & 3,464 & 4,0 & 400 \\
\hline $\mathrm{C} 200$ & 200 & 4,00 & 6,928 & 8,0 & 800 \\
\hline
\end{tabular}

Fonte:(NBR 6856,1992)

A Tabela 3.2 apresenta os valores obtidos ao se aplicar tensão nos terminais secundários do TC, monitorando os valores de tensão medidos nos terminais de enrolamento primário e os valores de corrente circulante no terminal secundário (corrente de excitação). 
Tabela 3.2 - Valores obtidos ao se aplicar tensão nos terminais secundários do TC

\begin{tabular}{c|c|c}
\hline \multicolumn{3}{|c}{ VALORES MEDIDOS } \\
\hline V Secundário Aplicada & V Primário & lexcitação (A) \\
\hline $15 \mathrm{~V}$ & 0,116 & 0,0083 \\
\hline $30 \mathrm{~V}$ & 0,242 & 0,0147 \\
\hline $45 \mathrm{~V}$ & 0,367 & 0,0200 \\
\hline $60 \mathrm{~V}$ & 0,494 & 0,0252 \\
\hline $75 \mathrm{~V}$ & 0,617 & 0,0306 \\
\hline $90 \mathrm{~V}$ & 0,743 & 0,0372 \\
\hline $105 \mathrm{~V}$ & 0,868 & 0,0455 \\
\hline $120 \mathrm{~V}$ & 0,994 & 0,0566 \\
\hline $135 \mathrm{~V}$ & 1,119 & 0,0745 \\
\hline $150 \mathrm{~V}$ & 1,241 & 0,116 \\
\hline $165 \mathrm{~V}$ & 1,366 & 0,253 \\
\hline $180 \mathrm{~V}$ & 1,483 & 0,457 \\
\hline $195 \mathrm{~V}$ & 1,602 & 0,707 \\
\hline $210 \mathrm{~V}$ & 1,728 & 1,014 \\
\hline $225 \mathrm{~V}$ & 1,847 & 1,367 \\
\hline $240 \mathrm{~V}$ & 1,961 & 1,786 \\
\hline $250 \mathrm{~V}$ & & \\
\hline
\end{tabular}

Fonte:(NBR 6856, 1992)

\subsubsection{TC de Medição x TC de Proteção}

De acordo com a finalidade de sua aplicação, os TCs são divididos em dois grupos:

- TC de Medição - devem operar corretamente em condições de regime permanente e dentro da faixa de 0 a 2 vezes 0 valor da corrente nominal;

- TC de Proteção - devem transformar a corrente primária, dentro de determinados limites de exatidão, tanto em condições normais de operação, quanto sob curto-circuitos (corrente de curto-circuito até 20 vezes o valor da corrente nominal);

De acordo com suas características construtivas, os TCs de proteção são divididos em dois grupos:

- TC de Baixa Reatância - tem característica de baixa reatância por possuir o enrolamento secundário distribuído uniformemente sobre um núcleo toroidal. Sua baixa reatância de dispersão de fluxo 
magnético não influencia significativamente no erro de relação de transformação (Figura 3.4).

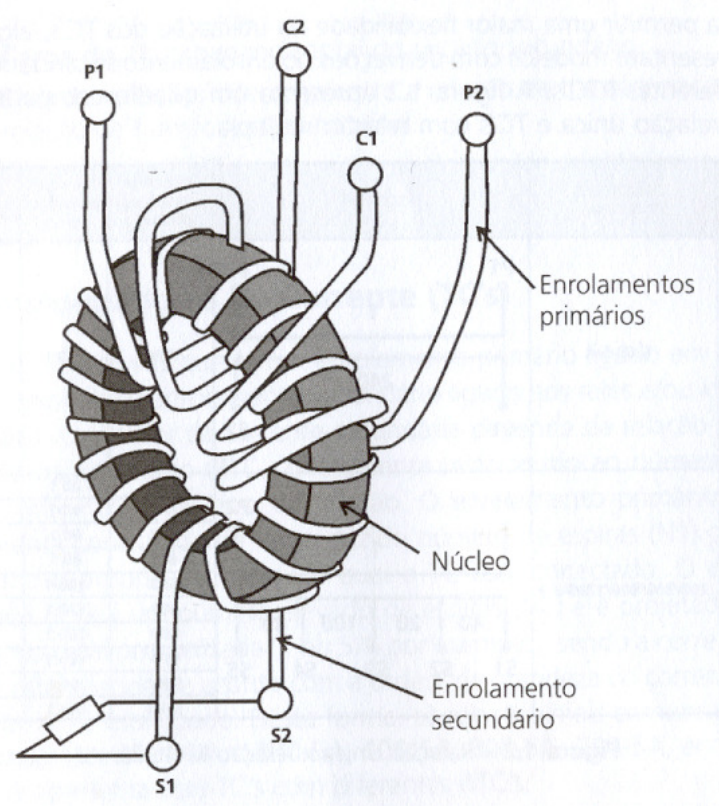

Figura 3.4 - TC de baixa reatância

Fonte:(Apostila de Proteção CPFL,2002)

- TC de Alta Reatância - tem característica de alta reatância de dispersão de fluxo magnético por possuir núcleo com outras geometrias, tendo o enrolamento secundário concentrado em partes desse núcleo (Figura 3.5).

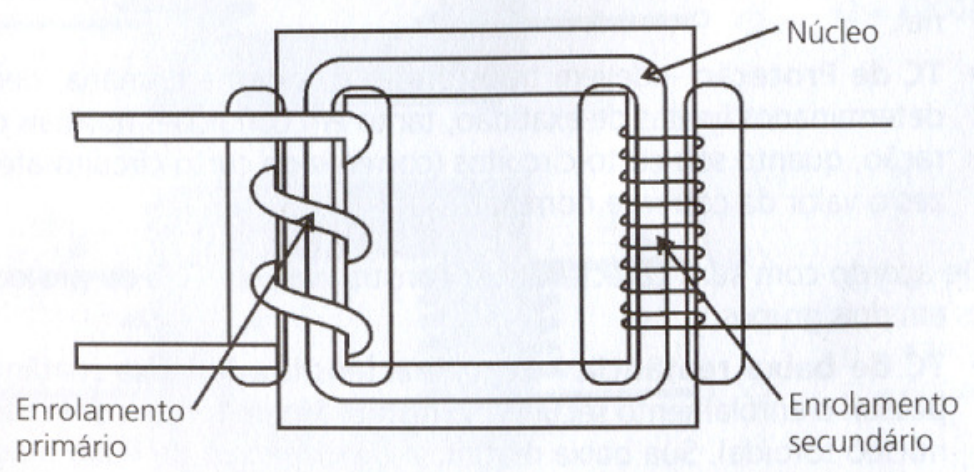

Figura 3.5 - TC de alta reatância

Fonte:(Apostila de Proteção CPFL,2002) 
Alguns exemplos de especificação de TCs, tendo em vista as normas ANSI (American National Standart Institute), ASA (American Standat Association) e ABNT (Associação Brasileira de Normas Técnicas), são apresentados na tabela 3.3.

Tabela 3.3 - Exemplos de especificação de TCs

\begin{tabular}{|c|c|c|c|c|}
\hline \multirow{2}{*}{ NORMA } & \multicolumn{2}{|c|}{ CLASSE DE EXATIDÃO } & \multirow{2}{*}{\multicolumn{2}{|c|}{ DESCRIÇÃO }} \\
\hline & ALTA REATÂNCIA & BAIXA REATÂNCIA & & \\
\hline ANSI & T100 & C200 & $(100$ e 200$)$ & $\begin{array}{l}\text { Volts secundário com } \\
20 \text { x Inom. x Z carga } \\
\text { máx. }\end{array}$ \\
\hline \multirow[b]{3}{*}{ ASA } & \multirow[b]{3}{*}{$10 \mathrm{H} 200$} & \multirow[b]{3}{*}{$10 \mathrm{~L} 200$} & $10 \%$ & Classe de exatidão \\
\hline & & & $\mathrm{H} / \mathrm{L}$ & High I Low \\
\hline & & & 200 & $\begin{array}{l}\text { (Reatância) } \\
\text { Volts secundário com } \\
20 \text { x Inom. x Z carga } \\
\text { máx. }\end{array}$ \\
\hline \multirow{4}{*}{ ABNT (Antiga) } & \multirow{4}{*}{ A10F20C50 } & \multirow{4}{*}{ B10F20C50 } & $A / B$ & $\begin{array}{ll}\text { Alta } \quad / & \text { Baixa } \\
\text { (Reatância) } & \end{array}$ \\
\hline & & & $10 \%$ & Classe de exatidão \\
\hline & & & F 20 & $\begin{array}{lll}\text { Múltiplo da } & \text { Inominal } \\
\text { para a a } & \text { classe } \\
\text { especificada } & \end{array}$ \\
\hline & & & C 50 & $\begin{array}{l}\text { Carga máxima em VA } \\
(\mathrm{VA}=\mathrm{Zx} \mid 2)\end{array}$ \\
\hline \multirow[b]{3}{*}{ ABNT (Atual) } & \multirow[b]{3}{*}{$10 \mathrm{~A} 200$} & \multirow[b]{3}{*}{$10 \mathrm{~B} 200$} & $10 \%$ & Classe de exatidão \\
\hline & & & $A / B$ & Alta $\quad$ I $\quad$ Baixa \\
\hline & & & 200 & $\begin{array}{l}\text { (Reatância) } \\
\text { Volts secundário com } \\
20 \text { x Inom. x Z carga } \\
\text { máx. }\end{array}$ \\
\hline
\end{tabular}

Fonte:(Araújo et al.,2005)

\subsubsection{Tipos de TCs mais utilizados}

\section{TC Tipo Bucha}

Possui o enrolamento secundário isolado e montado no núcleo, sendo o enrolamento primário representado por um condutor isolado. Este condutor é parte componente de um equipamento, como um transformador de potência, ou um disjuntor.

O núcleo maior evita a saturação do núcleo magnético. Logo, para correntes elevadas o TC não sofre saturação tornando-se mais precisos nestas situações. No entanto, são menos precisos para valores baixos de corrente, em virtude da maior corrente de excitação.

A Figura 3.6 apresenta um TC instalado na bucha de alta tensão (138kV) de um transformador de potência. 


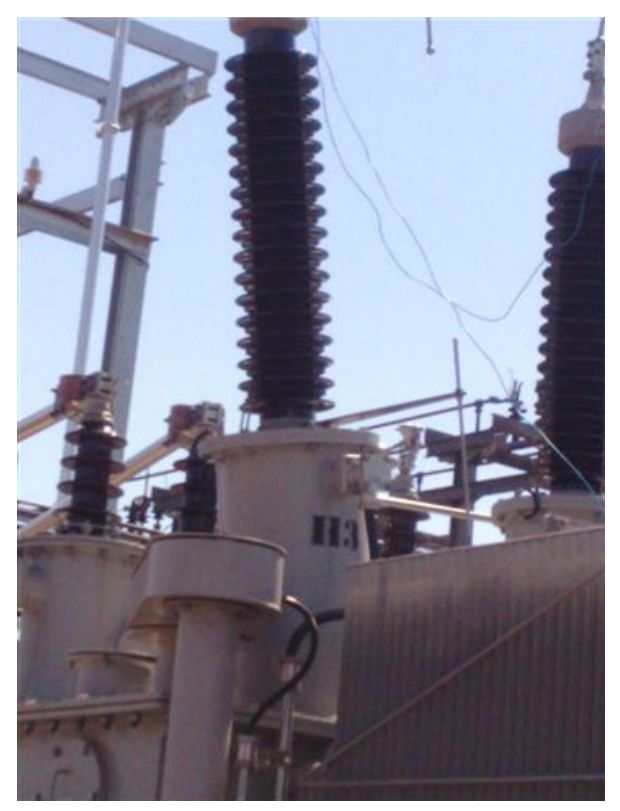

Figura 3.6 - TC tipo bucha

Fonte:(Companhia Paulista de Força e Luz (CPFL), 2010)

\section{TC Tipo Janela}

Possui o enrolamento secundário isolado e montado no núcleo, sendo que o condutor representa o enrolamento primário. É construído de maneira análoga ao tipo bucha, sendo muito utilizado em classe de tensão de 13,8 kV.

A Figura 3.7 apresenta TCs que podem ser instalados na saída de alimentadores de $13,8 \mathrm{kV}$.

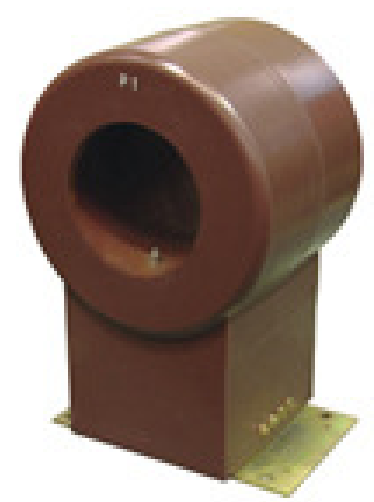

Figura 3.7 - TC tipo janela Fonte:(Companhia Paulista de Força e Luz (CPFL), 2010) 


\section{TC Tipo Barra}

Possui os enrolamentos primário e secundário isolados e montados no núcleo. O primário consiste de uma barra (condutor) que é colocada no interior da janela do núcleo.

Este TC é adequado para resistir aos esforços de grandes sobrecorrentes, sendo que deve-se tomar cuidado na montagem para evitar destruir a barra por esforços magnéticos.

A Figura 3.8 apresenta TCs que podem ser instalados na saída de alimentadores de 13,8kV.

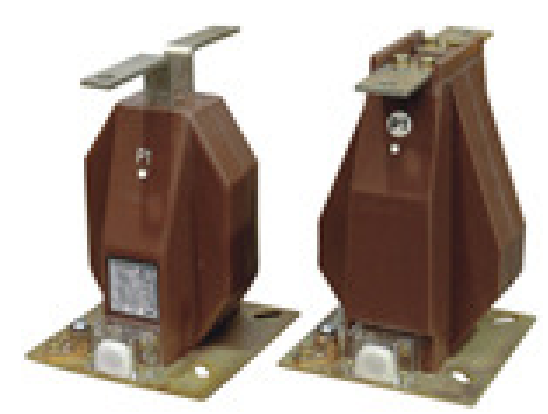

Figura 3.8 - TC tipo barra

Fonte:(Companhia Paulista de Força e Luz (CPFL), 2010)

\section{TC Tipo Pedestal}

Possui primário e secundário enrolados num núcleo toroidal, sendo largamente utilizado nas classes de tensão de 25 e $138 \mathrm{kV}$.

A Figura 3.9 apresenta TCs instalados em uma linha de transmissão de $138 \mathrm{kV}$. 


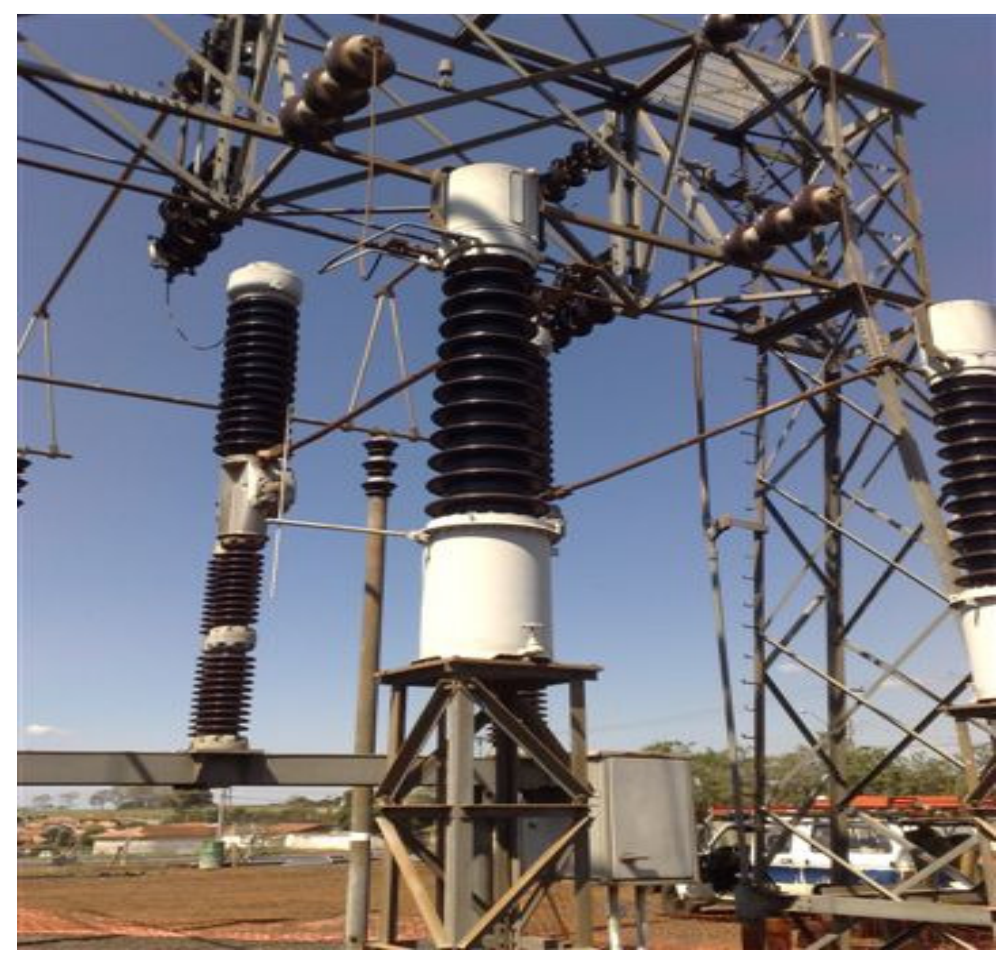

Figura $3.9-$ TC tipo pedestal

Fonte:(Companhia Paulista de Força e Luz (CPFL), 2010)

\subsection{A Saturação dos Transformadores de Corrente}

O desempenho dos TCs sob condições de carga nominal não é preocupante, visto que o TC é projetado para atender a estas correntes. Além disso, os TCs são projetados para suportar por um curto período de tempo (1/4 de ciclo), correntes de falta que podem atingir valores até cinqüenta vezes a magnitude da corrente de carga, porém nos casos de faltas muito graves estas correntes pode ultrapassar estes valores causando a saturação do TC, Horowitz e Phadke (1995).

Além destes valores elevados de corrente, durante uma falta, a corrente pode conter parcelas significativas de componentes CC, Segatto (2005).

Segundo Reimert (2006) a impedância do circuito secundário e a corrente sendo reproduzida determina a tensão secundária do TC como definida pela equação:

$$
V_{t c}=Z_{b} \frac{I_{P}}{N}
$$


$\mathrm{Na}$ qual Vtc é a tensão secundária necessária produzida pelo TC, $Z b$ é igual à impedância secundária total do circuito incluindo a resistência do TC, IP é igual à corrente primária e $N$ é igual ao número de espiras.

A habilidade do TC para produzir essa tensão é governada pela quantidade do fluxo que o núcleo magnético do TC pode gerar.

É importante notar pela (equação 3.2) que a tensão secundária ( $e$ ) não é determinada pela magnitude de fluxo no núcleo do transformador, mas pela quantidade de troca do fluxo $\left(\frac{d \varphi}{d t}\right)$ ligando o enrolamento secundário e o número de espiras $(N)$.

$$
e=N \frac{d \varphi}{d t}
$$

Isso não significa que não exista relação entre tensão e magnitude do fluxo do núcleo. Se a tensão secundária do TC é baixa, uma pequena quantidade de troca é necessária sobre um ciclo e o fluxo total construído no fim de cada ciclo também será baixo. Uma tensão mais alta necessita uma quantidade de troca mais alta que resultará num fluxo de núcleo de magnitude mais alto no fim de cada ciclo.

Um TC só pode produzir uma dada tensão secundária se o núcleo suportar o fluxo resultante no final de cada ciclo associado com aquela tensão. A magnitude do fluxo pode ser determinada pela equação (3.3).

Resolvendo pela troca no fluxo e integrando, o fluxo necessário para produzir uma dada tensão. É então:

$$
\varphi=\frac{1}{N} \int e d t
$$

A integral da tensão com respeito ao tempo é efetivamente a área debaixo da tensão secundária versus o espaço de tempo. A capacidade de um TC é as vezes avaliada nos princípios da capacidade da tensão versus o espaço de tempo. Assumindo a corrente secundária e tensão senoidal, a expressão para o fluxo do núcleo se torna:

$$
\begin{aligned}
v & =E \sin (\omega t) \\
\varphi & =\frac{E}{N} \int \sin (\omega t) d t
\end{aligned}
$$




$$
\varphi=-\frac{E}{N \omega} \cos (\omega t)
$$

Na qual $v$ é igual à tensão secundária instantânea do TC; $E$ é igual ao pico da tensão secundária $\omega=2 \pi * f ; N$ é o número de espiras; e $\varphi$ é fluxo em webers.

A relação entre a tensão do TC, corrente de excitação e o fluxo do núcleo para uma operação do TC no âmbito da sua capacidade de fluxo é mostrado na Figura 3.10.

Note que a tensão ( Vtc ) é positiva enquanto que a mudança de fluxo (Flux) é positiva e negativa quando a mudança de fluxo é negativa. Também nota-se que a corrente de excitação ( $I e$ ), está em fase com o fluxo. O nível máximo de fluxo ocorre quando a tensão é zero.

Então, os picos de fluxo máximo e mínimo ocorrem em $\mathrm{t}=0$ e em $\omega t=\pi$. Durante esse período, a variação de fluxo é de máximo positivo para um valor mínimo negativo. O fluxo requisitado do núcleo pode ser calculado por:

$$
\begin{aligned}
2 \varphi_{\max } & =\frac{1}{N} \int_{0}^{\pi} \sqrt{2} E_{R M S} \sin (\omega t) d t \\
& =\frac{\sqrt{2} E_{R M S} \cos (\omega t)_{0}^{\pi}}{N \omega} \\
\varphi_{\max } & =\frac{\sqrt{2} E_{R M S}}{N \omega}
\end{aligned}
$$

O material do núcleo e as dimensões físicas do núcleo determinam o nível de fluxo que um TC pode suportar. O aço usado na maioria das aplicações de um TC pode suportar um fluxo de 1,8 Weber $/ m^{2}$. Se um TC 600/5 (relação 120/1) é necessário para produzir 200 V RMS, o núcleo deve ser capaz de sustentá-lo.

$$
\varphi_{\max }=\frac{\sqrt{2} E_{R M S}}{N \omega}=\frac{\sqrt{2} \times 200}{120 \times 377}=0,0063[\text { Weber] }
$$

O núcleo de aço pode suportar $1,8 \mathrm{~Wb} / \mathrm{m}^{2}$, conseqüentemente, o TC tem que ter a área do núcleo de 0,0069 $\mathrm{m}^{2}$ (Reimert, 2006). 


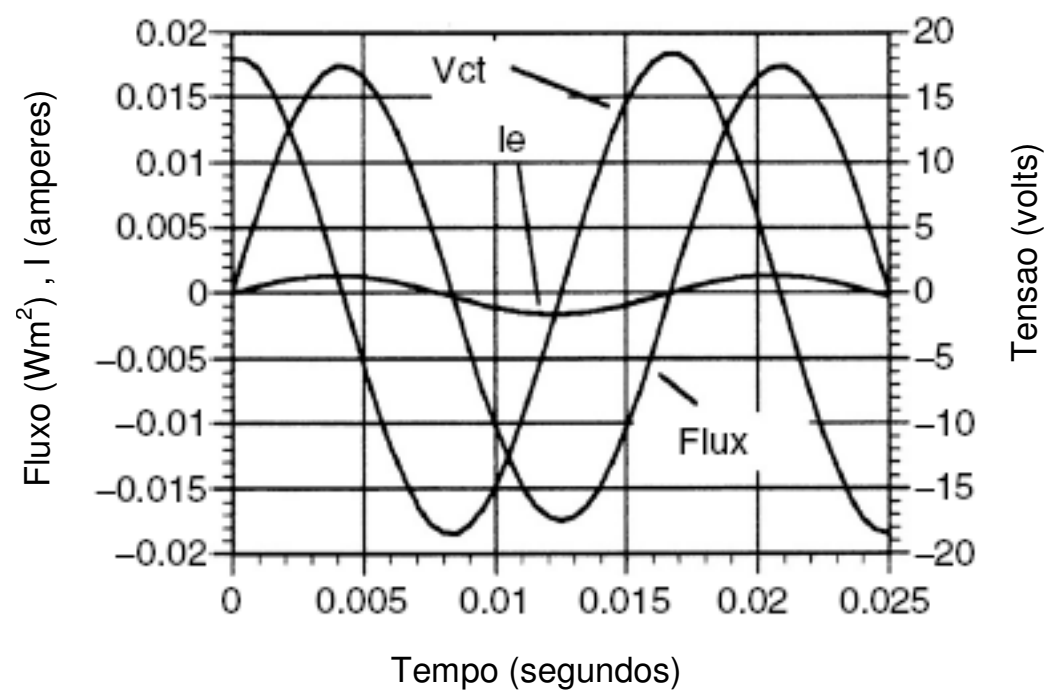

Figura 3.10 - Corrente e fluxo do TC em saturação

Fonte:(Reimert,2006)

Se o TC com impedância de carga de 3,2 $\Omega$ fosse submetido a uma corrente de falta de $11 \mathrm{KA}$, o TC produziria:

$$
\frac{11.000}{120} * 3,2=293 \mathrm{~V}
$$

Este nível de tensão exigiria uma densidade de fluxo maior que 1,8 Weber $/ \mathrm{m}^{2}$, logo haveria saturação do núcleo.

No entanto, não existe uma definição completa de quando uma saturação realmente ocorre. Quando a tensão e o fluxo do núcleo aumentam, aumenta também a corrente de excitação. Quando a densidade do fluxo do núcleo se aproxima da capacidade do núcleo (densidade do fluxo de saturação), a corrente de excitação começa a aumentar numa razão desproporcional. Esse aumento rápido é demonstrado na Figura 3.3.

Uma densidade de fluxo versus a intensidade de campo ou gráfico de B-H define suas propriedades magnéticas. A Figura 3.11 representa a característica $\mathrm{B}-\mathrm{H}$ do material do núcleo de um TC típico. 


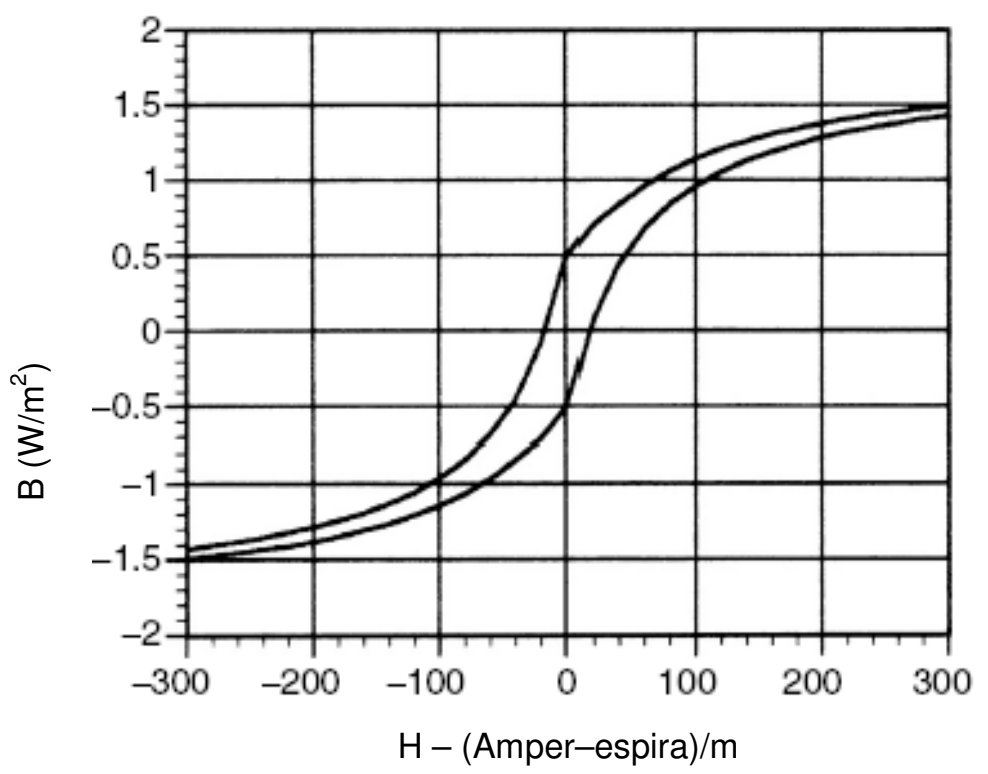

Figura 3.11 - B (Fluxo Magnético) H (Força Magnética) com histerese

Fonte:(Reimert,2006)

O eixo da ordenada y (B) representa a densidade do fluxo magnético (fluxo/área), enquanto o eixo da abscissa $\times(\mathrm{H})$ representa a força magnética $\mathrm{H}$ em (amper-espira) fornecidas pela corrente de excitação por unidade de comprimento por espira (amper-espira)/m. A curva tem duas características notáveis, histerese e não-linearidade.

Quando o campo magnético aplicado em um material for aumentado até a saturação e em seguida for diminuído, a densidade de fluxo B não diminui tão rapidamente quanto o campo $\mathrm{H}$. Dessa forma, quando $\mathrm{H}$ chega a zero, ainda existe uma densidade de fluxo remanescente.

Ainda, considerando-se uma representação simplificada do núcleo conforme a Figura 3.12. O declive da marca B-H é íngreme e regularmente linear entre -1 e 1, até a região onde o núcleo satura, próximo de $B=1,8 \mathrm{~Wb} / \mathrm{m}^{2}$. Abaixo da saturação, um pequeno aumento na corrente de excitação produz grande modificação em fluxo. 


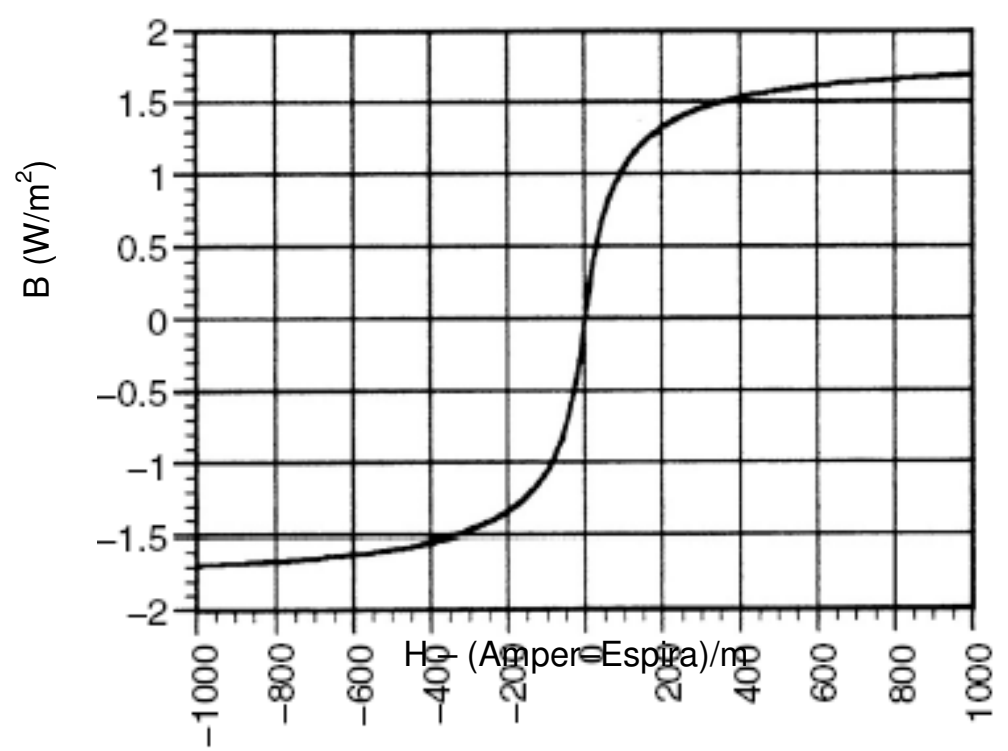

Figura 3.12 - B (Fluxo Magnético) H (Força Magnética) sem histerese

Fonte:(Reimert,2006)

Torna-se importante lembrar que a tensão é proporcional à taxa de variação do fluxo, e não a magnitude do fluxo, pouquíssima corrente de excitação é necessária para produzir a tensão secundária. Após a saturação, as características magnéticas do núcleo se degradam. Assim, o núcleo produzirá elevada corrente de excitação $\mathrm{CA}$, porém, essa mudança produzirá uma pequena mudança no fluxo. Se desconsiderar a variação do fluxo, a tensão e a corrente de saída do TC tenderão a zero.

A corrente de saída do TC e o fluxo do núcleo mostrados na Figura 3.13 (conforme se apresenta mais adiante) são típicos para um TC que tenta reproduzir a corrente primária senoidal, mas opera ligeiramente acima da saturação.

A parcela de fluxo se torna plana quando a densidade de fluxo de saturação é atingida. Sem mudança no fluxo, a tensão do TC e a corrente de saída decaem e a corrente de excitação se torna muito intensa. Se uma tensão secundária mais alta é necessária, o fluxo atingirá o limite de saturação mais cedo, como mostrado na Figura 3.14. 


\subsubsection{Transformadores de Corrente e Replicação de Correntes de Falta}

As Figuras 3.13 e 3.14 representam o resultado da saturação de uma corrente primária senoidal. Estas figuras provêm uma idéia sobre a teoria de operação de transformadores de corrente, mas elas não refletem o atual ambiente de falta no qual o transformador de corrente e o relé diferencial devem estar operando (isto é, não pode ser dito que as figuras representem uma situação real de operação). O relé diferencial é projetado para atuar com alta velocidade. Dessa forma, todos os relés de corrente de alta velocidade devem ser capazes de intervir tanto em correntes de falta CA como nas CC.

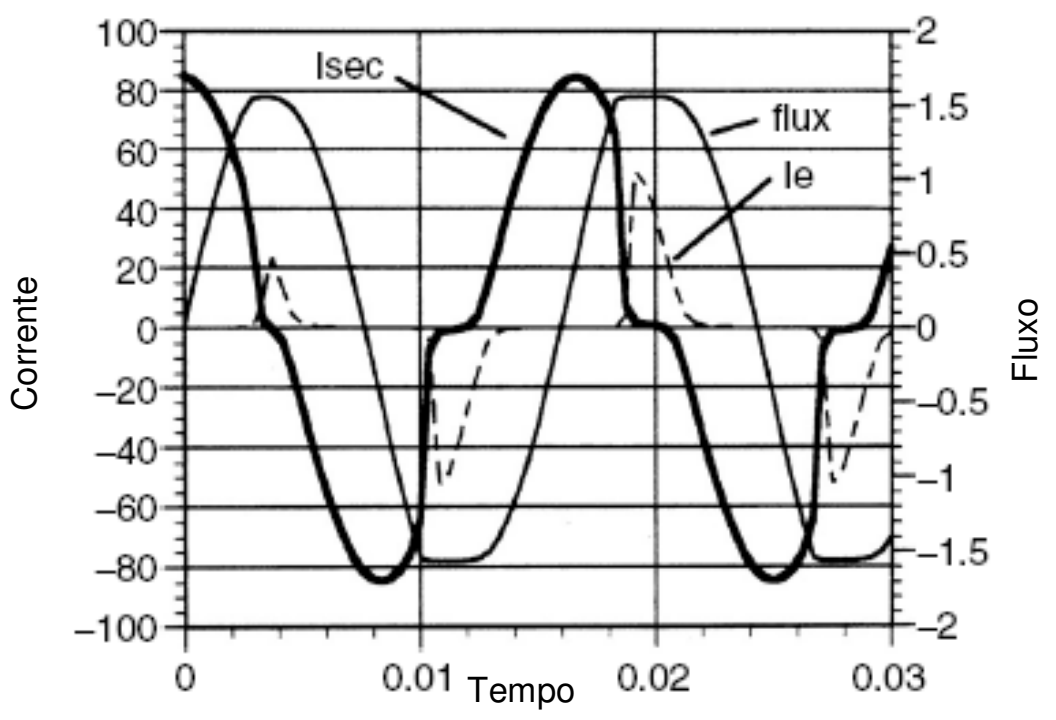

Figura 3.13 - Corrente e fluxo do TC com pequena saturação CA 


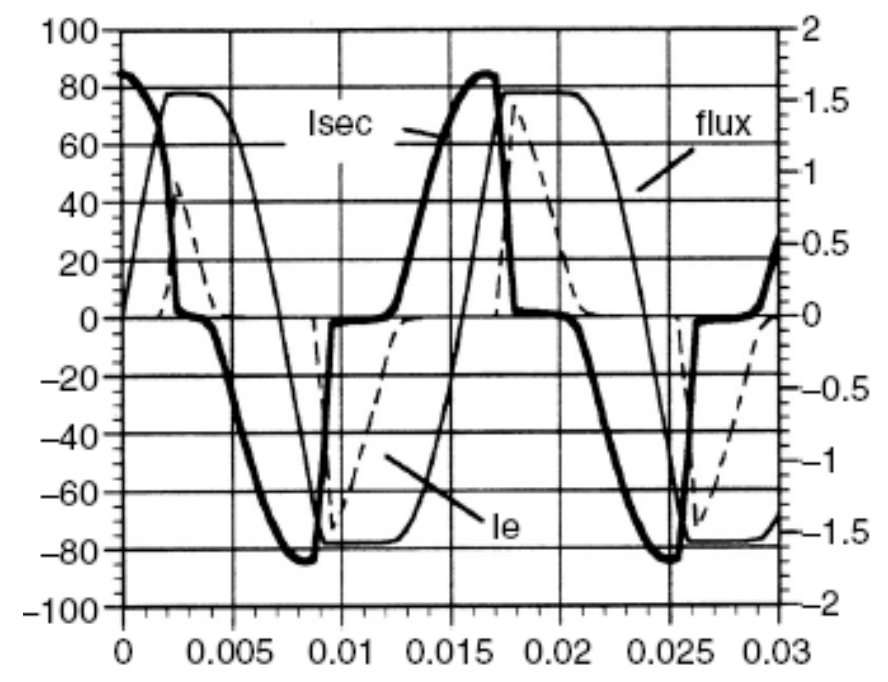

Figura 3.14 - Corrente e fluxo do TC com moderada saturação CA

Fonte:(Reimert,2006)

Em particular, para a função diferencial do gerador, tem-se o efeito indesejável da componente $\mathrm{CC}$ sobre os transformadores de corrente.

A expressão (3.8) representa a corrente de falta em termos de componente CA e CC. Esta representa a pior condição quando o ângulo de incidência ocorre no máximo valor $\mathrm{CA}$. Assim, esta condição produz o máximo componente $\mathrm{CC}$ e uma forma de onda CA deslocada totalmente do eixo zero.

$$
i=I_{m}\left[e^{-t / \mathrm{T}}-\cos (\omega t)\right]
$$

Os termos $i$ e $I_{m}$ podem representar quantidades primárias ou secundárias de TC.

A replicação do componente $C A$ no circuito secundário requer a criação de uma tensão secundária senoidal e o fluxo do núcleo senoidal, alternando-se variações positivas e negativas da mudança do fluxo que geram a tensão $C A$. A inversão do sentido limita a magnitude de fluxo para cada ciclo. A replicação do componente $\mathrm{CC}$ requer uma tensão $\mathrm{CC}$ e uma variação do fluxo unidirecional até que a componente $\mathrm{CC}$ se dissipe.

A Figura 3.15 mostra o fluxo transitório do núcleo resultante de ambos os componentes CA e CC. Nota-se, então, que o aumento rápido no fluxo transitório do núcleo, devido ao componente CC, é evidente nos dois primeiros segundos. 


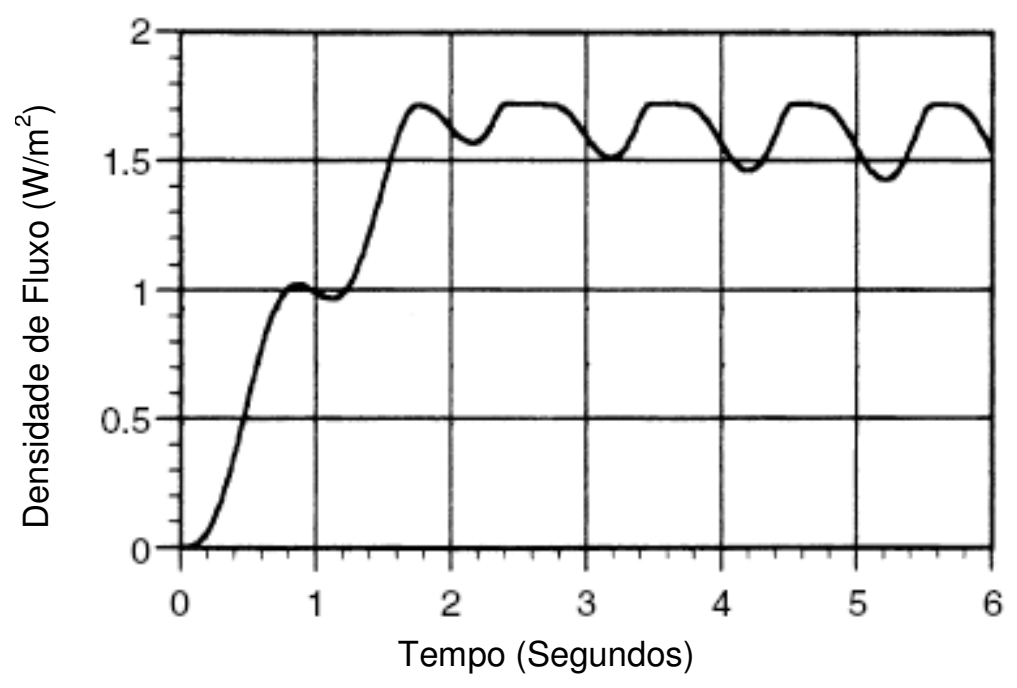

Figura 3.15 - Fluxo do núcleo com as componentes CA e CC

Fonte:(Reimert,2006)

Durante este período, as variações positivas e negativas necessárias para reproduzirem o componente CA também são visíveis. Contudo, depois de dois ciclos, o componente $\mathrm{CC}$ leva o núcleo à sua densidade de fluxo de saturação. Desde que o núcleo não seja capaz de produzir o fluxo em excesso nessa quantidade, a mudança de troca positiva necessária para reproduzir a metade do ciclo positivo do componente CA não pode ser obtida.

$\mathrm{Na}$ Figura 3.16, é exemplificada a saída do TC com saturação CC, utilizando-se de dois TCs e identificando-os como TC1 e TC2.

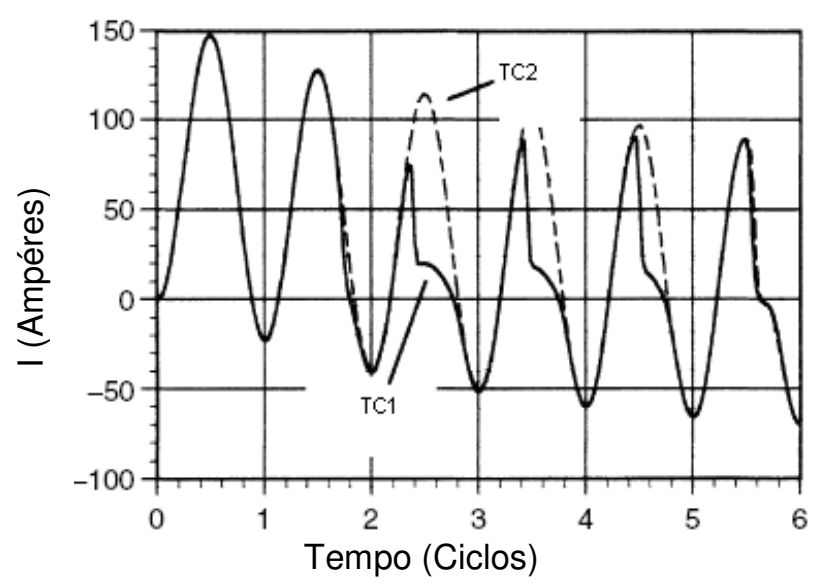

Figura 3.16 - Saída do TC com saturação CC 
Ambos os TCs reproduzem exatamente a corrente secundária por dois ciclos, então a distorção ocorre no TC1; distorção esta não vista no TC2 até o sexto ciclo. Também observa-se que a forma de onda do TC1 recupera-se enquanto o componente CC se dissipa. Os exemplos apresentados assumiram que 0 componente CC inicial foi da polaridade positiva.

Em seguida, entende-se também como é de relevante importância abordar o que se tem na literatura como sistema de proteção de geradores, conforme se apresenta no próximo capítulo. 


\section{PROTEÇÃO DE GERADORES}

Este capítulo abrange os sistemas de proteção de geradores, onde serão descritos as perturbações que podem ocorrer no sistema elétrico e na máquina síncrona, abrangendo os tipos de proteção do gerador síncrono, com especificação dos tipos de proteção (digital, diferencial ideal e percentual). Dentro do contexto de proteção digital foi mostrado os principais sub-sistemas de um relé computadorizado, além da definição sobre a proteção diferencial longa que abrange geradortransformador.

\subsection{Proteção de geradores}

Segundo Caminha (1999), como os geradores são componentes de fundamental importância do SEP, justifica-se a preocupação de proteger de maneira eficaz este equipamento. Os geradores podem ser submetidos a um grande número de diferentes condições anormais de operação e essa diversidade de condições anormais resulta numa considerável gama de funções de proteção que devem ser previstas pelos projetistas. Assim, o desejo de protegê-los contra essas possíveis condições anormais, ao mesmo tempo mantendo a proteção simples e confiável, pode resultar em consideráveis divergências de opinião. Isso porque uma operação intempestiva pode ser, às vezes, tão grave quanto uma falha ou demora de atuação da proteção.

A Tabela 4.1 serve como base de partida sobre os tipos razoáveis de proteção, em função somente da potência dos elementos. Os fabricantes oferecem sugestões semelhantes a essa em seus catálogos de produtos. 
Tabela 4.1 - Indicações-base para proteção de geradores (critérios de potência e de tipo da turbina).

\begin{tabular}{|c|c|c|c|c|}
\hline \multicolumn{5}{|l|}{ a) Proteção do gerador, em geral } \\
\hline \multirow{2}{*}{ Tipo de proteção indicada } & \multicolumn{4}{|c|}{ Regime nominal MW } \\
\hline & $<1$ & $\geq 1$ & $\geq 10$ & $>100$ \\
\hline Diferencial & - & - & $\bar{x}$ & $\bar{x}$ \\
\hline Terra restrita & - & - & $x$ & $x$ \\
\hline Falta entre espiras do estator & - & - & - & $x$ \\
\hline Sobrecorrente com restrição por tensão & $x$ & $x$ & - & - \\
\hline Sobrecarga & $x$ & $x$ & $x$ & $x$ \\
\hline Sobretemperatura (detetor) & - & $x$ & $\mathrm{x}$ & $x$ \\
\hline Corrente de sequência negativa & - & - & $\mathrm{x}$ & $x$ \\
\hline Perda de carga & - & - & - & $x$ \\
\hline Antimotorização (perda de vapor) & $x$ & $x$ & $\mathrm{x}$ & $x$ \\
\hline Perda de campo & - & - & $x$ & $x$ \\
\hline Perda de sincronismo & - & - & - & $x$ \\
\hline Sobrevelocidade (máquinas hidráulicas) & $x$ & $x$ & $x$ & $x$ \\
\hline Sobretensão (idem) & $\mathrm{x}$ & $x$ & $\mathrm{x}$ & $\mathrm{x}$ \\
\hline \multicolumn{5}{|l|}{ b) Proteção do rotor e mancais } \\
\hline Falta à terra & - & - & $\mathrm{x}$ & $\mathrm{x}$ \\
\hline Perda de campo & - & - & $\mathrm{x}$ & $x$ \\
\hline Indicador de vibração & - & - & $\mathrm{x}$ & $x$ \\
\hline Temperatura do mancal & - & - & $x$ & $x$ \\
\hline Isolamento do mancal & - & - & - & $x$ \\
\hline
\end{tabular}

c) Proteção só atuando alarmes ou desligamentos também Condição anormal verificada, em função da A vapor, máquina motriz

refrigerada a Hidráulica

a) Alarme

Baixo vácuo no condensador

Anormal pressão, temperatura ou densidade do $\mathrm{H}$

Baixa pressão de óleo no mancal

Alta temperatura no enrolamento do transformador do bloco GT

Alta temperatura no mancal

Pressão de óleo do regulador

Falta de água de refrigeração

Alta temperatura do ar no estator

Falha de abertura de válvula

Relé Buchholz dos transformadores

Temperatura do óleo dos transformadores

Falha no regulador de tensão

Falta à terra do rotor

Falta de campo

Baixa tensão nas baterias

$\mathrm{Ar}$ $\mathrm{H}$

b) Desligamento

Faltas no estator

Curto-circuito nos transformadores

Sobretensão e/ou sobrevelocidade

\begin{tabular}{|c|c|c|}
\hline$X$ & $x$ & - \\
\hline 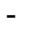 & $x$ & - \\
\hline$x$ & $X$ & $X$ \\
\hline$X$ & $x$ & $x$ \\
\hline- & - & $x$ \\
\hline - & - & $X$ \\
\hline - & - & $x$ \\
\hline - & - & $x$ \\
\hline- & - & $x$ \\
\hline$X$ & $x$ & $x$ \\
\hline$x$ & $x$ & $x$ \\
\hline$X$ & $x$ & $x$ \\
\hline$x$ & $x$ & $x$ \\
\hline$x$ & $x$ & $x$ \\
\hline$x$ & $x$ & $x$ \\
\hline$X$ & $x$ & $x$ \\
\hline$x$ & $x$ & $x$ \\
\hline$x$ & $x$ & $x$ \\
\hline
\end{tabular}

Fonte - Caminha, (1999) 
Em geral, a proteção do gerador é feita contra dois tipos de faltas:

a) Falha de isolamento, conduzindo a curto-circuitos entre espiras, fasefase, fase-terra ou trifásica

b) Condições anormais de funcionamento como perda de campo, carga desequilibrada do estator, sobrevelocidade, vibrações, sobrecarga, etc..

A falha de isolamento, conduzindo a curto-circuito, é devida normalmente seja a sobretensões, a sobreaquecimentos (corrente desequilibrada, ventilação deficiente, etc.), ou a movimentos do condutor (força do curto-circuito, perda de sincronismo, etc.).

Ainda mais, a proteção do gerador deve:

a) Funcionar rápido para faltas internas;

b) Ser sensível às faltas externas à zona de proteção estabelecida;

c) Limitar o valor da corrente de defeito para a terra;

d) Assinalar condições anormais e mesmo eliminá-las quando se tornarem perigosas.

Finalmente, é preciso prover a proteção:

a) Do gerador, propriamente dito;

b) Da turbina ou máquina motriz;

c) Do conjunto gerador-turbina;

d) Dos auxiliares (fonte de corrente contínua, etc.).

Segundo Kindermann (2008), a máquina síncrona, operando como gerador, é um equipamento vital ao sistema elétrico e sua capacidade de geração limita a demanda que pode ser suprida. Assim, o sistema elétrico é mantido por poucos geradores, sendo que sua carga está distribuída em milhares de pontos.

Sendo o gerador um equipamento complexo, o qual possui peças girantes, está sujeito a maiores riscos. 
O princípio de funcionamento da máquina síncrona, como gerador, está simbolicamente representado na Figura 4.1.

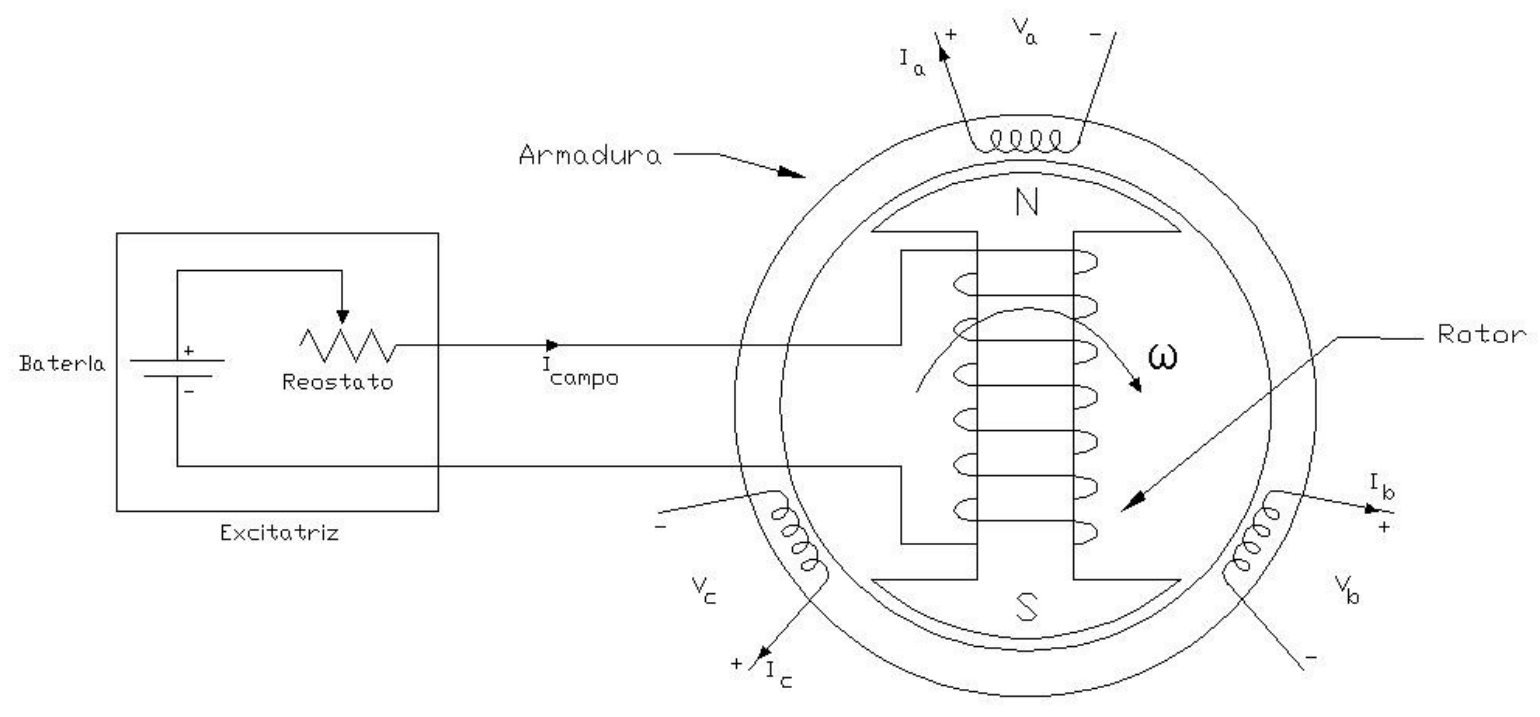

Figura 4.1 - Máquina síncrona operando como gerador

Fonte - Kindermann, (2008)

A máquina síncrona é composta, basicamente, dos seguintes componentes:

- Armadura: que corresponde ao estator, onde estão alojadas as bobinas das fases. Quando a máquina for de 2 pólos, essas bobinas, construtivamente, estarão distribuídas ao longo do estator, tendo uma em relação à outra uma defasagem mecânica de 120․ Desse modo, na bobinas serão induzidas tensões elétricas defasadas de $120^{\circ}$ elétricos;

- Rotor: é a peça constituída por um núcleo magnético, envolvido por uma bobina. A bobina é alimentada por corrente contínua, para criar o campo magnético de excitação, necessário para induzir as tensões nas bobinas do estator;

- Excitação: é a fonte de tensão contínua, necessária para gerar a corrente de campo de excitação da bobina do rotor. Existem vários esquemas de excitatriz, com escovas ou sem escovas (brushless);

- Fonte Motriz: é a fonte geradora de potência mecânica motriz, necessária para efetuar o giro do rotor da máquina síncrona. A fonte 
motriz é a fonte da energia que será transformada em energia elétrica.

\subsection{Perturbações na máquina síncrona}

A máquina síncrona, acoplada ao sistema elétrico, está sujeita a diversos tipos de perturbações provenientes do:

- Sistema elétrico

- Da própria máquina síncrona $\left\{\begin{array}{l}\text { Armadura } \\ \text { Rotor }\end{array}\right.$

As perturbações no sistema elétrico são decorrentes da:

- Retirada súbita de carga;

- Inserção de cargas que necessitem de maior potência (ativa e reativa);

- Retirada súbita de geração;

- Curto-circuitos (ЗФ (trifásicos), 3Ф-t (trifásicos terra), 2Ф(bifásicos), 2Ф- t (bifásicos terra) e 1Ф- t (monofásicos terra));

- Sobrecargas;

- Abertura de fase;

- Cargas fortemente desequilibradas;

- Descargas atmosféricas diretas e indiretas.

As perturbações na máquina síncrona são:

- Na armadura

- Falha na isolação entre espiras

- Falha na isolação entre bobinas e carcaça

- Movimentação das espiras devido às forças elétricas e magnéticas, provocadas pelas correntes de curto-circuito

- Aquecimento nas bobinas e materiais do estator

- Não equalização de campos elétricos e magnéticos no material do núcleo da armadura

- Abertura de espiras 
- No rotor

- Falha na isolação entre espiras

- Falha na isolação entre as bobinas e a carcaça

- Movimentação das espiras, devido às forças elétricas e magnéticas provocadas pelas correntes dos curtos-circuitos

- Movimentação das espiras, devido à força centrífuga provocada pela sobrevelocidade do rotor

- Aquecimento nas bobinas e material do rotor

- Não equalização de campos elétricos e magnéticos no material do núcleo do rotor

- Abertura de espiras

- Perdas de campo (excitação)

- Problemas mecânicos e de aquecimento dos maçais do rotor

- Problemas na escova

- Nos Serviços Auxiliares

Problemas nos equipamentos que compõem os serviços auxiliares, próprios para a operação e regulação da máquina, afetam as condições de operação do gerador síncrono.

- Fonte Motriz

Problemas em qualquer componente vital, principalmente nas turbinas, comprometem a operação do conjunto da geração. Os problemas principais são os decorrentes da vibração ou movimento irregular das palhetas nas turbinas térmicas, e outros no distribuidor.

Apresenta-se, na tabela 4.2, um levantamento estatístico das taxas de falhas dos equipamentos de uma usina hidrelétrica, onde se verifica a importância desses dados, visto que podermos ter uma idéia mais precisa de quais os equipamentos que mais falham, com isso poderemos montar um plano de ação para as manutenções preventivas. 
Tabela 4.2- Levantamento estatístico e percentual de falhas dos equipamentos de uma usina hidrelétrica.

\begin{tabular}{cc}
\hline \multicolumn{2}{c}{ Usina Hidrelétrica } \\
\hline Equipamento & Percentual de falhas \\
\hline Gerador & $28,73 \%$ \\
\hline Regulador de Velocidade & $21,28 \%$ \\
\hline Turbina Hidráulica & $12,23 \%$ \\
\hline Excitação & $10,10 \%$ \\
\hline Adução/Sucção & $8,51 \%$ \\
\hline Mancal & $13,30 \%$ \\
\hline Serviço Auxiliar & $4,25 \%$ \\
\hline Quadro de Comando & $1,60 \%$
\end{tabular}

Fonte - Kinderman, (2008)

\subsection{A Proteção do gerador síncrono}

Os geradores síncronos estão sujeitos a diversas condições anormais de operação quando conectados ao sistema elétrico de potência, sendo assim, a proteção utilizada no gerador síncrono é, principalmente, devido a:

- Curto-circuito

- Entre espiras

- Entre fases

- Fase e carcaça

○ Trifásico

- Falha de funcionamento

- Perda de excitação

- Carga desequilibrada

- Sobrevelocidade

- Vibração

- Sobrecarga

○ Sobretensão

\subsection{Tipos de proteções do gerador síncrono}

Visando cobrir todos os defeitos e demais anormalidades as proteções mais utilizadas em geradores síncronos são as seguintes: 
- Proteção de sobrecorrente $(50,51)$

- Proteção diferencial (87)

- Proteção de subtensão (27)

- Proteção de sobretensão (59)

- Proteção de sequência negativa (46)

- Proteção de imagem térmica (49)

- Proteção de perda de excitação (40)

- Proteção de sobreexcitação (24)

- Proteção de distância (21)

- Proteção direcional de potência (32)

- Proteção de freqüência (81)

- Proteção de perda de sincronismo (78)

- Proteção de balanço de tensão (60)

- Proteção de terra (ground) (64)

- Proteção de balanço de corrente (61)

- Proteção de mancal (38)

- Proteção contra vibrações (39)

\subsection{Proteção digital}

Atualmente, os relés digitais de proteção são os equipamentos mais utilizados nos sistemas de proteção dos sistemas elétricos. Os projetos de novas subestações de energia elétrica fazem uso exclusivamente da tecnologia dos relés de proteção digitais. Os relés de proteção eletromecânicos e de estado sólido, instalados em subestações antigas, vêm também, gradativamente, sendo substituídos por modernos relés digitais, Coury, et al., (2007).

As proteções utilizadas nos sistemas elétricos começaram com os relés eletromecânicos, os quais utilizavam principalmente componentes como eletroímãs, molas, discos e mancais, entre outros componentes móveis para medição e atuação. No final da década de 60 e início da década de 70 surgiram os relés estáticos. 0 termo estático foi originado em oposição aos relés eletromecânicos, já que o relé estático era caracterizado essencialmente pela ausência de movimentos mecânicos, pois eram construídos com dispositivos eletrônicos. Estes já inseriram certo grau de 
sofisticação nos relés, através da eletrônica analógica. A partir da década de 90 surgiram os relés digitais.

Atualmente, as proteções estão sendo providas através dos relés digitais, os quais utilizam eletrônica digital, de forma a exercer as mesmas funções dos outros relés, porém com maior precisão, maior velocidade de processamento e principalmente com muito mais versatilidade e capacidade de adaptação a diferentes sistemas, Coury, et al., (2007). Além disto, os relés digitais disponibilizam várias informações relativas ao sistema, como oscilografias e sequência de eventos.

Os relés digitais consistem de sub-sistemas com funções bem definidas. $O$ diagrama de blocos da Figura 4.2 mostra os principais sub-sistemas de um relé digital.

Nos sistemas elétricos de potências as correntes e tensões são normalmente expressas em KV (kilovolts) e KA (kiloampères), valores muito elevados para serem tratados por um dispositivo eletrônico. Para que estes valores possam ser reduzidos a valores adequados aos componentes eletrônicos dos relés digitais são utilizados TCs e transformadores de potencial (TPS). Os circuitos secundários destes dispositivos reproduzem fielmente as formas de onda do sistema, porém em valores nominais secundários tipicamente de $1 \mathrm{~A}$ ou $5 \mathrm{~A}$ para os TCs e 100V ou 120V para os TPs.

Os valores provenientes dos secundários dos TCs e TPs ainda são elevados para serem tratados por equipamentos eletrônicos, além de expor estes circuitos às faltas que podem ocorrer no sistema. Para evitar danos aos circuitos eletrônicos são utilizados circuitos condicionadores de sinais, compostos principalmente por capacitores, transformadores e diodos zener para efetuar 0 isolamento entre os secundários dos medidores e os circuitos eletrônicos, além de já tratarem o sinal de forma a reduzir ainda mais seus valores, Johns, Salman (1995).

Também são aplicados filtros passa baixa com função anti-aliasing para filtrar as altas freqüências indesejadas que por ventura possam estar presentes nos sinais obtidos. Circuitos sample and hold são empregados para que vários sinais possam ser tratados de forma serial sem perder sincronismo pelos circuitos multiplexadores que efetuam a transmissão de sinais provenientes de vários canais de entrada.

Os dados provenientes dos multiplexadores são então tratados pelo conversor analógico digital (A/D). Este componente transforma os dados analógicos 
que representam o comportamento do sistema em sinais digitais equivalentes, que então podem ser tratados e processados pelo software do relé.

A parte final do sistema digital de proteção é a unidade auxiliar do relé, a qual é responsável por transformar os sinais de disparo de baixa potência da saída do relé em sinais capazes de atuar sobre disjuntores e outras chaves que efetuam o desligamento do objeto protegido.

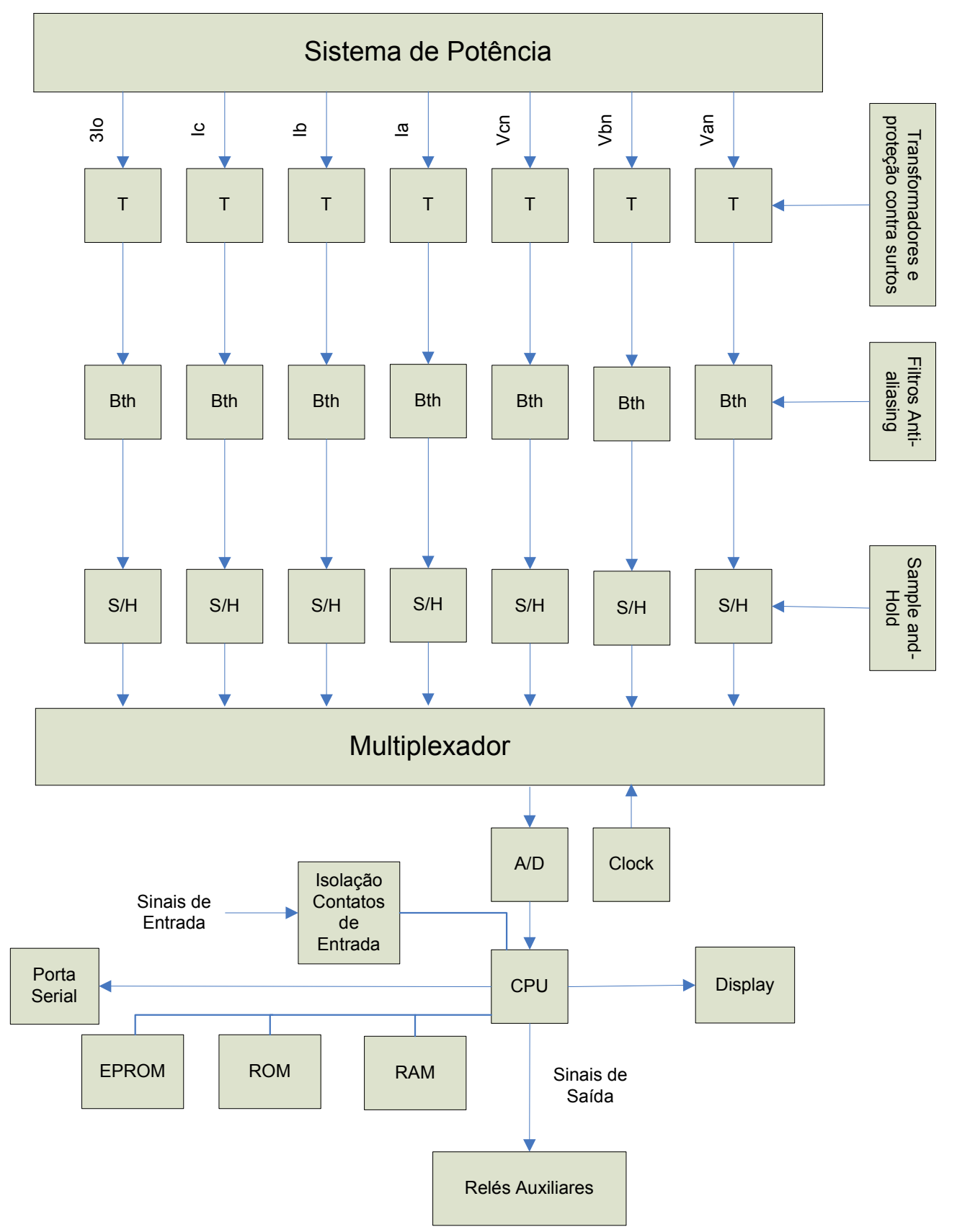

Figura 4.2 - Principais sub-sistemas de um relé computadorizado 


\subsection{Proteção diferencial}

Segundo Reimert (2006) e Kindermann (2008), a proteção diferencial (87), protege o gerador dos curtos-circuitos, associados com o enrolamento (bobina) do estator, que produz elevadas correntes de curto-circuito. Os efeitos térmicos dessas correntes podem causar danos à isolação; ou ainda, as forças magnéticas associadas com essas correntes podem deformar os enrolamentos e submeter 0 eixo e os acoplamentos a choques mecânicos.

O esquema da proteção diferencial de gerador é o mesmo utilizado no transformador, mas com a facilidade de que, na proteção do gerador, a magnitude das correntes de entrada e saída é a mesma para o mesmo enrolamento (fase) e para a condição normal de operação. Dessa forma, pode-se empregar TCs com mesma relação de transformação, diminuindo os erros de relação de transformação, tão comuns em transformadores de potência.

A Figura 4.3 mostra a proteção diferencial típica utilizada na proteção dos enrolamentos do estator (armadura) da máquina síncrona.

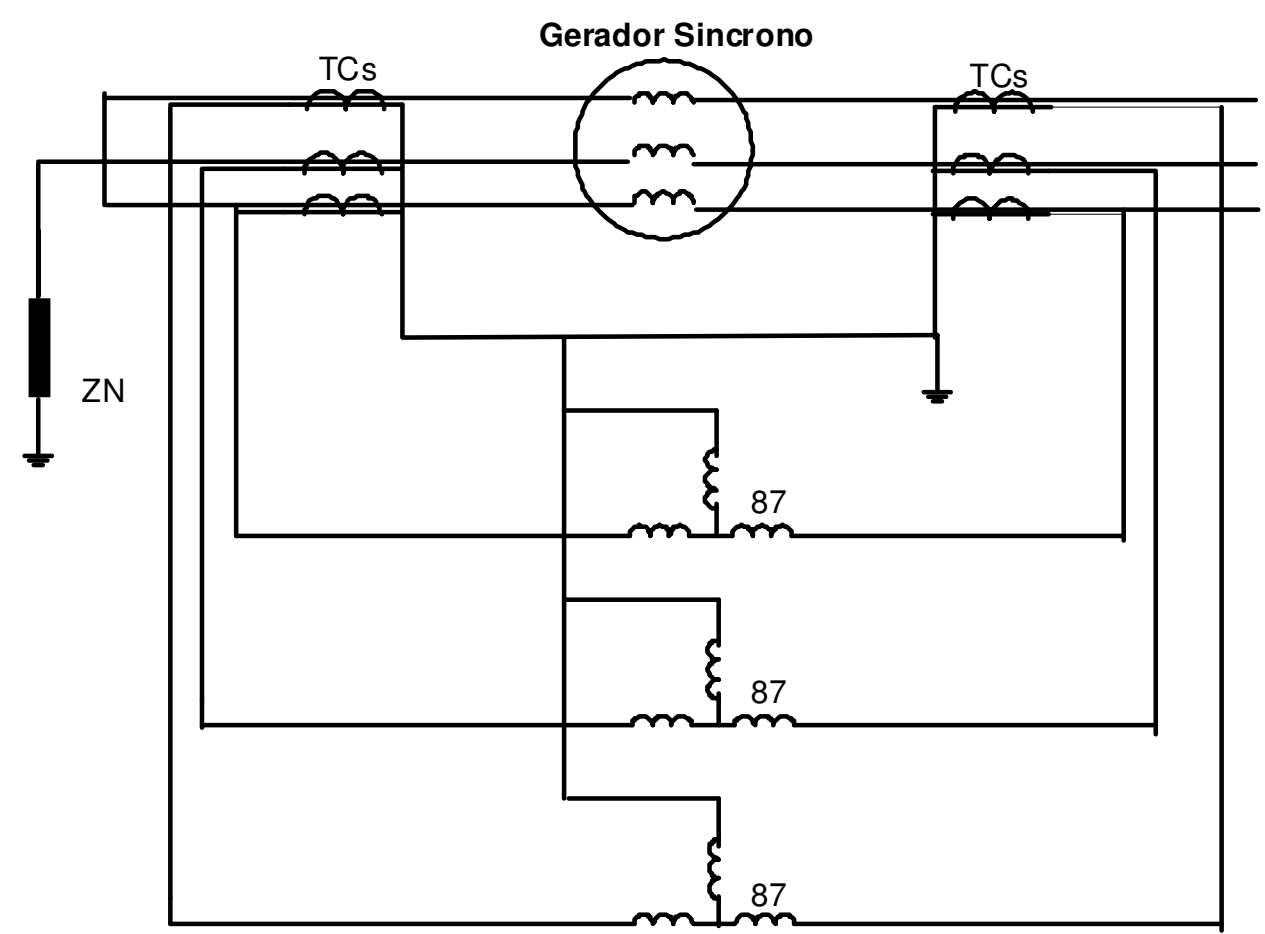

Figura 4.3 - Proteção diferencial dos enrolamentos da máquina síncrona 
Essa proteção é adequada para defeitos que causam curtos-circuitos nos enrolamentos do estator, que são:

- Curto-circuito trifásico;

- Curto-circuito bifásico;

- Curto-circuito monofásico para a carcaça, em gerador síncrono com aterramento sólido do neutro;

- Curto-circuito monofásico para a carcaça (terra) com alguma restrição, nos geradores que tenham aterramento com alta impedância no neutro.

Outro esquema de proteção diferencial do tipo autobalanço, utilizada em máquinas de pequeno porte, é apresentado na Figura 4.4.

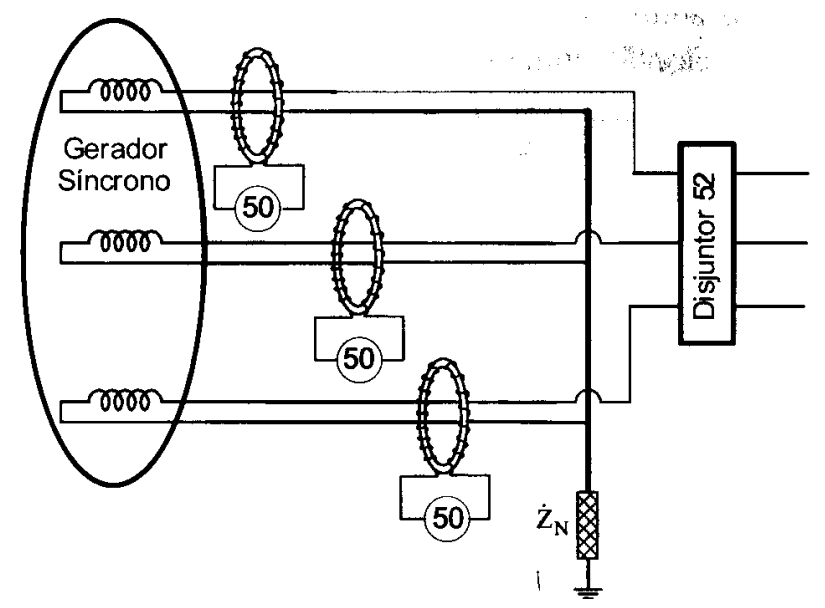

Figura 4.4 - Proteção diferencial tipo autobalanço

Fonte:(kindermann, 2008)

A proteção utilizada é a de sobrecorrente que está exercendo a função da proteção diferencial. O TC é do tipo janela, com núcleo toroidal, na qual, em operação normal, as correntes elétricas de entrada e saída, são iguais. Um defeito interno provoca um desbalanço de corrente, tal que, se a diferença for maior do que o ajuste da proteção, o relé de sobrecorrente atua. Nesse tipo de proteção para máquinas de pequeno porte é requerido que os TCs sejam de baixa relação e, para evitar a saturação, os relés utilizados, devem ser de baixa carga (burden). Nota-se que TC de baixa relação fornece no secundário uma corrente elétrica de amplitude mais elevada, sensibilizando melhor o relé de sobre corrente. 
Quando a proteção diferencial engloba a unidade de geração, constituída pelo conjunto gerador e transformador elevador, como apresentado na Figura 4.5, a proteção é chamada de diferencial longa.

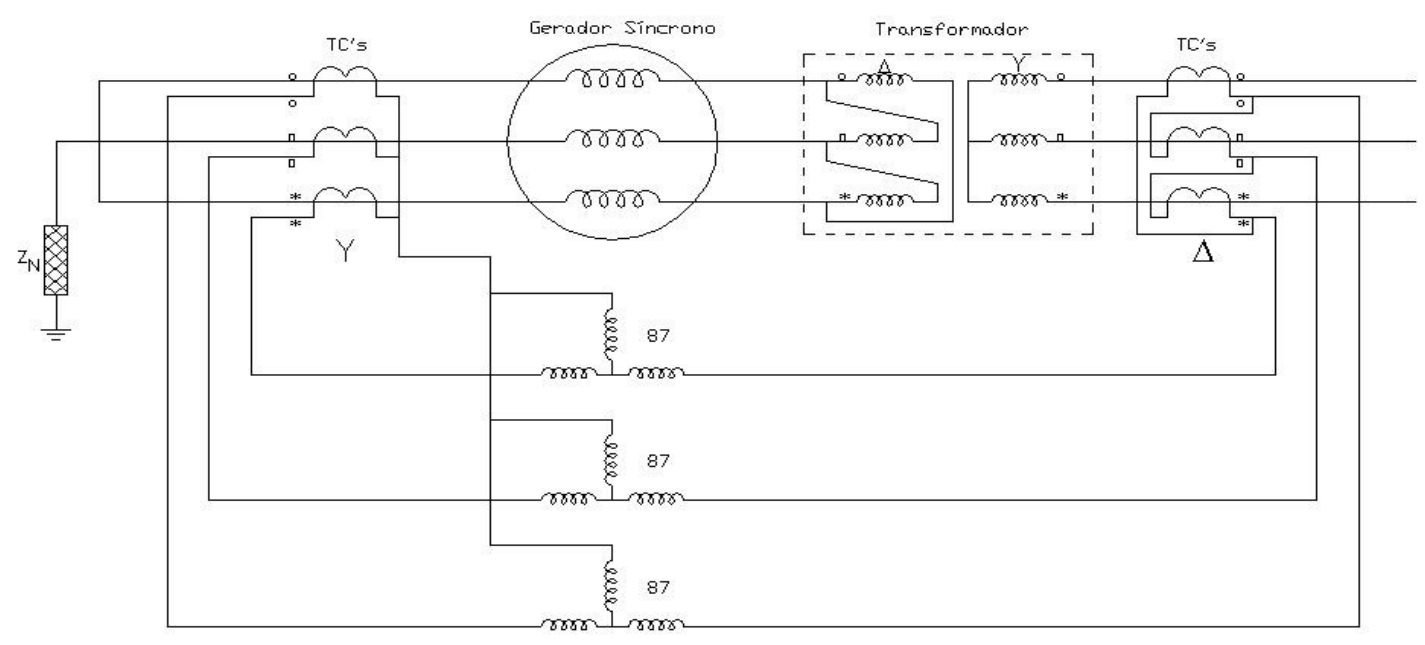

Figura 4.5 - Proteção diferencial longa

Fonte:(kindermann, 2008)

$\mathrm{Na}$ Figura 4.5 observa-se que o transformador elevador, conectado ao gerador síncrono, é do tipo $\Delta$ - Y. Por esta razão as correntes de operação, no lado primário e secundário, estão defasadas de $\pm 30^{\circ}$, o que faria a proteção diferencial atuar desnecessariamente. Para contornar este problema há a necessidade de compensar a rotação de $\pm 30^{\circ}$, fazendo as ligações dos TCs como indicado por (Kindermann, 2008).

Este tipo de fechamento de transformador é preferido porque todos os curto-circuitos monofásicos à terra, no lado do sistema elétrico, não passam pelo aterramento do gerador síncrono; e as harmônicas de $3^{\text {a }}$ ordem e seus múltiplos, normalmente geradas no gerador síncrono, não passam ao sistema elétrico.

\subsection{Relé diferencial ideal}

A forma mais simples de uma proteção diferencial é fornecida por um relé instantâneo conectado como mostra a Figura 4.6. A direção de fluxo de corrente mostrado é para carregamento ou para uma falta fora da zona de proteção do 
diferencial. Assumindo correntes ideais nos TCs, as correntes $I_{1}$ e $I_{2}$ serão idênticas e a corrente de operação do relé $I_{0}$ será zero.

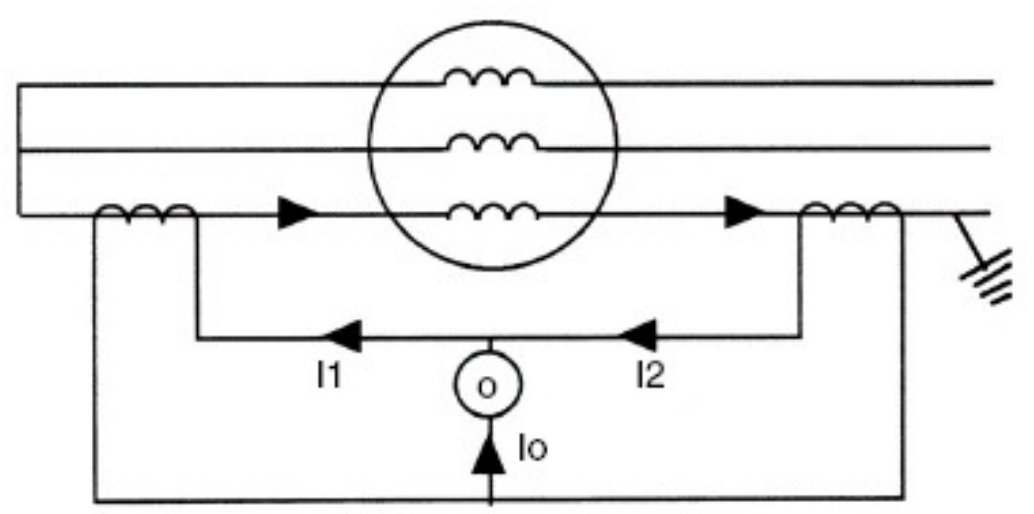

Figura 4.6 - Falta externa ao relé diferencial

Fonte:(Reimert,2006)

Quando ocorre uma falta dentro da zona de proteção do diferencial, como mostra a Figura 4.7, a corrente de um TC irá inverter-se e a corrente no relé torna-se a corrente de curto circuito total como refletida pela relação do TC, $I_{0}=I_{1}+I_{2}$. O único limite para a sensibilidade e o tempo de operação deste esquema seria a faixa ajustável e a velocidade do relé instantâneo escolhido.

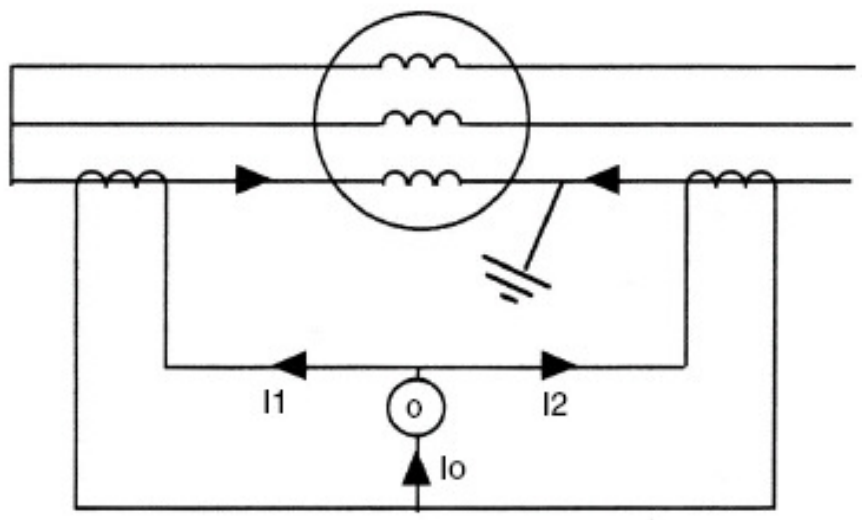

Figura 4.7 - Falta interna ao relé diferencial

Fonte:(Reimert,2006)

É importante notar que esse esquema diferencial não detecta a falta entre espiras no enrolamento do estator. Este tipo de falta pode causar correntes de fases diferentes, isso porque a corrente diferencial em cada TC será igual, e o relé não detectará essa falta. 
Para obter-se a proteção de defeitos entre espiras, utiliza-se uma proteção diferencial especial, chamada função 61 , a qual pode ser realizada por vários relés, e que depende do porte do gerador e do esquema adotado.

Muitos geradores síncronos não usam proteção para defeito entre espiras, por ser rara essa ocorrência. Outra razão deve-se ao aspecto construtivo da máquina síncrona de grande porte, onde são colocadas, uma ou duas espiras por ranhura. Desse modo, o nível da tensão elétrica entre espiras é baixo, não forçando a isolação. Entretanto, se o gerador não tiver proteção para defeito entre espiras, na ocorrência dessa falha, este defeito evolui, gerando outros danos, que só serão eliminados com a atuação de alguma proteção existente. Geralmente, o defeito evolui rapidamente para um curto-circuito à carcaça.

\subsection{Proteção diferencial percentual}

A proteção diferencial envia o sinal de abertura aos disjuntores do gerador, aos disjuntores de campo e inicia a parada imediata da fonte motriz. Os relés eletromecânicos que desempenham essa função possuem uma bobina de operação (O) e uma bobina de restrição (R), como mostra a Figura 4.8.

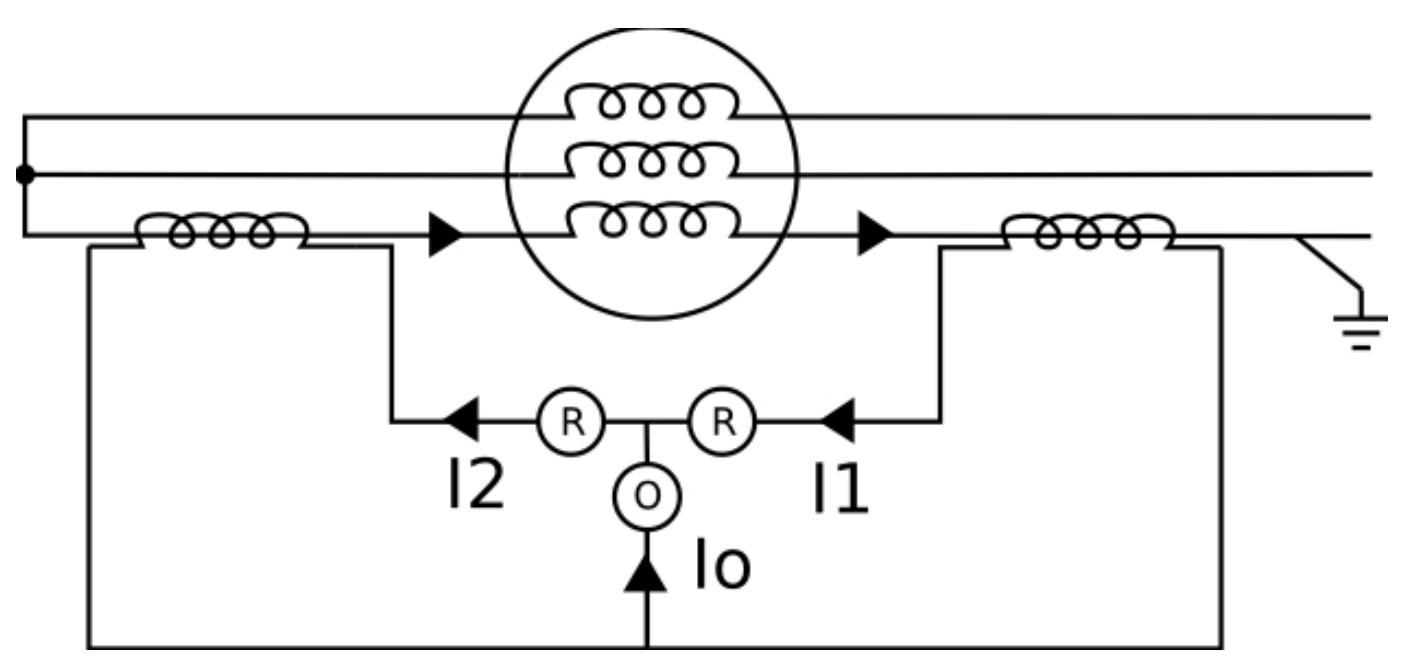

Figura 4.8 - Proteção diferencial percentual 
A corrente na bobina de restrição produz um torque de abertura do contato, e a corrente na bobina de operação produz torque de fechamento do contato. Os contatos serão fechados quando o valor da corrente de operação exceder o valor da corrente de restrição, devido a uma determinada percentagem, que é referida como a inclinação da reta de ajuste. Este esquema proporciona um aumento automático da corrente de operação, necessário para o disparo do relé, quando a corrente de carga e o erro podem aumentar, ou seja, o erro aumenta com a corrente de carga.

Para faltas externas, as correntes de operação $I_{0}$ e restrição $I_{r}$ são dadas por:

$$
\begin{aligned}
& I_{0}=I_{1}-I_{2} \\
& I_{r}=\frac{\left|I_{1}+I_{2}\right|}{2}
\end{aligned}
$$

Em casos de faltas internas, as correntes de operação e restrição são dadas por:

$$
\begin{gathered}
I_{0}=I_{1}+I_{2} \\
I_{r}=\frac{I_{1-} I_{2}}{2}
\end{gathered}
$$

A figura 4.9 mostra um exemplo de curva de ajuste empregada neste tipo de proteção.

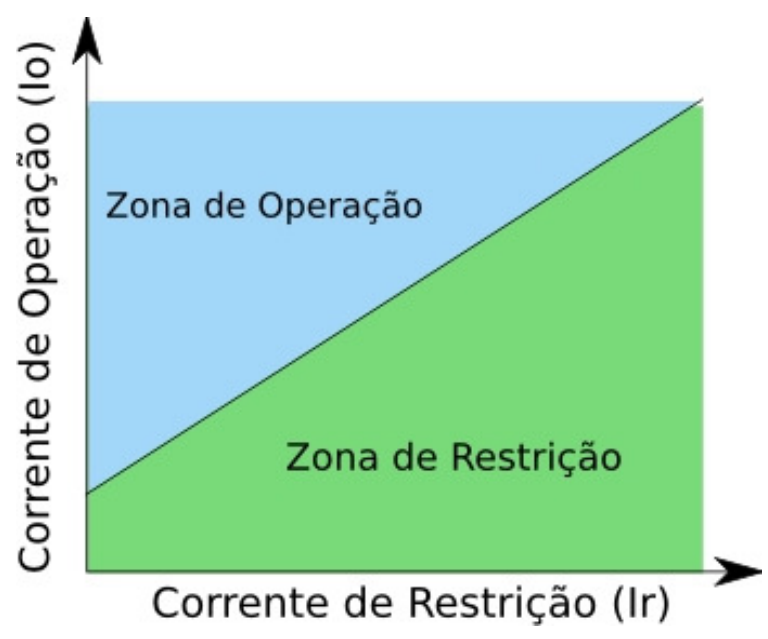

Figura 4.9 - Curva de ajuste para proteção diferencial percentual 
É importante frisar que a proteção diferencial não é capaz de detectar faltas entre espiras do enrolamento do estator. Neste tipo de falta, a corrente que entra em um enrolamento e dele sai é a mesma, não sensibilizando a proteção diferencial.

\subsection{Considerações práticas}

$\mathrm{Na}$ prática, transformadores de corrente não-ideais impõem uma sensibilidade significante e restrições de velocidade operante neste esquema. Nesse sentido, o esquema ideal é baseado na suposição de que os TCs providenciem uma reprodução precisa da corrente primária, o que, infelizmente, não ocorre.

Um TC como qualquer outro transformador, deve desenvolver uma tensão secundária para produzir uma corrente secundária. Isto requer estabelecer um fluxo magnético no núcleo do TC e uma corrente de excitação para manter este fluxo no núcleo.

A Figura 4.10 é um circuito equivalente para um TC, em que a saída do TC é a corrente secundária ideal $\left(I_{p} / N\right)$ menos a corrente de excitação $\left(I_{e}\right)$. Quando a tensão secundária do TC aumenta, também eleva a corrente de excitação e, com isso, o erro do TC.

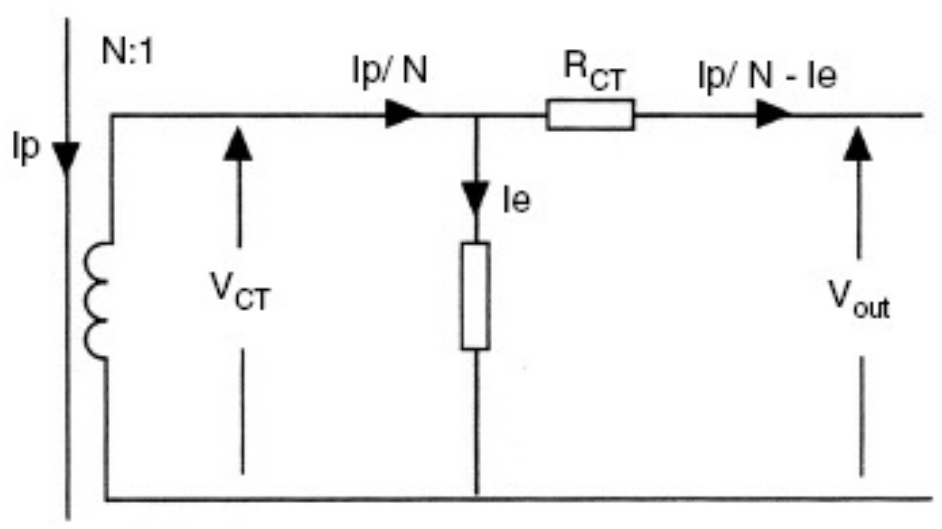

Figura 4.10 - Circuito equivalente do transformador de corrente

Fonte:(Reimert,2006) 
O impacto do erro do TC no esquema diferencial é demonstrado na Figura 4.11. No esquema diferencial ideal, a corrente de carga ou uma falta externa à zona de proteção do diferencial não produzirá corrente no relé.

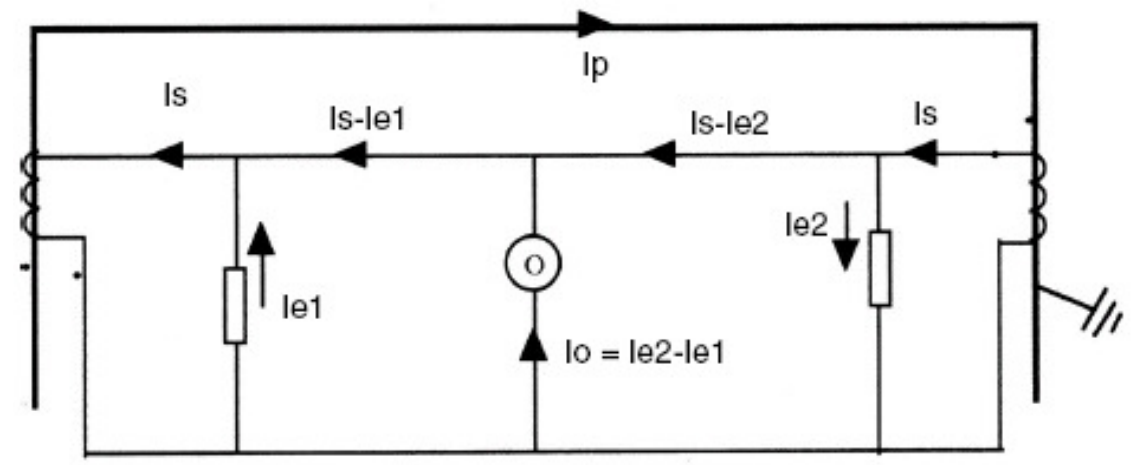

Figura 4.11 - Corrente de erro

Fonte:(Reimert,2006)

Quando TCs práticos são considerados, uma corrente de erro igual à diferença de duas correntes de excitação fluirá no relé. A consideração principal no projeto e a aplicação de qualquer relé diferencial é que a corrente de erro, resultante de uma falta externa à zona do diferencial, não induzirá com que o esquema opere erroneamente.

Pode-se verificar, então, que a variação da corrente de excitação com a tensão secundária não é linear.

A corrente secundária e a impedância total do circuito secundário do TC determinam qual tensão o TC deve produzir. Essa impedância é conhecida como a carga (Burden) do TC, que é a sua própria resistência, a resistência de condutores do circuito de corrente, e a impedância do circuito de entrada (Input) do relé diferencial.

Quando o TC esta operando em carga máxima (5 A no circuito secundário), a tensão do TC é mínima. A corrente de excitação para cada TC está na proximidade de milésimos de Amper ( $\mathrm{mA})$, e a corrente de erro é muito baixa. Uma corrente de falta, fora da zona do diferencial, pode requerer centenas de volts. Nessa condição extrema, diferenças nas características de excitação e carga resultarão em grandes variações na corrente de excitação entre os dois TCs. Assim, um relé instantâneo teria que ser ajustado acima da corrente de erro para prevenir falha de operação. 
A sensibilidade máxima de um relé é obtida minimizando a diferença em correntes de excitação para condições de falta externa. O projeto ideal seria, então, incluir TCs com características idênticas de excitação e carga. Contudo, o circuito de carga esta a mercê do local físico do equipamento e do direcionamento dos cabos. Mesmo quando os TCs são do mesmo tipo e fabricante, podem resultar em uma grande corrente de erro por causa de tolerâncias de fabricação, Reimert (2006).

Apresenta-se na Figura 4.12, o diagrama unifilar de proteção de uma unidade, gerador síncrono e transformador elevador, de grande porte, de uma usina hidrelétrica. $O$ intuito da figura 4.12 é mostrar que o trabalho de pesquisa engloba somente a proteção diferencial do gerador síncrono (87G), sendo que esta se encontra destacada na cor em vermelho, apesar de ter outras proteções importantes no gerador que já foram mencionadas nesse capítulo, mas que não são o foco desse trabalho. 


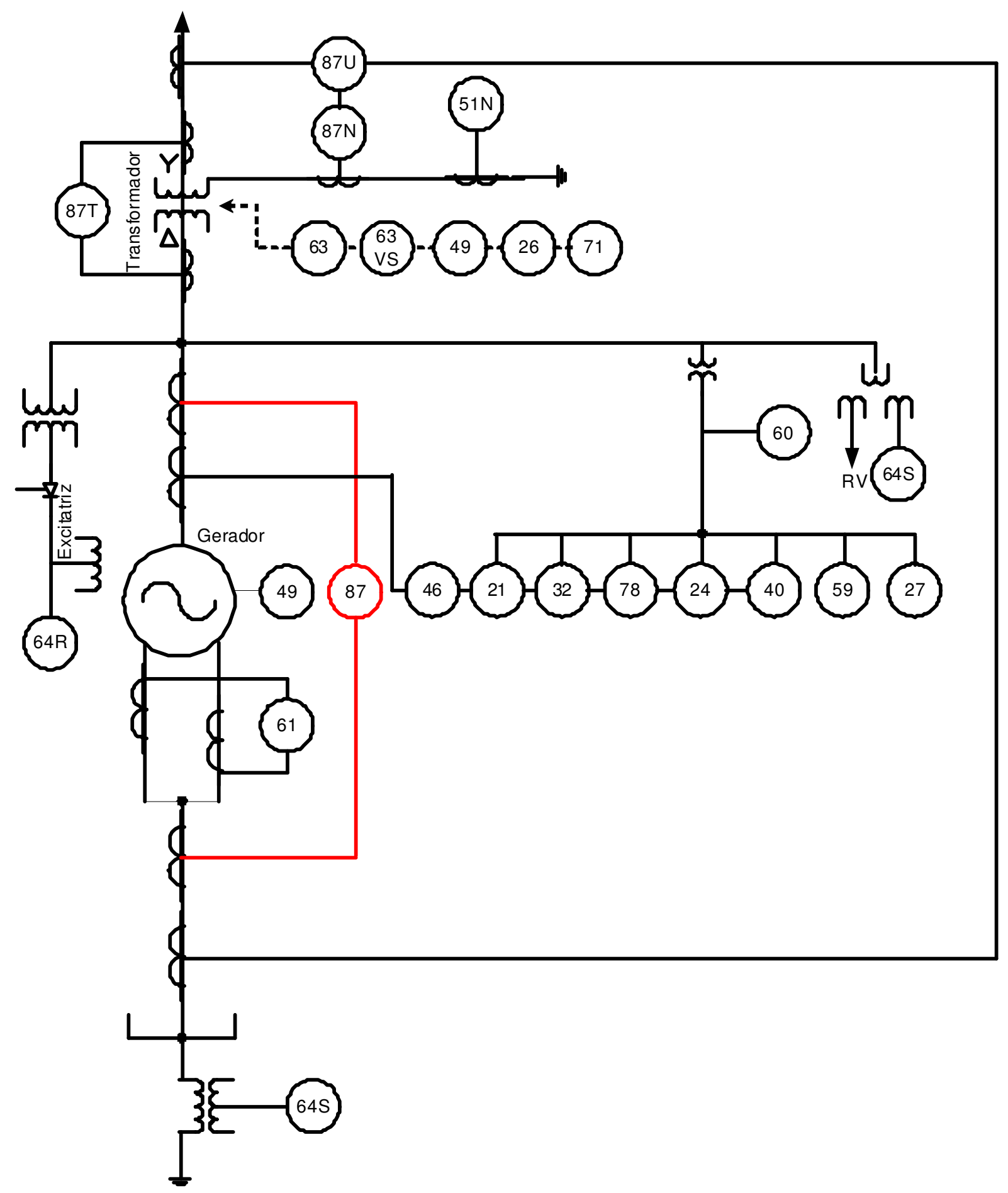

Figura 4.12 - Proteção de um gerador síncrono e transformador elevador de uma usina hidrelétrica 
Conforme já enunciado, neste estudo o enfoque será na proteção diferencial de gerador (87G) como ilustrado em vermelho na Figura 4.12, apesar de o diagrama unifilar mostrar outras proteções que fazem parte do gerador e transformador. Outro ponto importante, já abordado no capítulo 3, é a saturação dos TCs.

Segundo Coury, et al., (2007), os transformadores de corrente empregados nos dois terminais (lado de alta e neutro) de um enrolamento de gerador são especialmente "casados" para reduzir a disparidade no seu desempenho. Isto é possível para o caso de geradores (e reatores) devido às correntes primárias idênticas nos dois TCs, o que não ocorre para um relé diferencial de transformador.

Também não é necessário nenhum artifício para considerar os erros causados pelas mudanças dos taps. Logo, um relé de proteção diferencial aplicado a um gerador pode ser extremamente sensível. Para o caso dos geradores, obviamente, não é preciso se preocupar com a corrente de magnetização presente nos transformadores de potência.

Uma vez abordada a proteção dos geradores e suas especificidades, no próximo capítulo, adentra-se para explanações sobre as RNAs e suas finalidades. 


\section{REDES NEURAIS ARTIFICIAIS}

O objetivo deste capítulo é traçar um panorama sobre a evolução dos estudos a respeito de (RNAs), sua aplicação e as características de sua arquitetura, abrangendo o perceptron de múltiplas camadas, o treinamento backpropagation e o treinamento Levenberg-Marquardt.

\subsection{Histórico}

As RNAs foram inspiradas no pouco que o homem já conhece sobre 0 funcionamento dos esquemas mentais do cérebro humano. $O$ final da década de 80 marcou o ressurgimento da área de RNAs, também conhecida como o conexionismo ou sistemas de processamento paralelo e distribuído. Esta forma de computação não-algorítmica é caracterizada por sistemas que, em algum nível, relembram a estrutura do cérebro humano. Por não ser baseada em regras ou programas, a computação neural se constitui em uma alternativa à computação algorítmica convencional.

Conforme Braga, Lurdemir e Carvalho (2000), as RNAs são sistemas paralelos distribuídos, compostos por unidades de processamento simples (nodos), que calculam determinadas funções matemáticas (normalmente não-lineares). Tais unidades são dispostas em uma ou mais camadas e interligadas por um grande número de conexões, geralmente unidirecionais. Na maioria dos modelos, estas conexões estão associadas a pesos, os quais armazenam o conhecimento representado no modelo e servem para ponderar a entrada recebida, individualmente, pelos neurônios da rede.

A solução de problemas através de RNAs é bastante atrativa, já que a forma como estes problemas são representados internamente pela rede, e o paralelismo natural inerente à arquitetura das RNAs criam a possibilidade de um desempenho superior ao dos modelos convencionais. Em RNAs, o procedimento usual, na solução de problemas, passa inicialmente por uma fase de aprendizagem, em que um conjunto de exemplos é apresentado para a rede, a qual extrai automaticamente as características necessárias para representar a informação fornecida. Essas características são utilizadas posteriormente para gerar respostas ao problema. 
A capacidade de aprender através de exemplos e de generalizar a informação aprendida é, sem dúvida, o atrativo principal da solução de problemas valendo-se de RNAs. A generalização, que está associada à capacidade de a rede aprender mediante um conjunto reduzido de exemplos e, posteriormente, fornecer respostas coerentes para dados não-conhecidos, é uma demonstração de que a capacidade das RNAs vai muito além do que simplesmente mapear relações de entrada e saída.

As RNAs são capazes de extrair informações não-apresentadas de forma explícita por intermédio dos exemplos. Não obstante, as RNAs são capazes de atuar como mapeadoras universais de funções multivariáveis, como custo computacional que cresce apenas linearmente com o número de variáveis. Outra característica importante é a capacidade de auto-organização e de processamento temporal, que, aliada àquelas citadas anteriormente, faz das RNAs uma ferramenta computacional extremamente poderosa e atrativa para a solução de problemas complexos.

A Figura 5.1 ilustra as características físicas do neurônio biológico com as características computacionais de um neurônio artificial.

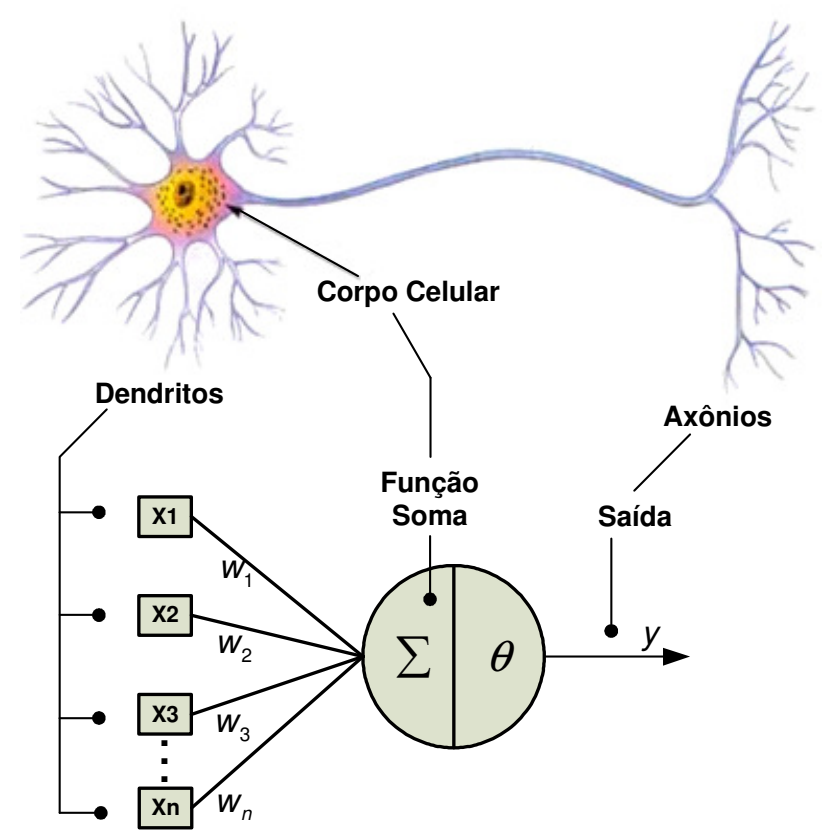

Figura 5.1 - Representação do neurônio artificial modelado por McCulloch e Pitts comparado a um neurônio biológico. 
Os neurônios são divididos em três seções: o corpo da célula, os dendritos e o axônio, cada um com funções específicas, porém, complementares. O corpo do neurônio mede apenas alguns milésimos de milímetros, e os dendritos apresentam poucos milímetros de comprimento. $\mathrm{O}$ axônio, contudo, pode ser mais longo e, em geral, tem calibre uniforme. Os dendritos tem por função receber as informações, ou impulsos nervosos, oriundas de outros neurônios e conduzi-las até o corpo celular. Aqui, a informação é processada, e novos impulsos são gerados. Estes impulsos são transmitidos a outros neurônios, passando através do axônio até chegar aos dendritos dos neurônios seguintes.

O ponto de contato entre a terminação axônica de um neurônio e o dendrito de outro é chamado de sinapse. É pelas sinapses que os nodos se unem funcionalmente, formando redes neurais. As sinapses funcionam como válvulas, e são capazes de controlar a transmissão de impulsos, isto é, o fluxo da informação entre os nodos da rede neural. O efeito das sinapses é variável, e é esta variação que dá ao neurônio capacidade de adaptação.

Os sinais oriundos dos neurônios pré-sinápticos são passados para o corpo do neurônio pós-sináptico, onde são comparados com os outros sinais recebidos por ele. Se o percentual em um intervalo curto de tempo é suficientemente alto, a célula "dispara", produzindo um impulso que é transmitido para as células seguintes (nodos pós-sinápticos). Este sistema simples é responsável pela maioria das funções realizadas pelo cérebro humano. A capacidade de realizar funções complexas surge com a operação em paralelo de todos os $10^{11}$ nodos do cérebro.

Conforme Haykin (1994), redes neurais são definidas como modelos matemático-computacionais inspirados no comportamento do cérebro humano. $O$ cérebro humano possui um sistema de processamento da informação extremamente complexo, não-linear e paralelo, ao passo que as redes neurais artificiais possuem um processamento paralelo que é distribuído pelas suas unidades de processamento, ou seja, os neurônios são favoráveis ao armazenamento de conhecimento, de forma a disponibilizá-lo para sua posterior utilização.

Portanto, as redes neurais artificiais são parecidas ao cérebro em duas características:

- Seu conhecimento é adquirido por um processo de aprendizado. 
- As conexões entre seus neurônios são utilizadas para armazenar o conhecimento adquirido.

As RNAs possuem como principais características a capacidade de aprender por intermédio de exemplos e a generalização das informações aprendidas. A generalização está atrelada à capacidade de a rede aprender pela apresentação de um conjunto reduzido de exemplos, onde ela deverá estar apta a fornecer respostas coerentes para dados que não tenham sido utilizados em sua etapa de aprendizado. Outras características como tolerância a falhas, auto-organização e capacidade de agrupar ou organizar dados também podem ser observadas em algumas arquiteturas de redes neurais.

Quanto à aplicação de RNAs, pode-se dizer que estas abrangem diversas áreas do conhecimento, como: Física, Matemática, Engenharia, Neurofisiologia, dentre outras. Pelo fato de as RNAs serem aptas a resolver problemas de cunho geral, tais como aproximação, classificação, categorização, predição etc., a gama de áreas onde podem ser aplicadas é bastante extensa.

Neste trabalho foram empregadas as RNAs com arquitetura de múltiplas camadas, denominada Multilayer Perceptron (MLP). Este tipo de arquitetura geralmente é aplicado em tarefas de reconhecimento de padrões, aproximação funcional, identificação e controle (Haykin, 1994). Assim, considerando-se o propósito do reconhecimento de padrões referentes à saturação dos TCs e, também, a aproximação funcional realizada para a correção da saturação, verifica-se, então, que esta arquitetura adere à tarefa proposta.

\subsection{Arquiteturas de redes neurais artificiais}

A arquitetura de uma RNA relaciona-se diretamente com o algoritmo de aprendizado empregado para o treinamento da rede e com sua capacidade para resolução de determinados tipos de problemas. Alguns parâmetros como número de camadas, quantidade de neurônios por camada, tipo de conexão entre os neurônios e a topologia da rede devem ser levados em consideração para determinar sua arquitetura.

Quanto ao número de camadas, estas podem ser categorizadas em: 
- Camada única ou;

- Múltiplas camadas.

Quanto aos tipos de conexão entre os neurônios, estes podem ser:

- Totalmente conectados ou;

- Parcialmente conectados.

Quanto à topologia da rede, estas podem ser principalmente divididas em:

- Feedforward e;

- Feedback.

A quantidade de neurônios por camada normalmente não segue uma regra e são determinadas de forma experimental.

Outro fator que normalmente não é utilizado para a especificação da arquitetura de uma RNA, porém, está fortemente ligado à sua arquitetura é a função de ativação de cada neurônio. Em geral, utiliza-se a mesma função de ativação para os neurônios de uma dada camada.

Algumas das funções de ativação mais utilizadas têm seus cálculos e formatos gráficos mostrados nas Figuras 5.2 a 5.8:

- Degrau bipolar

$$
y(n)=\left\{\begin{array}{c}
y=1, \text { se } n>0 \\
y=0, \text { se } n=0 \\
y=-1, \text { se } n<0
\end{array}\right.
$$

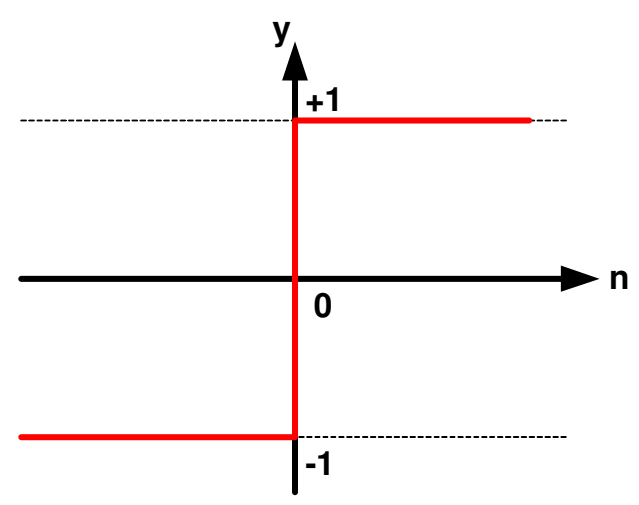

Figura 5.2 - Representação da função de ativação do tipo degrau bipolar.

- Degrau 


$$
y(n)=\left\{\begin{array}{l}
y=1, \text { se } n \geq 0 \\
y=0, \text { se } n<0
\end{array}\right.
$$

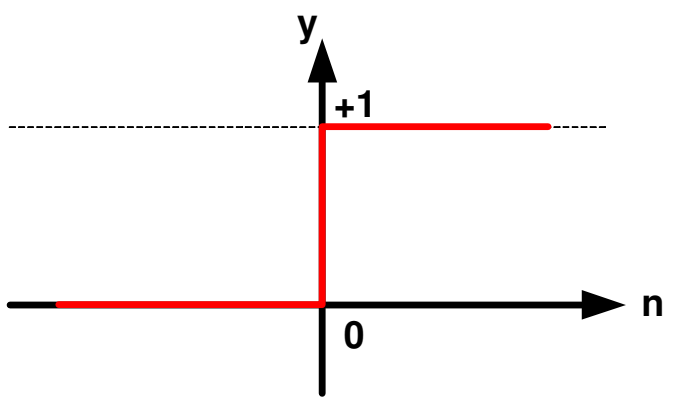

Figura 5.3 - Representação da função de ativação do tipo degrau.

- Linear

$$
y(n)=n
$$

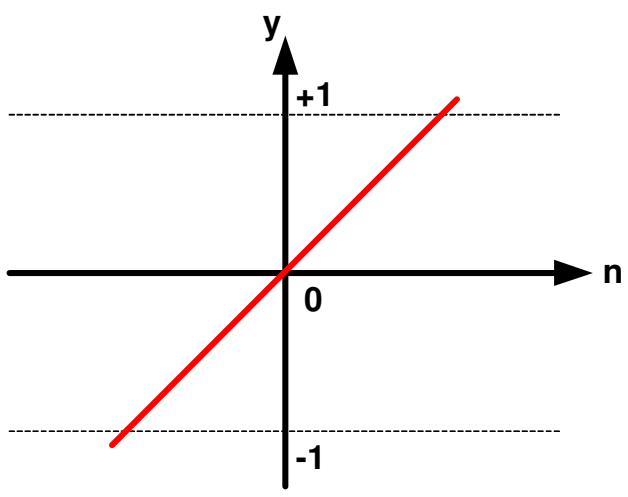

Figura 5.4 - Ilustração da função de ativação do tipo linear.

- Tangente hiperbólica 
$y(n)=\frac{1-e^{-\beta n}}{1+e^{\beta n}}$, onde $\beta$ é o parâmetro de excentricidade

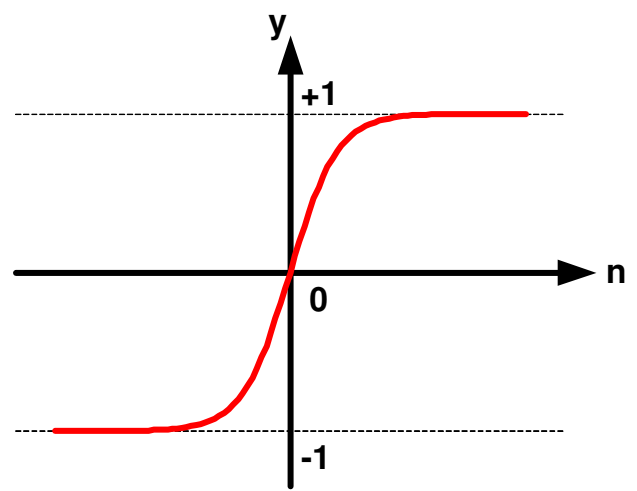

Figura 5.5 - Representação gráfica da função de ativação do tipo tangente hiperbólica.

- Logística (sigmóide)

$$
y(n)=\frac{1}{1+e^{-\beta n}} \text {, onde } \beta \text { é o parâmetro de excentricidade }
$$

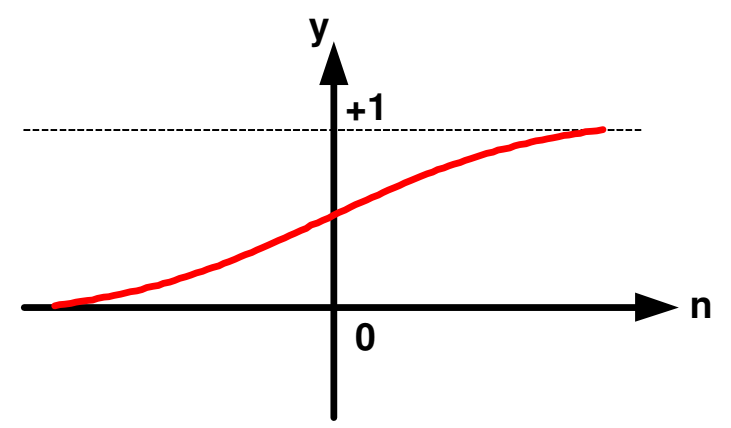

Figura 5.6 - Ilustração da função de ativação do tipo logística (sigmóide).

- Rampa

$$
y(n)\left\{\begin{array}{c}
y=1, \text { se } n>1 \\
y=n, \text { se }-1 \leq n \leq 1 \\
y=-1, \text { se } n<0
\end{array}\right.
$$




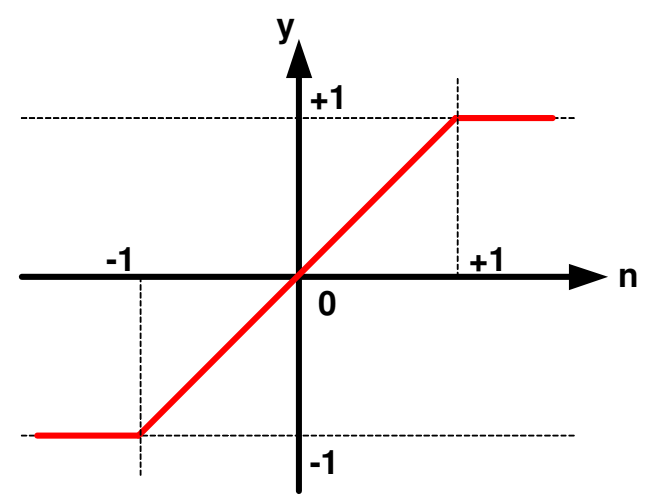

Figura 5.7 - Representação gráfica da função de ativação do tipo rampa.

- Base radial (gaussiana)

$$
y(n)=e^{-\left(\frac{(\sigma n)^{2}}{2 \sigma^{2}}\right)}
$$

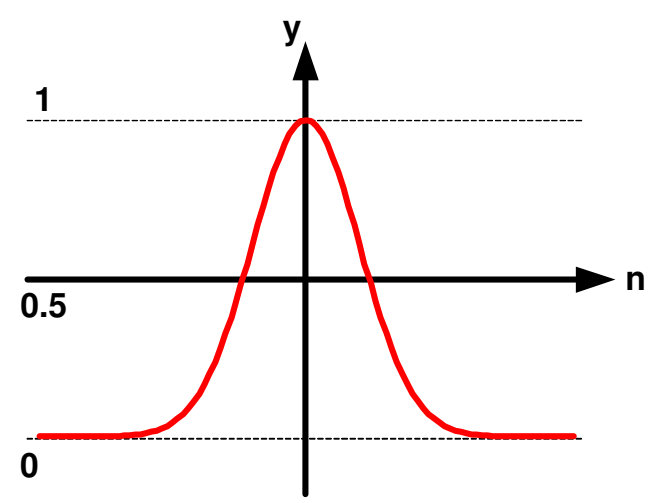

Figura 5.8 - llustração da função de ativação de base radial (gaussiana).

\subsubsection{Perceptron de múltiplas camadas}

Como descrito por Haykin (1994), as redes MLP possuem arquitetura feedforward de múltiplas camadas, sendo constituídas pela camada de entrada, uma ou mais camadas neurais intermediárias e a camada neural de saída.

A camada de entrada recebe os sinais provenientes do processo, as camadas neurais intermediárias têm como função a extração e armazenamento do conhecimento, e a camada neural de saída deverá emitir uma resposta coerente ao estímulo dado na entrada da rede. 
Uma grande vantagem apresentada por esta arquitetura é a vasta quantidade de aplicações como: aproximador funcional, reconhecimento de padrões, otimização e controle de processos, entre outras.

Por utilizarem a topologia feedforward, seu fluxo de dados deve ser passado camada a camada, partindo-se da camada de entrada que irá receber um vetor, contendo os sinais provenientes do sistema, e que serão propagados aos neurônios das camadas intermediárias onde serão devidamente processados. Feito 0 processamento nas camadas intermediárias, estes são emitidos à camada neural de saída que fornecerá o parecer final da rede.

De forma, meramente ilustrativa, apresenta-se pela Figura 5.9 uma rede $M L P$ com apenas uma camada intermediária.

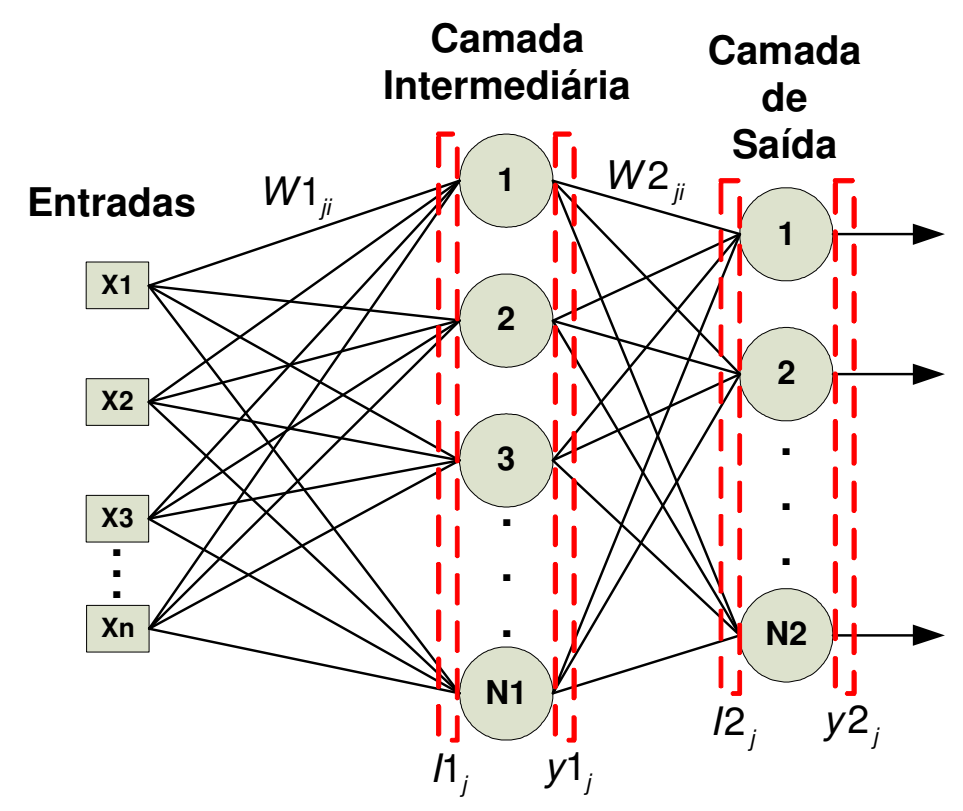

Figura 5.9 - Arquitetura de uma rede neural do tipo MLP

Como pode ser visualizado na Figura 5.9, em redes do tipo MLP os neurônios de cada camada apenas são conectados aos neurônios da camada imediatamente superior, não existindo qualquer outro tipo de conexão entre neurônios. Todo o conhecimento obtido pelo processamento dos neurônios da camada intermediária será armazenado na forma de pesos sinápticos, representados por $W 1_{j i}, W 2_{j i}$.

Porém, assim como uma diversidade de outros métodos para treinamento de redes neurais, o método de Levenberg-Marquardt baseia-se no algoritmo de backpropagation (retro-propagação). Por este motivo, apresenta-se, primeiramente, 
o funcionamento do algoritmo de backpropagation, de forma a fornecer maior embasamento aos aspectos conceituais e matemáticos do algoritmo de LevenbergMarquardt que foi utilizado nesta pesquisa durante a etapa de treinamento das RNAs.

\subsubsection{Treinamento Backpropagation}

Para se treinar uma rede neural do tipo $M L P$ com o algoritmo de backpropagation, apresenta-se um exemplo de entrada, normalmente em formato vetorial que será propagado camada a camada até que a rede forneça uma resposta. Tal resposta deverá ser comparada a uma resposta desejada pré-definida para o exemplo de entrada. Portanto, para todos os exemplos utilizados no treinamento da rede neural, necessita-se de suas respectivas saídas desejadas.

Esta diferença entre a saída da rede e a saída desejada é realizada para se obter o erro quadrático produzido pela rede neural que será retropropagado com o intuito de melhor ajustar os pesos sinápticos. Com o erro quadrático obtido para cada um dos exemplos de treinamento, calcula-se, então, o Erro Quadrático Médio (EQM) que será utilizado como critério de parada ao treinamento da rede neural. Enquanto o EQM não estiver dentro de um limite aceitável, todos os passos anteriores são repetidos, Braga (2000).

\subsubsection{Treinamento Levenberg-Marquardt}

O algoritmo de backpropagation utiliza a direção oposta ao gradiente para encontrar uma solução considerada satisfatória dentro do espaço de busca do problema, porém, este método além de não ser considerado tão favorável para a localização do ótimo global, ainda requer um grande esforço computacional. Devido às características apresentadas pelo algoritmo de backpropagation, empregou-se neste trabalho o algoritmo de Levenberg-Marquardt que se sobrepõe a estas desvantagens.

Muitas técnicas para a otimização do treinamento de RNAs foram propostas na literatura, porém, a técnica de Levenberg-Marquardt que se baseia no método dos mínimos quadrados destaca-se entre as que apresentam uma mais rápida convergência. Tal velocidade durante a convergência é garantida devido ao método 
de Levenberg-Marquardt fazer uso de informações de $2^{\text {a }}$ ordem, visto que 0 algoritmo de backpropagation usa informações de 1aㅡ ordem.

Explicitados o hitórico sobre a evolução e o funcionamento das RNAs e as razões da escolha do algoritmo de Levenberg-Marquardt para a realização deste estudo, no próximo capítulo, aborda-se, então, o sistema elétrico analisado. 


\section{O SISTEMA ELÉTRICO EM ANÁLISE}

Este capítulo traz um histórico sobre o programa Alternative Transients Program (ATP), juntamente com o modelo do sistema elétrico estudado. São apresentados, também, os cálculos realizados para a construção dos arquivos de dados utilizados e seus respectivos formatos, além de gráficos que ilustram algumas das situações envolvidas no trabalho.

Cabe ressaltar que, as simulações realizadas e mostradas neste capítulo são de fundamental importância para o trabalho, pois constituem a base do banco de dados gerados para o treinamento e os testes da ferramenta de inteligência artificial implementada.

\subsection{Histórico do programa ATP}

O programa Electro-Magnetic Transients Program (EMTP), do qual o ATP é originado, foi desenvolvido a partir da década de 60 por Herman W. Dommel, para a Bonneville Power Administration (BPA) (Coury, Campos e Tavares, 1998). Inicialmente, o software trabalhava, simulando circuitos monofásicos mediante modelos de indutâncias, capacitâncias e resistências em linhas sem perdas, incluindo uma chave e uma fonte de excitação. Com o passar do tempo, o programa sofreu modificações de vários autores.

A partir de 1973, Scot Meyer assumiu a coordenação e o desenvolvimento do programa na $B P A$, estabelecendo um método de desenvolvimento em conjunto com os usuários do EMTP, que o tornou poderosa ferramenta em estudos de transitórios em sistemas elétricos. Algumas divergências entre Scott Meyer e o Electric Power Research Institure (EPRI), que investiu no projeto do EMTP a partir de 1984, levaram à criação de uma nova versão do EMTP, a qual foi enviada para a Bélgica onde se instalou o Leuven EMTP Center (LEC). Esta nova versão foi denominada Alternative Transients Program (ATP), que representa a continuação das versões precedentes do programa (Coury, Campos e Tavares, 1998). 
O programa EMTP-ATP trabalha com arquivos de dados em formato de texto, de fácil edição e, após efetuar o processamento destes, gera outros arquivos, incluindo o estudo efetuado. Há também a possibilidade da geração de um outro arquivo, apresentando os resultados obtidos na simulação de tensão, corrente, potência e energia. Estes arquivos são gravados de acordo com instruções previamente informadas no início da execução do processamento (Coury, Campos e Tavares, 1998).

$\mathrm{O}$ arquivo de dados fornecido para 0 ATP tem um formato rigidamente prefixado, de modo que os dados são inseridos em posições definidas, sob pena de erro de processamento. O ATP possui, também uma crítica do arquivo de dados de entrada (extensão.lis). Assim, caso haja a ocorrência de erros, muitas vezes é possível corrigi-los simplesmente pela análise da resposta constante no arquivo de saída (extensão.pl4).

\subsection{Sistema elétrico estudado}

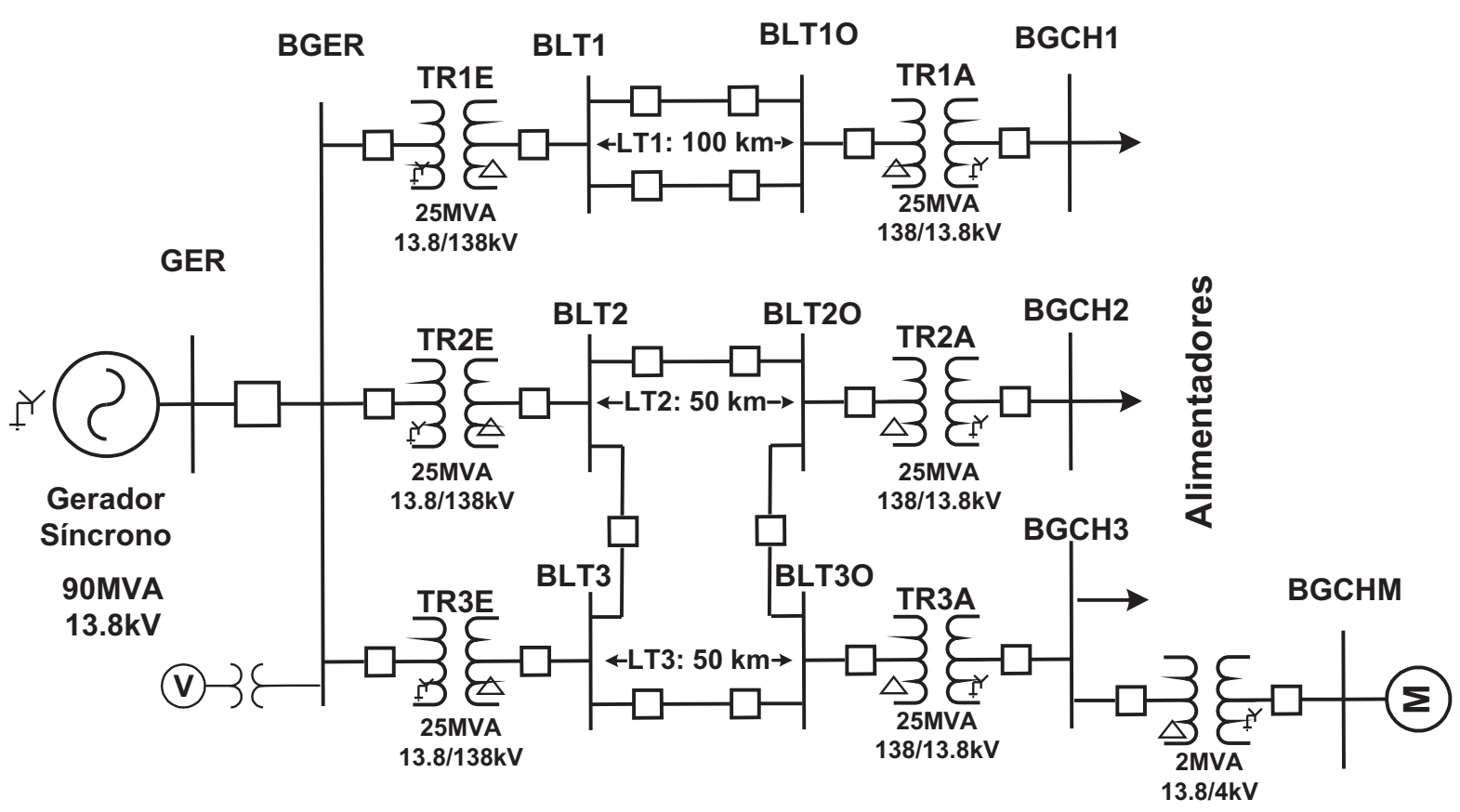

Figura 6.1 - Sistema elétrico estudado

O sistema elétrico utilizado para o desenvolvimento dessa pesquisa é uma variante do sistema amplamente estudado pelo laboratório de Sistemas de Energia 
Elétrica (LSEE), Barbosa, et al. (2007 e 2008), os parâmetros elétricos dos diversos componentes foram obtidos de equipamentos reais.

O sistema elétrico inicial, Figura 6.1, consiste de um gerador síncrono com potência de 90 MVA em tensão de $13,8 \mathrm{kV}$, conectados a uma barra de geração onde estão conectados três transformadores elevadores de 25 MVA de potência, com relação de transformação de 13,8 kV no primário para 138 kV no secundário, em ligação estrela aterrado - triângulo e seguindo três linhas de transmissão, sendo duas de $50 \mathrm{~km}$ e uma de $100 \mathrm{~km}$. Seguindo-se o diagrama unifilar, têm-se, então, três SEs abaixadoras em 138 kV no primário para 13,8 kV no secundário, em ligação triângulo-estrela aterrado, e a saída para três alimentadores de distribuição.

A base de dados, ou seja, os sinais de corrente dos terminais do gerador foram gerados a partir de simulações executadas no SEP apresentado anteriormente. A base de dados foi constituída por 44 faltas internas ao gerador e 44 faltas externas, onde se variou o tipo de falta e o seu ângulo de incidência. Os dados foram gerados com uma taxa de amostragem de $1920 \mathrm{~Hz}$, que nos fornece 32 pontos por ciclo, em uma freqüência de $60 \mathrm{~Hz}$. Chegou-se a 88 tipos de faltas (internas e externas), devido estar cobrindo todos os tipos de faltas possíveis, conforme pode ser verificado no apêndice $A$.

O conjunto de dados foi criado a partir de diversas situações de falta, sendo que as condições que estas ocorrem têm influência direta sobre a corrente solicitada. Determinadas situações podem causar o surgimento de componentes contínuas com decaimento exponencial positivo ou negativo de acordo com o ângulo de incidência.

Aqui cabe relatar, que para se fazer as simulações no ATP, não se tem acesso a todos os terminais do gerador ou mesmo aos enrolamentos, pois, o modelo de gerador já é previamente fechado em estrela, o que dificulta a simulação de faltas internas. Embora o modelo de gerador do ATP não permita simular diretamente as faltas internas no gerador, foram simuladas as faltas nos terminais do gerador como pode ser verificado através da Figura 6.3.

As Figuras 6.2 e 6.3 exemplificam um caso de falta interna no sistema elétrico real e no sistema elétrico simulado no ATP. É importante esclarecer que mesmo com a limitação do modelo do ATP, o sistema elétrico é semelhante, ou seja, a corrente $I_{G}$ que passa pelo TC1 é a mesma tanto no sistema real quanto no simulado, não tendo prejuízos nas simulações executadas. 


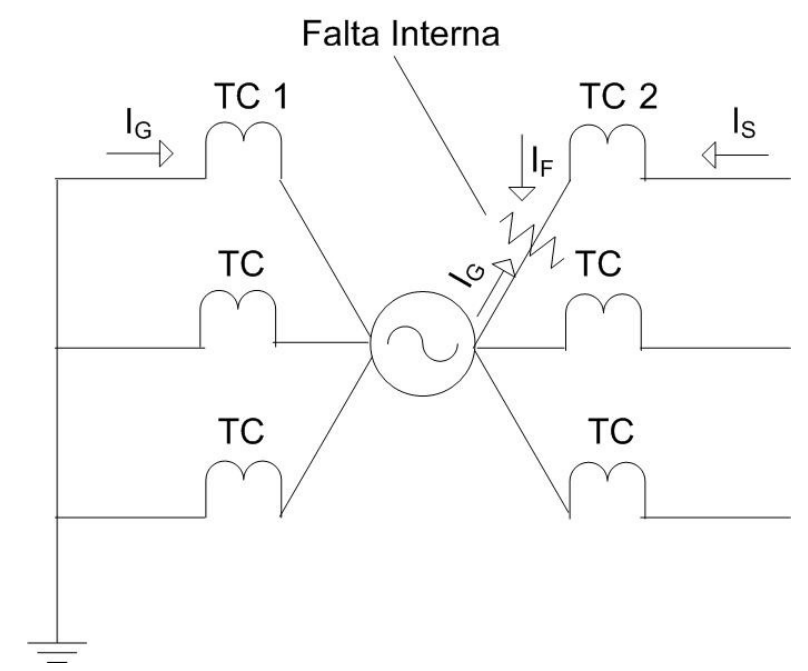

Figura 6.2 - Sistema elétrico real simulando uma falta interna ao gerador.

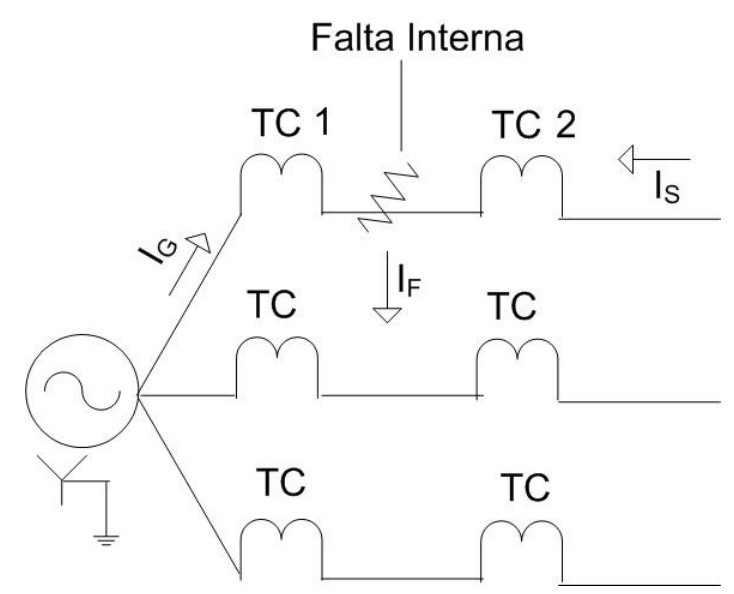

Figura 6.3 - Sistema elétrico simulado no ATP simulando uma falta interna ao gerador.

A mesma regra explicitada acima, no caso dos exemplos para as faltas internas, vale para as faltas externas conforme ilustram as Figuras 6.4 e 6.5, a mudança é que as faltas externas acontecem após o TC2, ou seja, no sistema de distribuição. 
Vale salientar que a corrente $\mathrm{I}_{\mathrm{G}}$ que passa pelo TC1 e TC2 é a mesma, tanto no sistema real quanto no simulado, não tendo prejuízos nas simulações executadas.

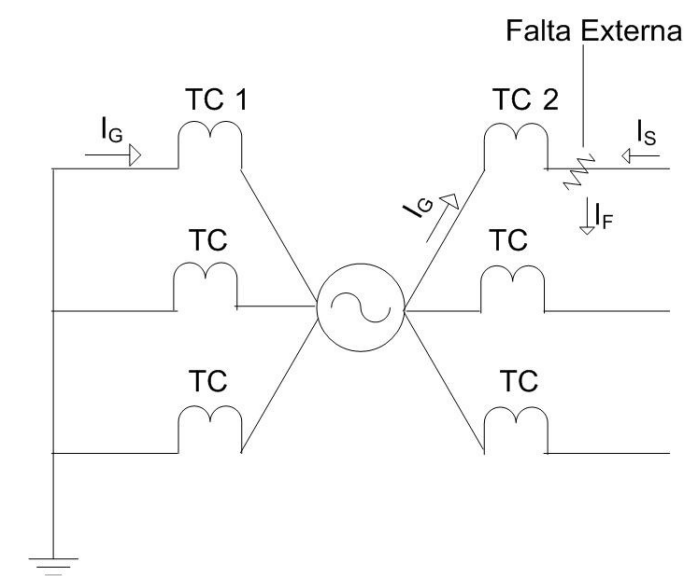

Figura 6.4 - Sistema elétrico real simulando uma falta externa ao gerador.

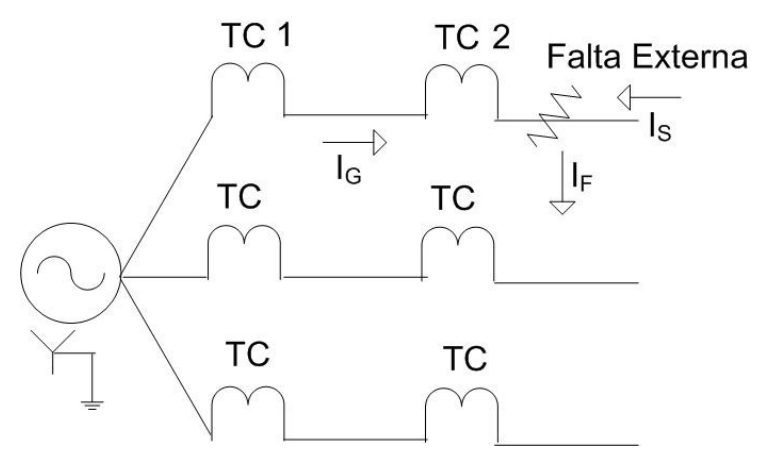

Figura 6.5 - Sistema elétrico simulado no ATP simulando uma falta externa ao gerador .

A simulação do TC foi realizada a partir de dados reais de fabricação. $O$ modelo elétrico empregado para a simulação é mostrado na Figura 6.6. 


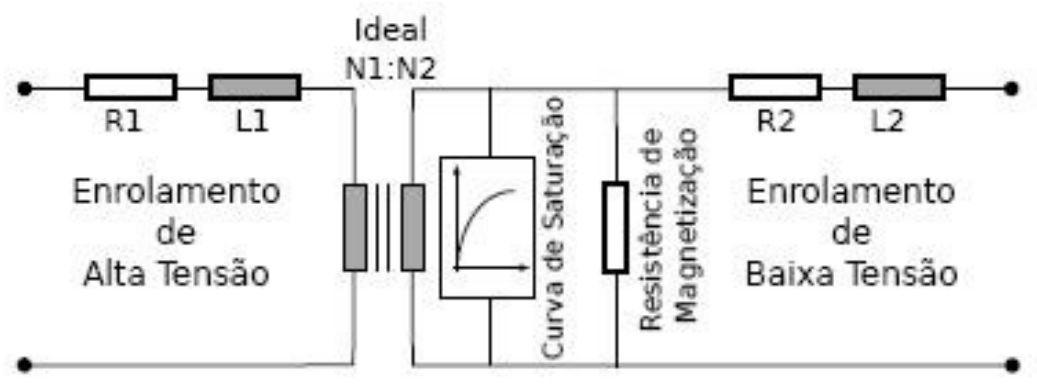

Figura 6.6 - Modelo elétrico do TC.

A seguir, são mostradas através da Tabela 6.1 as características elétricas do TC e na Figura 6.7 a curva de magnetização dos TCs empregados.

Através da Figura 6.7, buscando aproximar da realidade, foi feita uma mudança na curva de saturação dos TCs próximo ao neutro do gerador e próximo aos terminais do gerador, ou seja, para mostrar que na fabricação dos TCs eles não são totalmente iguais, fazendo com isso que a proteção diferencial atue erroneamente e justificando a aplicação das RNAs neste trabalho para a correção da corrente distorcida do secundário do TC.

Pode-se evidenciar também na Figura 6.7 que o TC representado pela curva preta satura antes do TC representado pela curva vermelha, essa diferença entre os dois TCs faz com que a proteção diferencial do gerador possa a vir atuar erroneamente.

Tabela 6.1- Dados do transformador de corrente.

\begin{tabular}{l|c}
\hline \hline Grandeza & Valor \\
\hline Indutância de dispersão do primário & $5,0 \mathrm{H}$ \\
Resistência de dispersão do primário & $0,85 \Omega$ \\
Indutância de dispersão do secundário & $1,0.10^{-3} \mathrm{H}$ \\
Resistência de dispersão do secundário & $1,0.10^{-4} \Omega$ \\
Relação de transformação & $2000: 5$ \\
\hline \hline
\end{tabular}




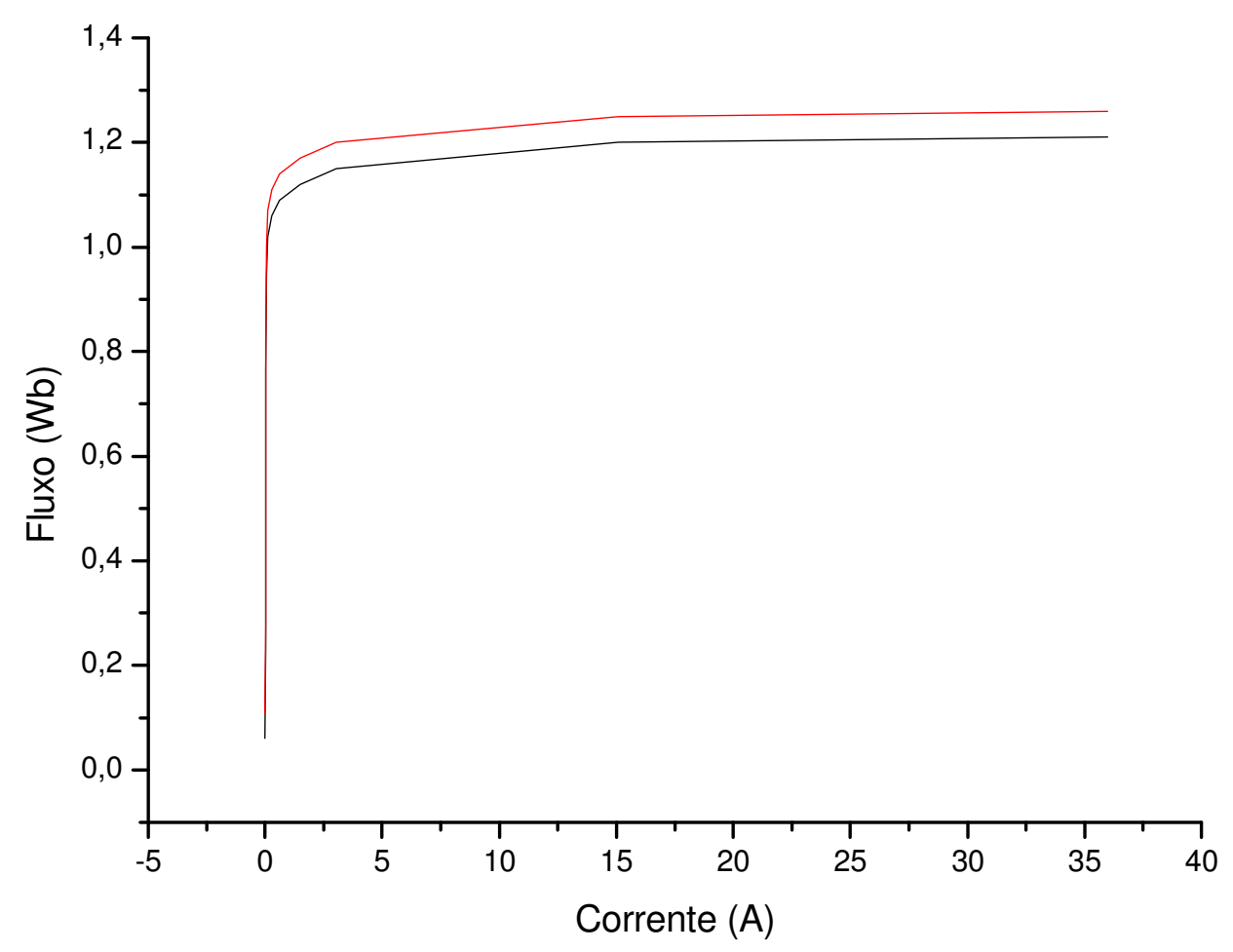

Figura 6.7 - Curva de magnetização do TC.

A seguir, são mostrados alguns dos resultados obtidos com a simulação do sistema elétrico de potência no programa ATP, referentes aos casos de faltas externas e internas.

Para alguns casos, são ilustradas situações nas quais ocorre o fenômeno de saturação dos TCs, para efeito comparativo entre os sinais estudados.

A Figura 6.8 mostra as correntes primárias em falta, reportando o caso de falta externa $A B$ com ângulo de $90^{\circ}$ que ocorre no instante de tempo de 415 (ms). 


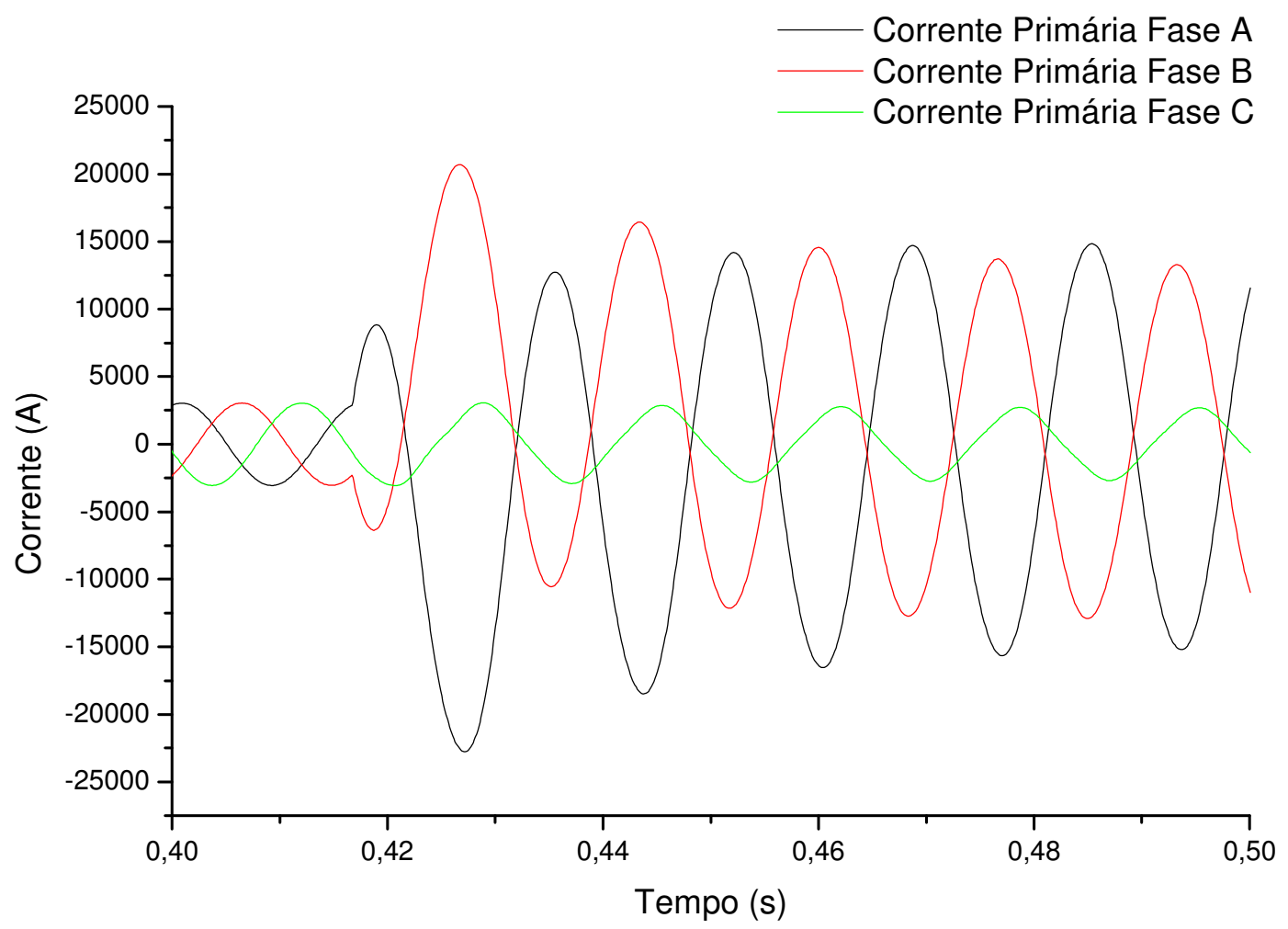

Figura 6.8 - Corrente primária sob falta externa $A B 90^{\circ}$

A Figura 6.9 mostra as correntes secundárias em falta e com a saturação do TC, reportando o caso de falta externa $A B$ com ângulo de incidência de $180^{\circ}$ que ocorre no instante de tempo de 415 (ms) e a saturação do TC ocorre próximo de 420 (ms). 


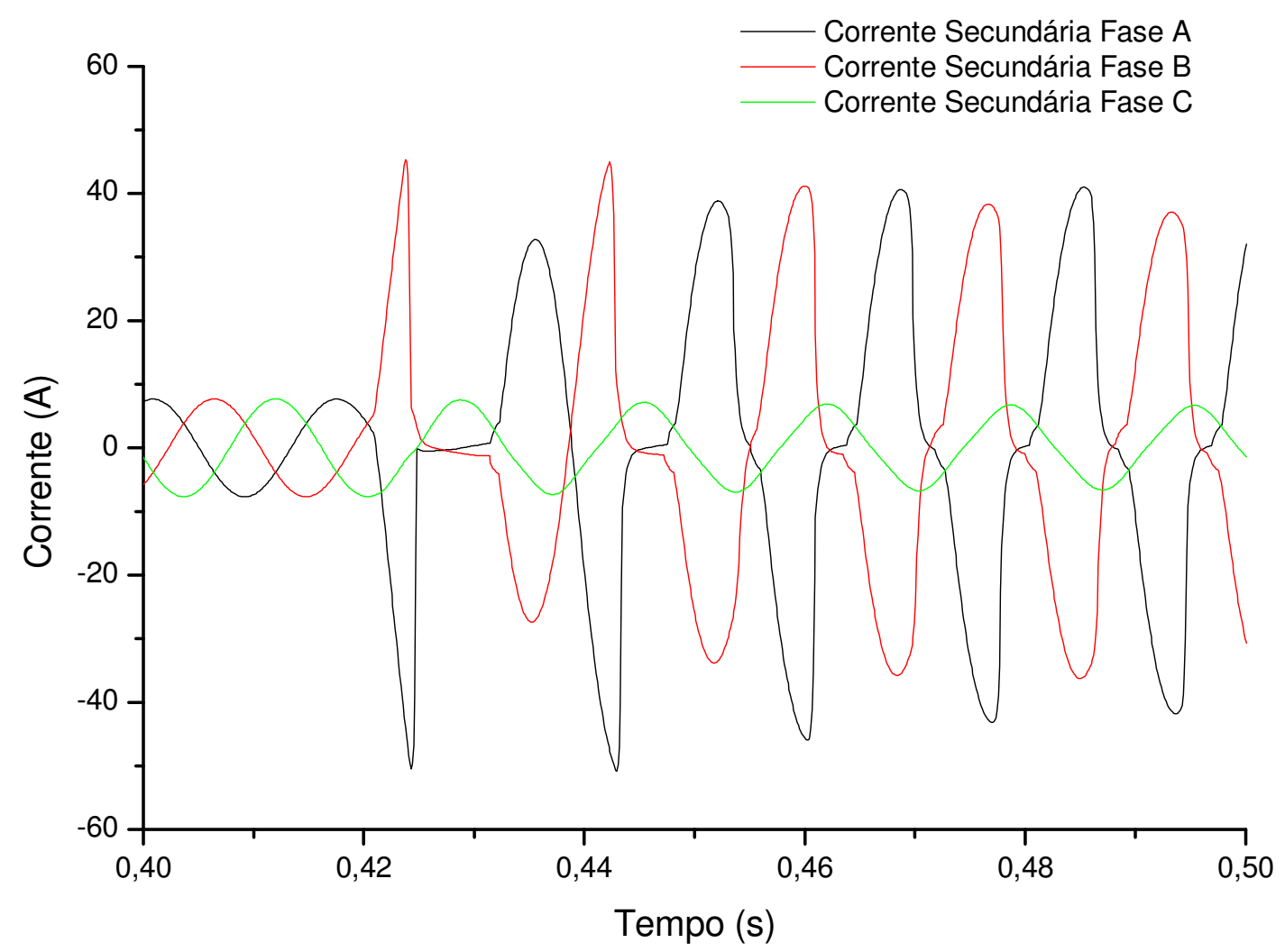

Figura 6.9 - Corrente secundária sob falta externa $\mathrm{AB} 180^{\circ} \mathrm{com}$ saturação do $\mathrm{TC}$

A partir desses dados, no próximo capítulo, adentra-se para o algoritmo aplicado ao sistema elétrico em análise e apresenta-se a descrição detalhada de todas as etapas de sua estruturação, em que podem ser identificados os resultados experimentais de um modelo de faltas internas, a estrutura da rede neural, o método de treinamento e os testes da rede. 


\section{ALGORITMO APLICADO À PROTEÇÃO DIFERENCIAL DO GERADOR}

Neste capítulo, aborda-se o processo de definição, treinamento e avaliação das RNAs e, o algoritmo aplicado à proteção diferencial do gerador síncrono com correção das ondas de correntes saturadas através de RNAs.

\subsection{Processo de definição, treinamento e avaliação das RNAs}

Como exposto no capítulo anterior, às simulações executadas no trabalho foram iniciadas pela obtenção da base de dados, a qual foi constituída por dados adquiridos a partir da simulação de um SEP com 44 faltas internas e 44 faltas externas, onde se variou o tipo de falta e o seu ângulo de incidência.

Foram gerados 88 casos, dos quais 56 foram utilizados para treinamento e os 32 restantes são empregados na validação das redes neurais. Para uma melhor visualização desses casos, vide apêndice A. Aqui cabe salientar, que os 88 casos escolhidos referem-se aos casos mais significativos, pois para as demais situações não foram encontrados resultados divergentes.

Após formada a base de dados, houve a necessidade de se realizar uma etapa de pré-processamento dos dados, com o intuito de melhor prepará-los às etapas de detecção e correção da saturação dos TCs.

$\mathrm{Na}$ etapa de pré-processamento, realizou-se o janelamento dos sinais, onde cada janela foi constituída por um total de 32 pontos amostrados, conforme pode ser verificado através da figura 7.4 da página 83.

Depois de aplicado o janelamento, os dados foram adequados para que pudessem ser submetidos às etapas de treinamento e validação das RNAs. Para tal tarefa, além das janelas, foram fornecidos como entradas o somatório dos pontos da janela respectivamente anterior à janela atual. Portanto, foram utilizadas 33 entradas, sendo 32 delas os pontos correspondentes à janela do sinal e 1 corresponde ao somatório dos pontos da janela anterior. Foi utilizado o toolbox do programa MATLAB para as etapas de treinamento e validação das RNAs.

Para o desenvolvimento desta pesquisa, empregou-se RNAs com arquitetura de múltiplas camadas, denominada MLP. Este tipo de arquitetura 
geralmente é aplicado em tarefas de reconhecimento de padrões, aproximação funcional, identificação e controle (Haykin, 1994). Assim, considerando o propósito do reconhecimento de padrões referentes à saturação dos transformadores de corrente e também a aproximação funcional realizada para a correção da saturação, optou-se então pela utilização desta arquitetura no trabalho.

Portanto, duas RNAs foram implementadas, sendo uma responsável por detectar a ocorrência de saturação nos TCs e outra responsável por corrigir os sinais das janelas onde foram detectados sinais saturados.

Com relação ao treinamento das RNAs, empregou-se para a rede neural detectora e corretora de saturação um algoritmo denominado Levenber-Marquardt, que se destaca por apresentar um processo de ajuste otimizado dos pesos, bem como maior velocidade de convergência.

\subsubsection{Rede neural detectora}

A topologia da RNA detectora foi selecionada após a realização de diversos testes com os 16.800 padrões de treinamento, ou seja, 56 casos vezes 300 amostras por caso e 9.600 padrões de validação, ou seja, 32 casos vezes 300 amostras por caso, onde se constatou que a topologia mais adequada a esta função conta com duas camadas neurais. A camada de entrada contém 33 entradas, das quais 32 são amostras anteriores do sinal de corrente e a uma é o somatório das 32 amostras anteriores a estas. Como o comportamento do TC em um dado ciclo é dependente do ciclo anterior, uma entrada da rede neural é usada para o somatório das amostras do ciclo anterior. Esse somatório é proporcional à integral da corrente no secundário e proporcional ao fluxo magnético no TC durante o ciclo anterior (D. C. Yu and Kojovic, 2001).

A rede neural é constituída por 33 entradas, sendo a $1^{\text {a }}$ entrada $x(n)$ equivalente a amostra atual do sinal, e a $2^{\mathrm{a}}$ entrada $x(\mathrm{n}-1)$ ao sinal da amostra anterior até o sinal da amostra $x(n-32)$. As amostras de $x(n-33)$ até $x(n-64)$ são somadas e entregue a $33^{2}$ entrada da rede neural.

Para se chegar na arquitetura ideal da RNA detectora, foram feitos vários testes, variando-se o número de neurônios na camada escondida e testando-a. Para uma melhor visualização dos tempos de treinamento e da validação dos neurônios, vide apêndice A. A topologia escolhida (33-26-1) possui 26 neurônios na camada 
escondida e na camada neural de saída, apenas 1 neurônio, sendo o neurônio da camada de saída responsável por fornecer uma resposta binária, onde -1 corresponde à não ocorrência da saturação do TC e 1 corresponde à ocorrência da saturação.

Para uma melhor compreensão da configuração utilizada, a topologia da rede detectora é mostrada na Figura 7.1.

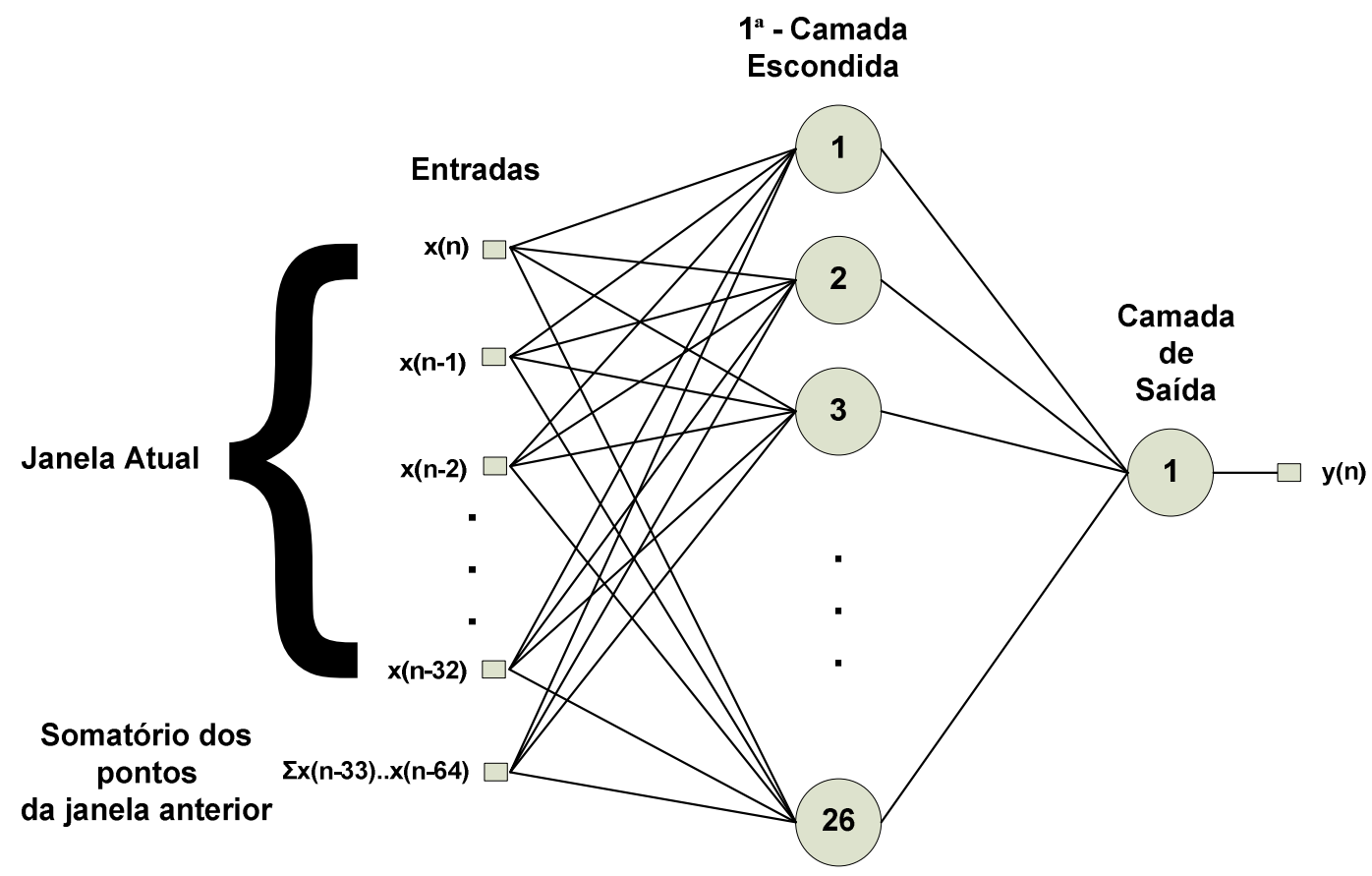

Figura 7.1 - Arquitetura da rede neural detectora

\subsubsection{Rede neural corretora}

Para esta RNA, também se utilizou uma arquitetura do tipo MLP, e com algoritmo de treinamento Levenber-Marquardt idêntico ao utilizado na RNA detectora. A topologia da RNA corretora foi selecionada após a realização de diversos testes com os 16.800 padrões de treinamento, ou seja, 56 casos vezes 300 amostras por caso e 9.600 padrões de validação, ou seja, 32 casos vezes 300 amostras por caso, onde se constatou que a topologia mais adequada a esta função conta com três camadas neurais. 
Com relação à RNA corretora, esta apenas recebeu as 33 entradas das quais a RNA anteriormente citada detectou a saturação dos TCs. A camada de entrada contém 33 entradas, das quais 32 são amostras anteriores do sinal de corrente e a uma é a somatória das 32 amostras anteriores à estas.

De modo análogo a RNA detectora, a RNA corretora é constituída por 33 entradas, sendo a $1^{\underline{a}}$ entrada $\times(n)$ equivalente a amostra atual do sinal, e a $2^{\underline{a}}$ entrada $x(\mathrm{n}-1)$ ao sinal da amostra anterior até o sinal da amostra $\times(\mathrm{n}-32)$. As amostras de $x(n-33)$ até $x(n-64)$ são somadas e entregue a $33^{a}$ entrada da rede neural.

Como citado acima, para se chegar a uma arquitetura ideal para a RNA corretora, foram feitos vários testes, onde foi feita uma variação no número de neurônios nas camadas escondidas e testando-a, ou seja, mantinha o número de neurônios na primeira camada escondida fixo e variou-se o número de neurônios na segunda camada, foi feito assim até se chegar a uma topologia RNA corretora satisfatória. Para uma melhor visualização dos tempos de treinamento e da variação dos neurônios, vide apêndice B. A topologia escolhida (33-23-18-1) possui na primeira camada escondida 23 neurônios e na segunda camada escondida conta com 18 neurônios. A camada neural de saída possui um único neurônio, o qual fornece o sinal da corrente corrigida, o que esta sendo mostrado no $y(n)$ é o valor do $x(n)$ corrigido. Para uma melhor visualização, a topologia da RNA corretora é mostrada na Figura 7.2.

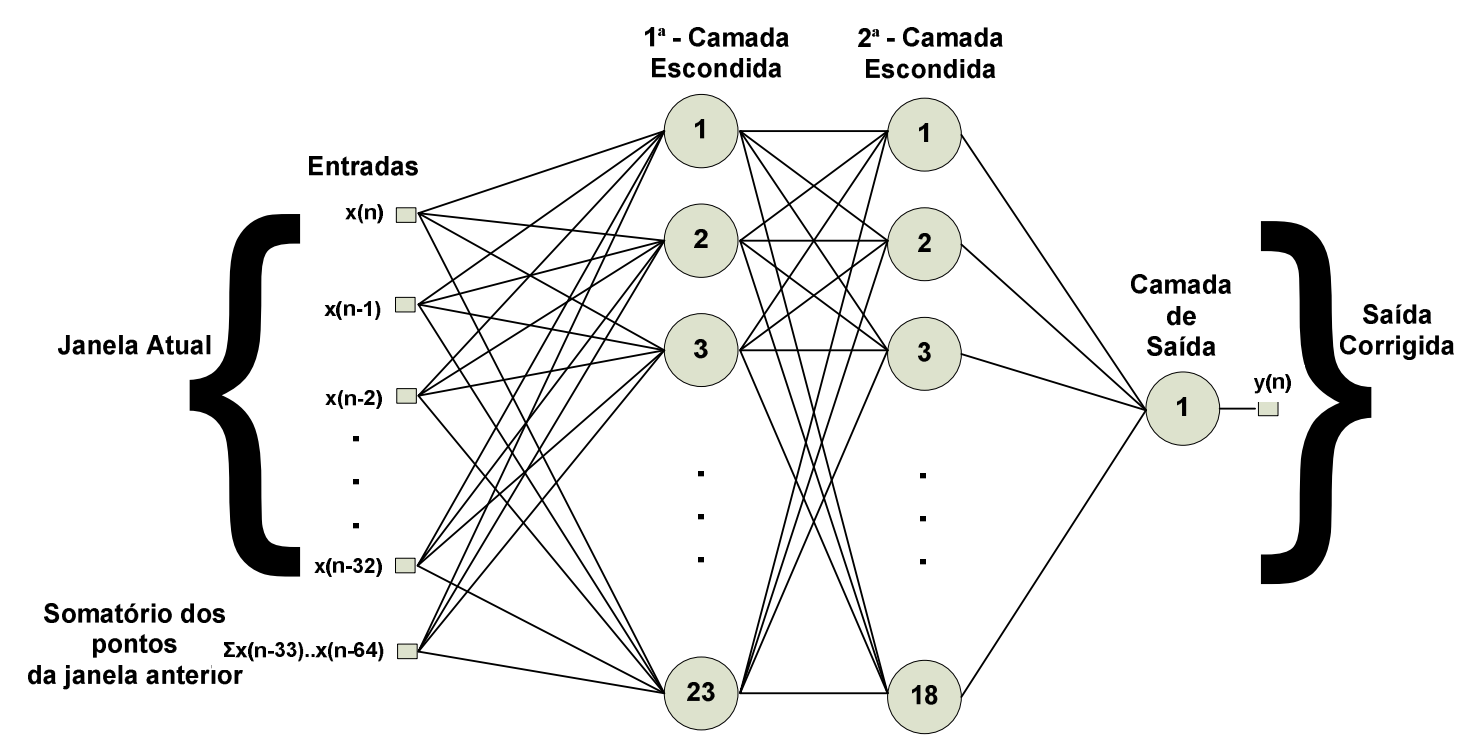

Figura 7.2 - Arquitetura da rede neural corretora 
Cabe ressaltar que, para ambas as RNAs empregaram-se, nos neurônios da camada neural intermediária, funções de ativação do tipo tangente hiperbólica e, para os neurônios da camada de saída, funções de ativação lineares.

\subsection{Fluxograma do algoritmo do rele diferencial}

O Fluxograma destacado na Figura 7.3 mostra todas as etapas que foram desenvolvidas e serão detalhadas nas seções a seguir. 


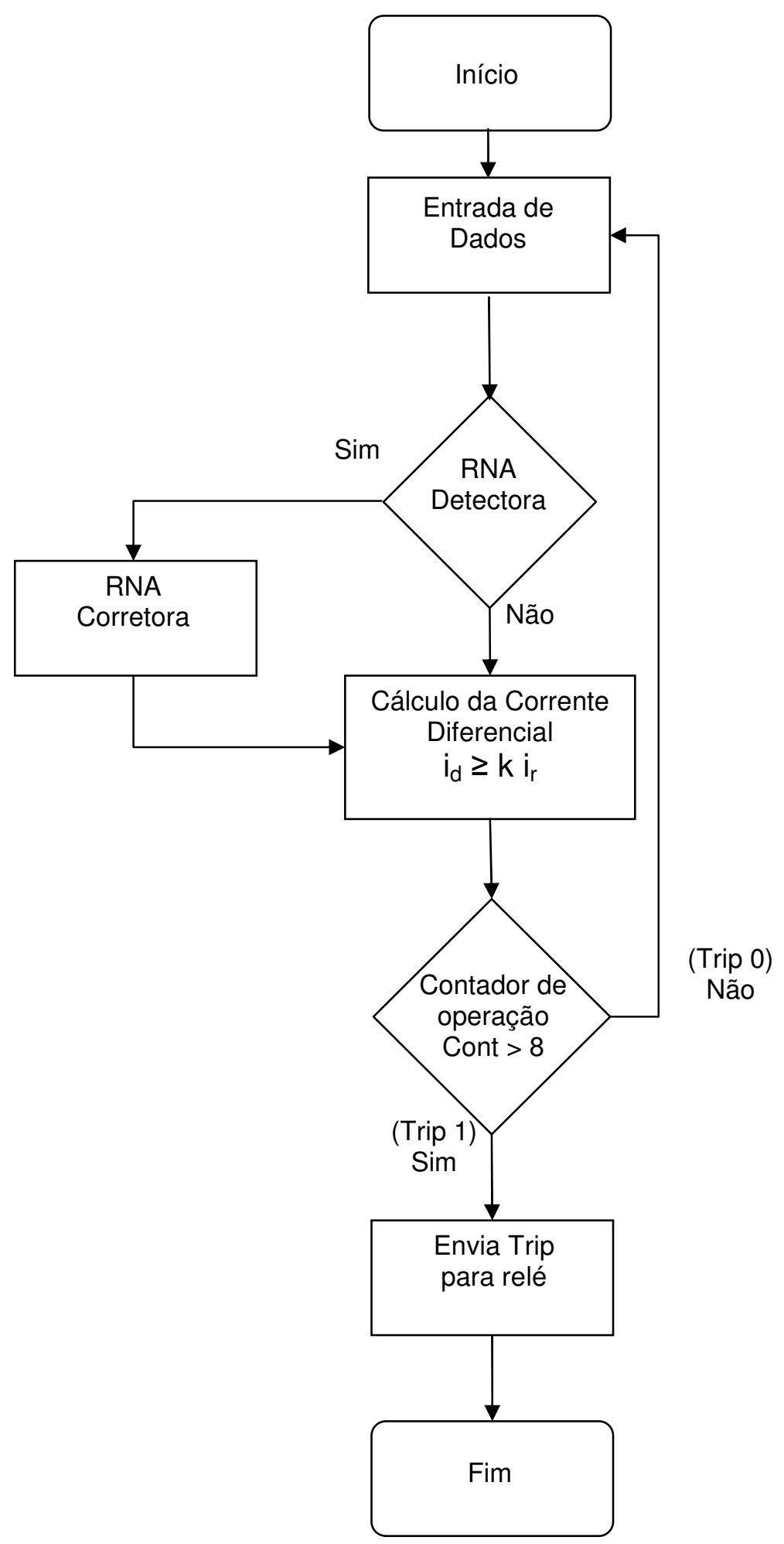

Figura 7.3 - Fluxograma do algoritmo do rele diferencial 


\subsubsection{Entrada de dados}

Como exposto anteriormente, foram empregados 44 casos para faltas internas e 44 casos para faltas externas, onde toda a simulação foi desenvolvida por meio do software ATP. Este estágio, na realidade, tem o objetivo de simular a entrada de dados, onde os sinas de corrente são obtidos via simulações com taxa de amostragem de $1920 \mathrm{~Hz}$ o que nos fornece 32 pontos por ciclo.

Embora a entrada de dados seja contínua, realiza-se a cada instante de tempo a coleta de uma nova amostra, sendo a apresentação das informações ao algoritmo realizada de forma janelada, onde cada janela foi constituída por um total de 32 pontos por ciclo, e com passo fixo de deslocamento de uma amostra. Assim, todas as demais etapas serão desenvolvidas para apenas uma janela de dados, de modo que o algoritmo de proteção e de monitoramento devera ser completamente executado a cada novo ciclo de processamento. De forma a fornecer melhor compreensão desse janelamento, a Figura 7.4 ilustra o passo da janela a cada amostra nova.

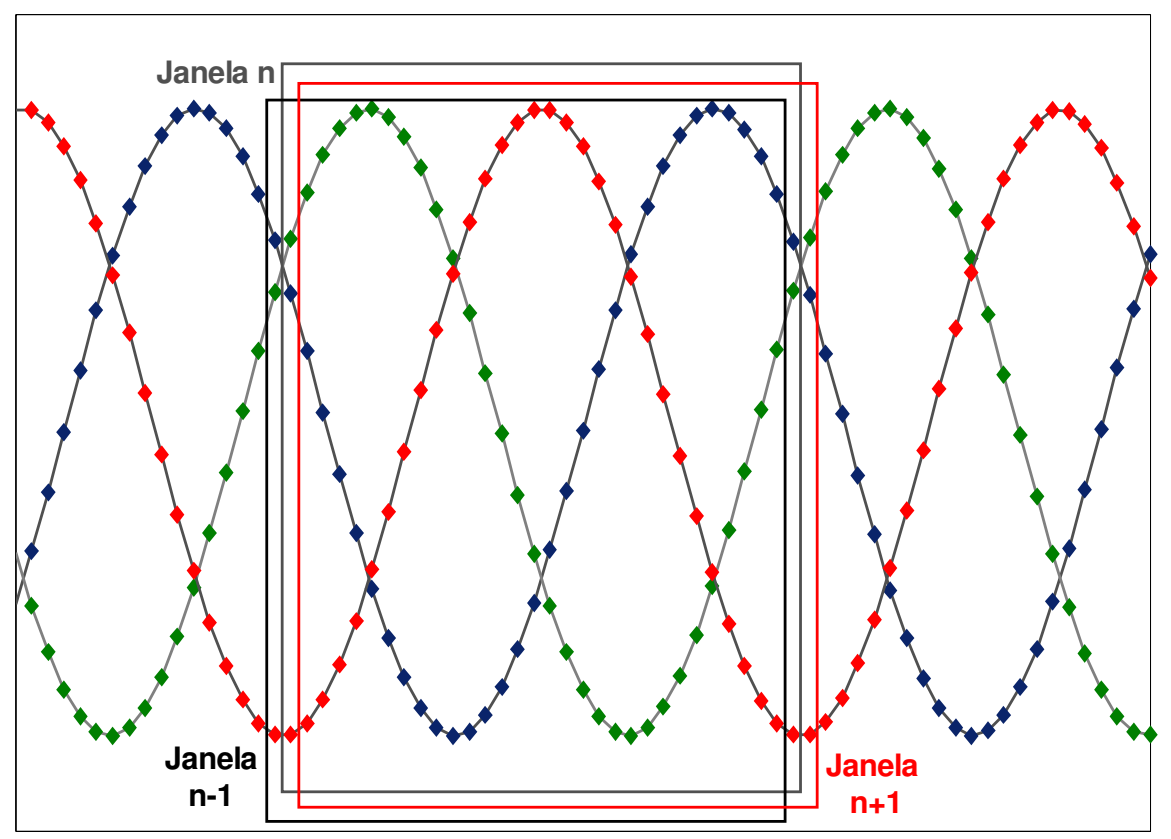

Figura 7.4 - Exemplo do janelamento do sinal 
Deve-se salientar que todos os sinais foram normalizados antes de serem submetidos ao processo de janelamento. Ressalta-se que o janelamento dos dados torna-se importante para verificar mais rapidamente em qual dos pontos amostrados esta acontecendo à falta para que a proteção possa atuar mais rapidamente.

\subsubsection{A detecção e a correção da saturação do TC}

Nesta etapa será mostrado o esquema empregado para detecção e correção das correntes distorcidas pelo efeito da saturação do núcleo do TC. Para isso duas redes neurais foram empregadas, como citado anteriormente.

Para a execução desta etapa, utilizou-se de duas RNAs tipo Multilayer Perceptron (MLP) com finalidades distintas (Monaro, et al., 2010). A primeira foi usada na detecção da saturação do TC (RNA detectora) e, a segunda, para a correção da forma de onda deformada pela saturação (RNA corretora). É importante observar na figura 7.3 que a RNA corretora só é solicitada quando há saturação do TC, o que permite um melhor desempenho do algoritmo de proteção desenvolvido, evitando assim, a inserção de imprecisões adicionais às formas de onda.

\subsubsection{Rede neural detectora}

A RNA detectora recebe as correntes do secundário do TC (32 amostras mais a 33a amostra) já treinada e com os pesos definidos e indica se ocorreu ou não a saturação. Essa rede neural detectora fornecerá como saída se o sinal está ou não saturado, caso esteja saturado acionará a rede corretora, caso contrário, processase o cálculo da proteção diferencial. A camada de saída é responsável por fornecer uma resposta binária, onde (-1) corresponde à não ocorrência da saturação do TC e 1 corresponde à ocorrência da saturação. 


\subsubsection{Rede neural corretora}

Com relação à RNA corretora, esta apenas recebeu as 33 entradas das quais a RNA anteriormente citada detectou a saturação dos TCs, sendo responsável pela correção dos valores de corrente a serem entregues ao relé de proteção.

Os dados referentes as 32 amostras mais a $33^{2}$ amostra são apresentadas a rede já treinada e com os pesos definidos e essa RNA fornecerá como saída o sinal reconstruído e sem saturação, o qual será utilizado para o cálculo da proteção diferencial, ou seja, essa rede neural recebe as correntes distorcidas do secundário do TC e entrega em sua saída as correntes corrigidas.

\subsubsection{Cálculo da corrente diferencial}

Como descrito anteriormente, o algoritmo apresentado na Figura 7.3 ilustra o principio lógico proposto para o relé diferencial, considerando o emprego de RNAs. Após as etapas de detecção e correção da saturação, é feito o cálculo da corrente diferencial como ilustrado na seção 4.7 , onde o algoritmo do relé faz a verificação das correntes, através dos TCs, próximo ao neutro e próximo aos terminais do gerador e verifica em qual das regiões características do relé (Figura 7.5) o sinal está classificado, ou seja, o relé determina se o sinal está contido na zona de restrição ou de operação, de acordo com o ajuste de restrição percentual escolhido. Se o sinal for classificado no interior da zona de restrição, o algoritmo retorna ao seu ponto inicial, e o relé retorna à entrada de dados, caso contrário, o algoritmo passa, então, a considerar a possibilidade de uma falta interna. Finalmente, o relé analisa se o contador de faltas excedeu a um limite preestabelecido e decide pelo envio do sinal de atuação ao disjuntor do gerador síncrono. 


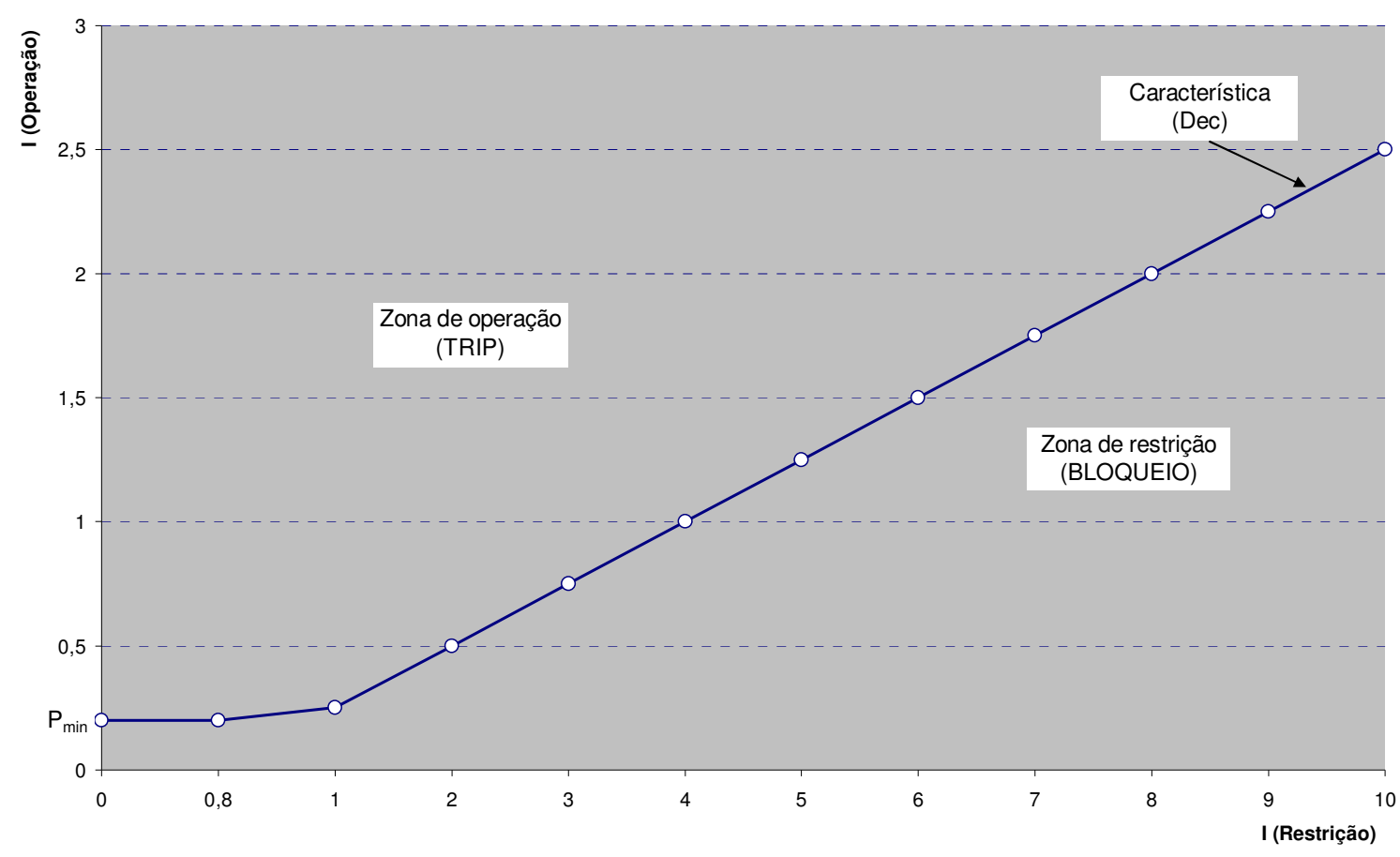

Figura 7.5 - Curva de ajuste para proteção diferencial

A Figura 7.5 ilustra uma característica de operação do relé diferencial, incluindo as suas zonas de restrição e operação. A característica consiste de uma linha inclinada (Dec), ou inclinação e uma reta horizontal definindo o limiar mínimo ou de pickup de corrente $\left(P_{\min }\right)$. A região de operação é localizada acima da característica inclinada, sendo que a região de restrição localizada abaixo da mesma curva. Foi utilizado no algoritmo da proteção diferencial desse trabalho o $\mathrm{P}_{\min }$ igual a 0,20 e Dec ou inclinação igual a 0,20.

\subsection{Resultados da aplicação de Redes Neurais na detecção e correção de sinais de TCs distorcidos pela saturação}

Nesta seção serão apresentados os resultados das redes propostas.

\subsubsection{Rede Detectora}

A topologia escolhida (33-26-1) para a função de detectar a saturação do TC, apresentou uma taxa de acerto de $99,6 \%$ das janelas que apresentaram 
saturação dos TCs durante a etapa de validação e durante a etapa de treinamento foi necessário apenas 50 épocas para a convergência. Portanto, no que segue, encontra-se apresentado por meio da Figura 7.6 a resposta da rede detectora para o caso de falta externa $A B$ com ângulo de incidência de $180^{\circ}$ (caso 57 ), sendo esta caracterizada pela cor verde.

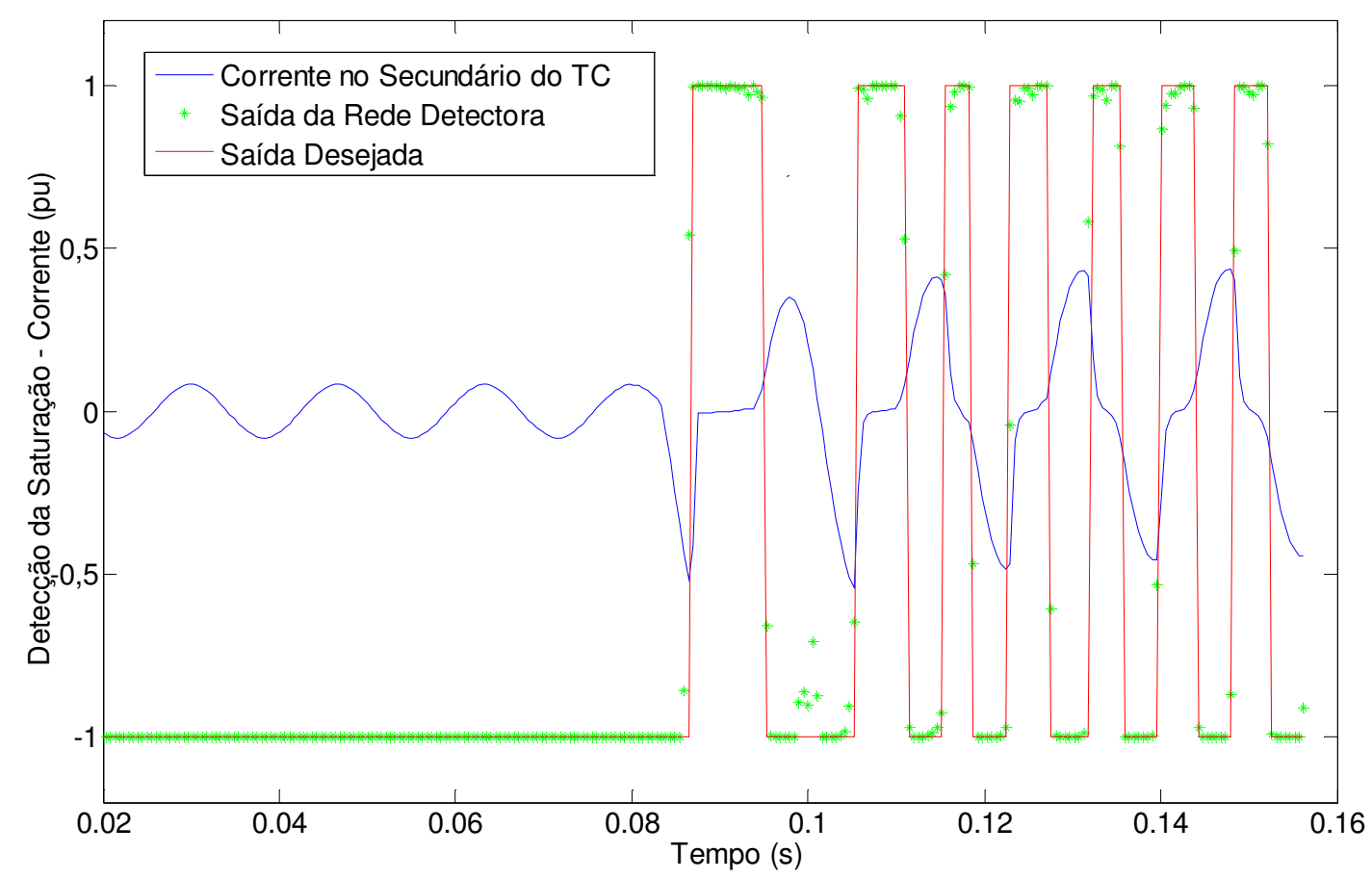

Figura 7.6 - Resposta da rede neural detectora falta externa $A B 180^{\circ}$

Podemos observar que a saída da rede detectora está identificando de forma satisfatória a saturação do TC, cuja forma de onda onde houve a saturação é mostrada na cor azul e ocorre após a ocorrência da falta, em um tempo aproximado de 0,085 segundos.

Na Figura 7.7 evidencia-se a resposta da rede detectora (pontos verdes) para o caso de falta externa $A B$ com ângulo de incidência de 360ํ (caso 58). Observa-se que a rede detectora identifica satisfatoriamente a parte da onda onde houve saturação (em azul). 


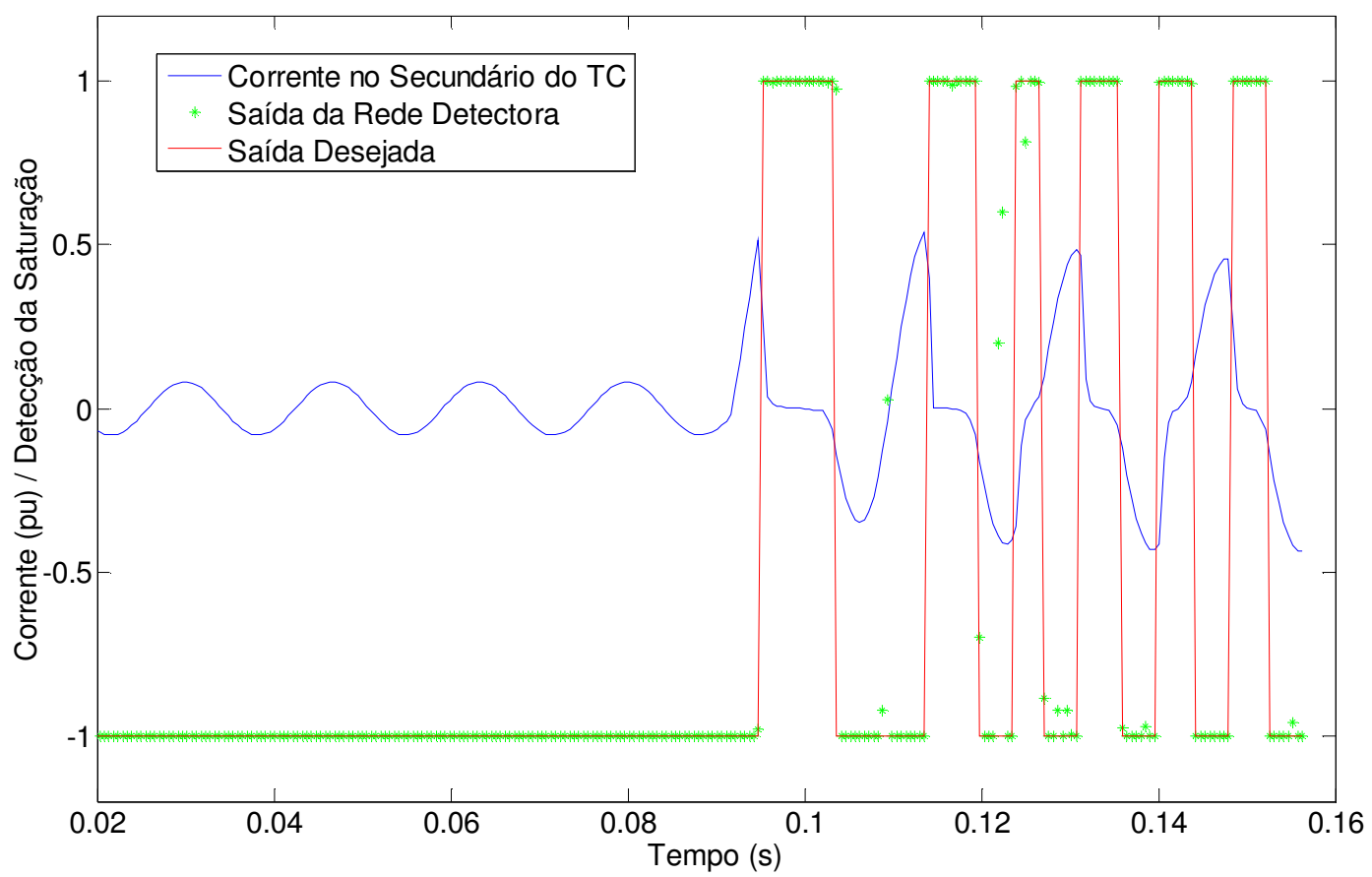

Figura 7.7 - Resposta da rede neural detectora falta externa $A B 360^{\circ}$

Observa-se também alguns pontos de classificação errônea da rede localizados principalmente na parte de transição da forma. Tal fato pode estar ocorrendo devido à dificuldade da rede em assimilar os padrões de transição de não saturado para saturado e vice-versa.

Pela Figura 7.8 evidencia-se a resposta da rede detectora para o caso de falta interna $A B C$ com ângulo de incidência de $180^{\circ}$ (caso 75), sendo esta caracterizada pela cor verde. 


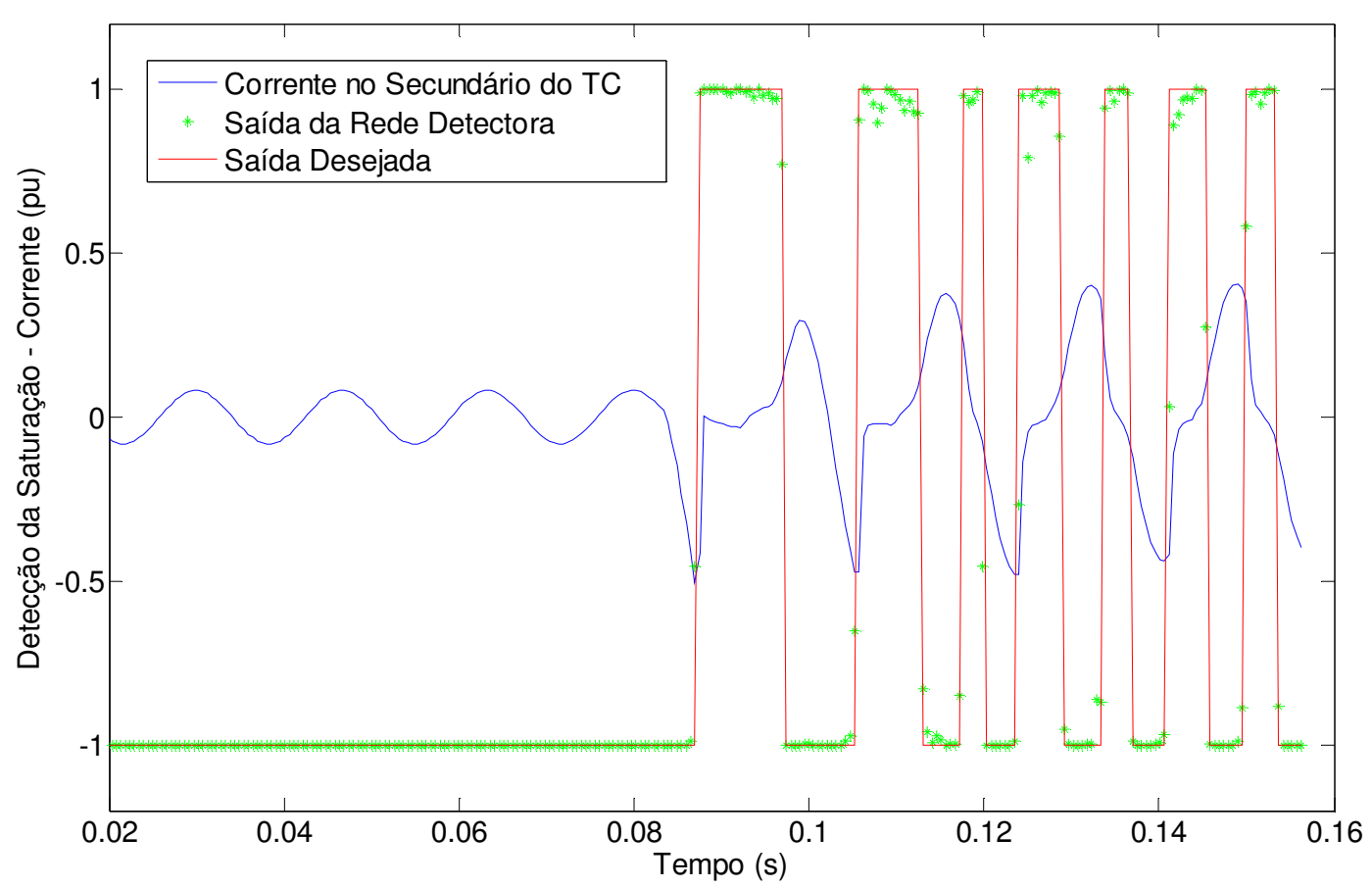

Figura 7.8 - Resposta da rede neural detectora falta interna $A B C 180^{\circ}$

Verifica-se que a saída da rede detectora está identificando de forma satisfatória a parte da onda onde houve saturação (em azul). Observa-se também que houve um pequeno aumento no número de pontos de classificação errônea da rede comparado com o caso de falta externa $A B$ com ângulo de incidência de $360^{\circ}$ (caso 58), localizados principalmente na parte de transição da forma. O fato pode estar associado à dificuldade da rede em assimilar os padrões de transição de saturado para não saturado e vice-versa. 


\subsubsection{Rede Corretora}

A topologia escolhida (33-23-18-1) para a função de corrigir a forma de onda com saturação proveniente do secundário do TC apresentou um erro médio de 0,66\% e uma variância de 0,81\% das janelas que apresentaram saturação dos TCs durante a etapa de validação e durante a etapa de treinamento a rede convergiu com 1000 épocas. Assim, de forma a melhor representar a resposta da rede neural corretora ilustra-se através das Figuras 7.9, 7.10 e 7.11.

A Figura 7.9 mostra a resposta da rede corretora para o caso de falta externa fase $A B$ com ângulo de incidência de $180^{\circ}$ (caso 57). Podemos verificar através do sinal da rede corretora caracterizada pela forma de onda na cor azul. Observa-se que a saída da rede corretora está bem próxima da saída desejada, sendo esta caracterizada pela forma de onda na cor verde, a qual se trata da corrente do primário referenciada no secundário.

Analisando a forma de onda da corrente no secundário do TC (cor vermelha) no primeiro ciclo de pós falta percebemos que a ocorrência da saturação acontece antes do pico mínimo da onda. Nessa situação a rede corretora apresenta uma pequena dificuldade na correção da forma de onda da rede corretora (cor azul). No entanto, esse desvio é pequeno se compararmos com o sinal da saturação sem a correção.

Pode-se justificar, a dificuldade da rede corretora em corrigir o sinal saturado no primeiro ciclo pós falta, devido ao fato de ser o primeiro ciclo com o sinal saturado, ou seja, temos nos ciclos de pré falta o sinal sem saturação e nos próximos ciclos de pós falta o sinal com saturação, essa junção de sinal com saturação e sem saturação pode ter sido a causa do sinal da rede corretora não estar próximo da saída desejada.

Dessa forma, a rede corretora corrigiu melhor as formas de onda quando o sinal é totalmente saturado. 


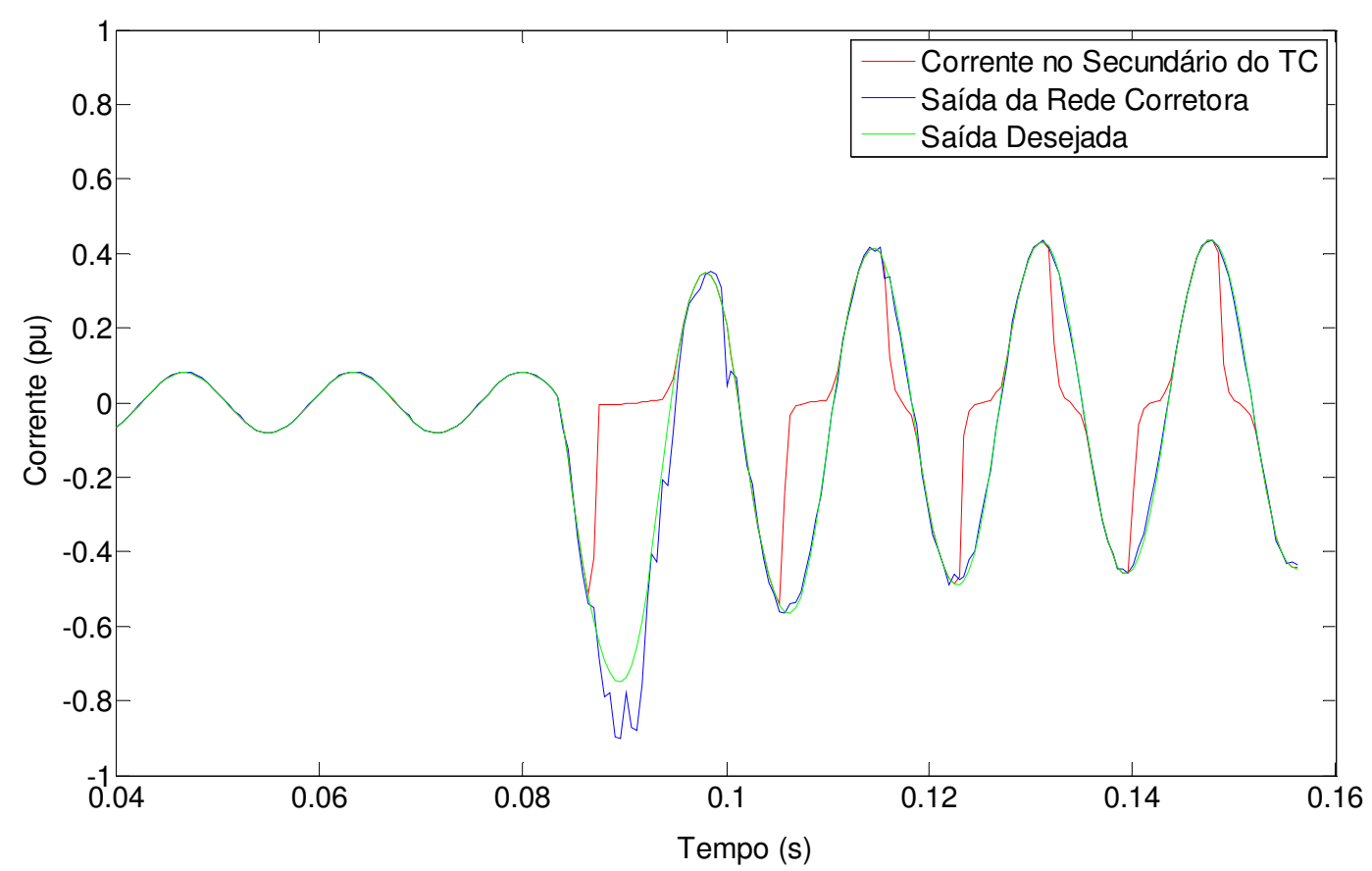

Figura 7.9 - Resposta da rede neural corretora falta externa fase $A B 180^{\circ}$

Através da Figura 7.10, podemos verificar a resposta da rede corretora (em azul) para o caso de falta externa fase AT com ângulo de incidência de $270^{\circ}$ (caso 64), onde se verifica através da forma de onda da rede corretora, ou seja, a saída da rede corretora bem próxima da saída desejada (em verde), onde se trata da corrente do primário refletida no secundário. Analisando a forma de onda da corrente no secundário do TC (em vermelho), que no primeiro ciclo de pós falta, percebemos que a ocorrência da saturação ocorre antes do pico máximo da onda, tanto na parte positiva quanto na parte negativa, onde percebemos uma leve dificuldade na correção da forma da rede corretora (em azul). 


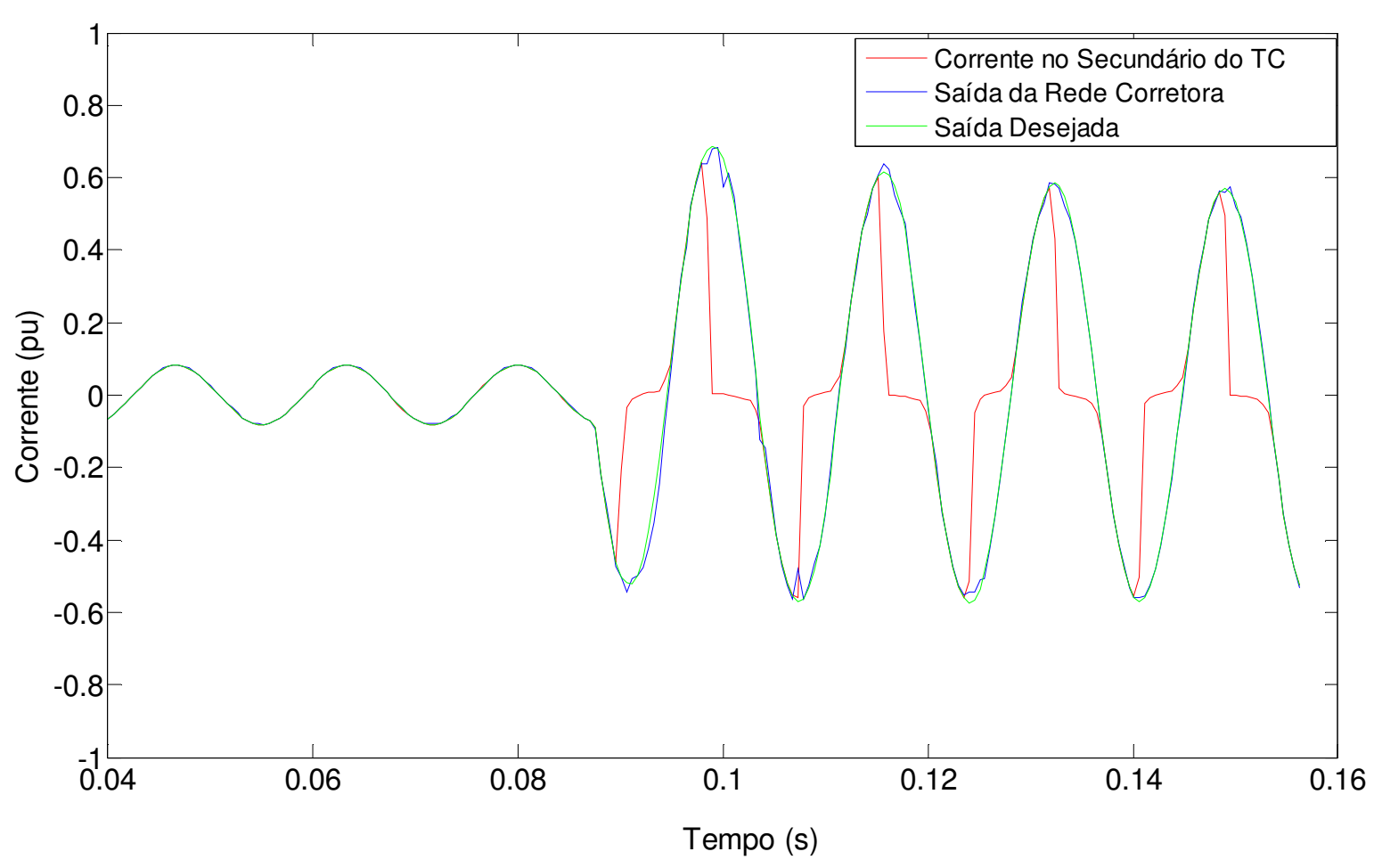

Figura 7.10 - Resposta da rede neural corretora falta externa AT 270은

A Figura 7.11 ilustra a resposta da rede corretora para o caso de uma falta externa fase ABT com ângulo de incidência de $90^{\circ}$ (caso 61). Pode-se observar que a forma de onda da rede corretora (em azul) ou sinal corrigido, é semelhante ao sinal da saída desejada (em verde) representada pelo sinal da corrente primária refletida no secundário do TC.

Analisando-se o primeiro ciclo de pós falta da onda da corrente no secundário do TC (em vermelho) e o sinal de saída da rede corretora (em azul), nota-se um ligeiro desvio na correção da forma de onda saturada, devido possivelmente a dificuldade da rede assimilar o padrão de uma pequena variação do sinal no final do primeiro meio ciclo do sinal de pós falta, causado por se tratar de uma área de transição de pré-falta para pós-falta. Todavia, o erro não se repete nos demais ciclos, possibilitando uma perfeita correção do sinal saturado. 


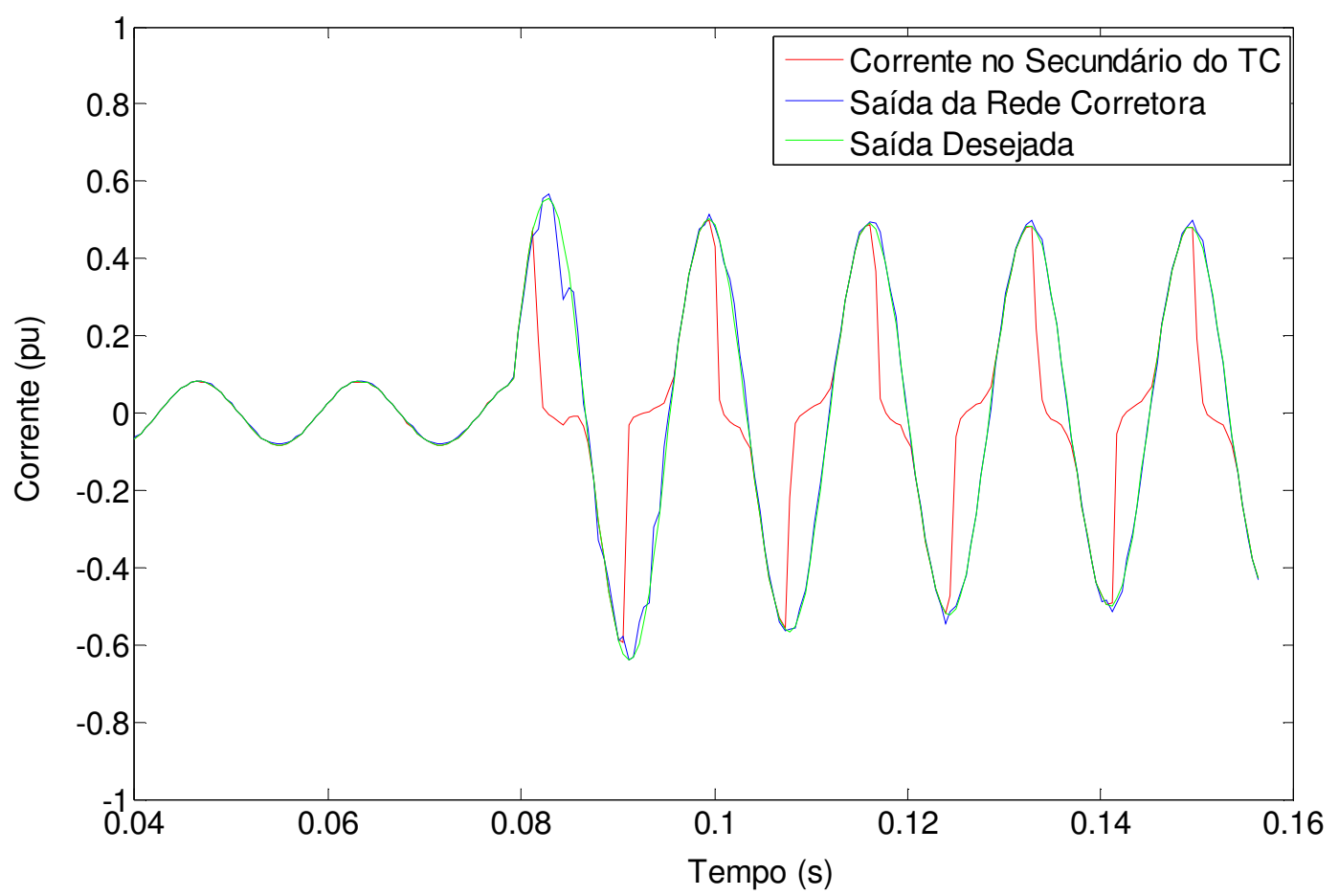

Figura 7.11 - Resposta da rede neural corretora falta externa ABT 90은

\subsubsection{Algoritmo de Correção e Detecção}

Em ambos os casos que serão apresentados através das Figuras 7.12, 7.13 e 7.14, evidencia-se também o bom desempenho da rede detectora quanto da rede corretora. No entanto, são observados as mesmas dificuldades relatadas anteriormente, ou seja, pequena dificuldade para detecção nos instantes de transição do sinal saturado e não saturado e dificuldade para correção do sinal durante o primeiro ciclo de transição de pré-falta para pós-falta. Contudo, ressalta-se que tais dificuldades não influenciaram a avaliação global da metodologia.

A Figura 7.12 traz o resultado do funcionamento do algoritmo, que engloba as redes detectora e corretora, para o caso de falta externa $A B C$ com ângulo de incidência de $270^{\circ}$ (caso 59 ). 


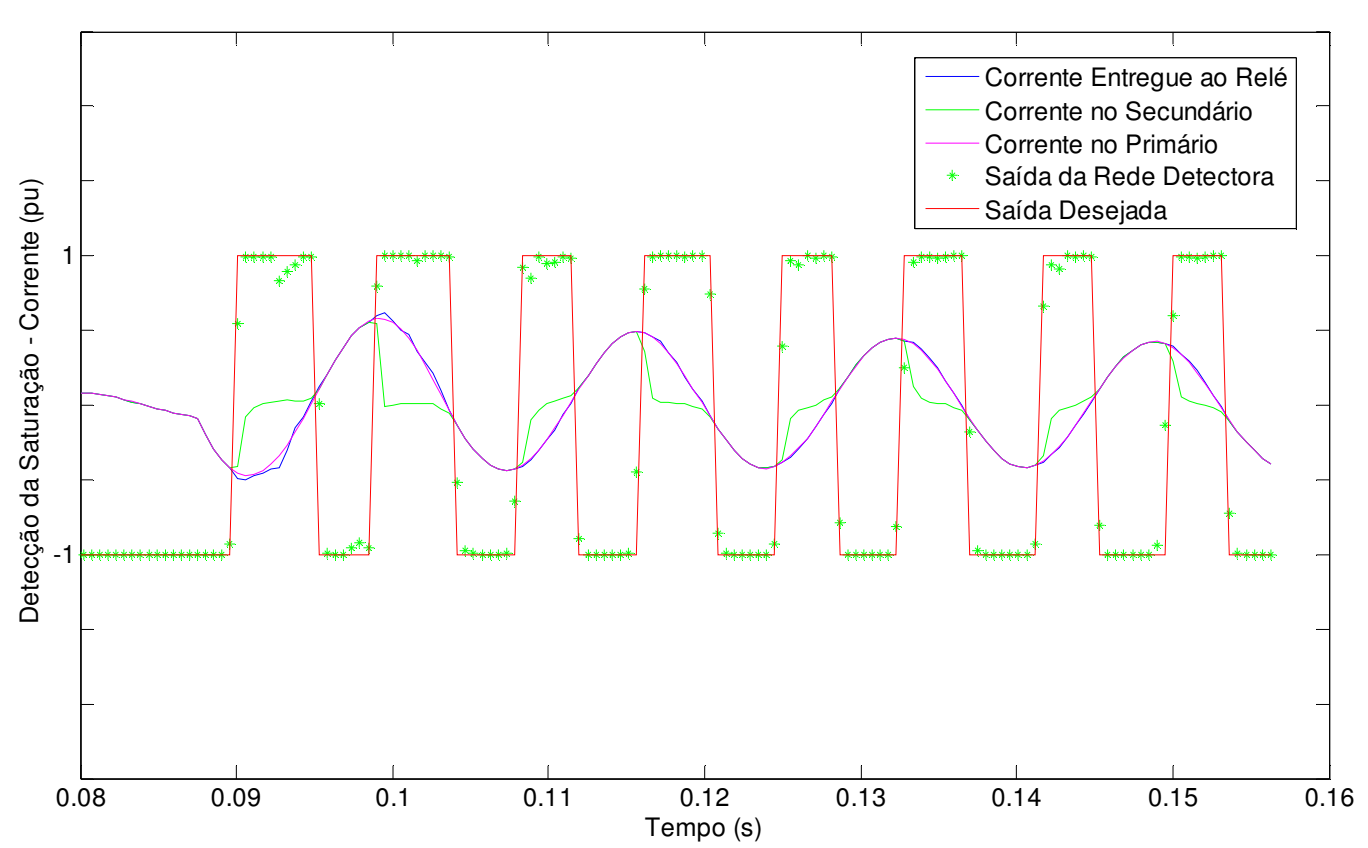

Figura 7.12 - Saída do algoritmo de detecção e correção falta externa ABC 270ํㅜ

A Figura 7.13 traz o resultado do funcionamento do algoritmo, que engloba as redes detectora e corretora, para o caso de falta externa ABT com ângulo de incidência de $90^{\circ}$ (caso 61).

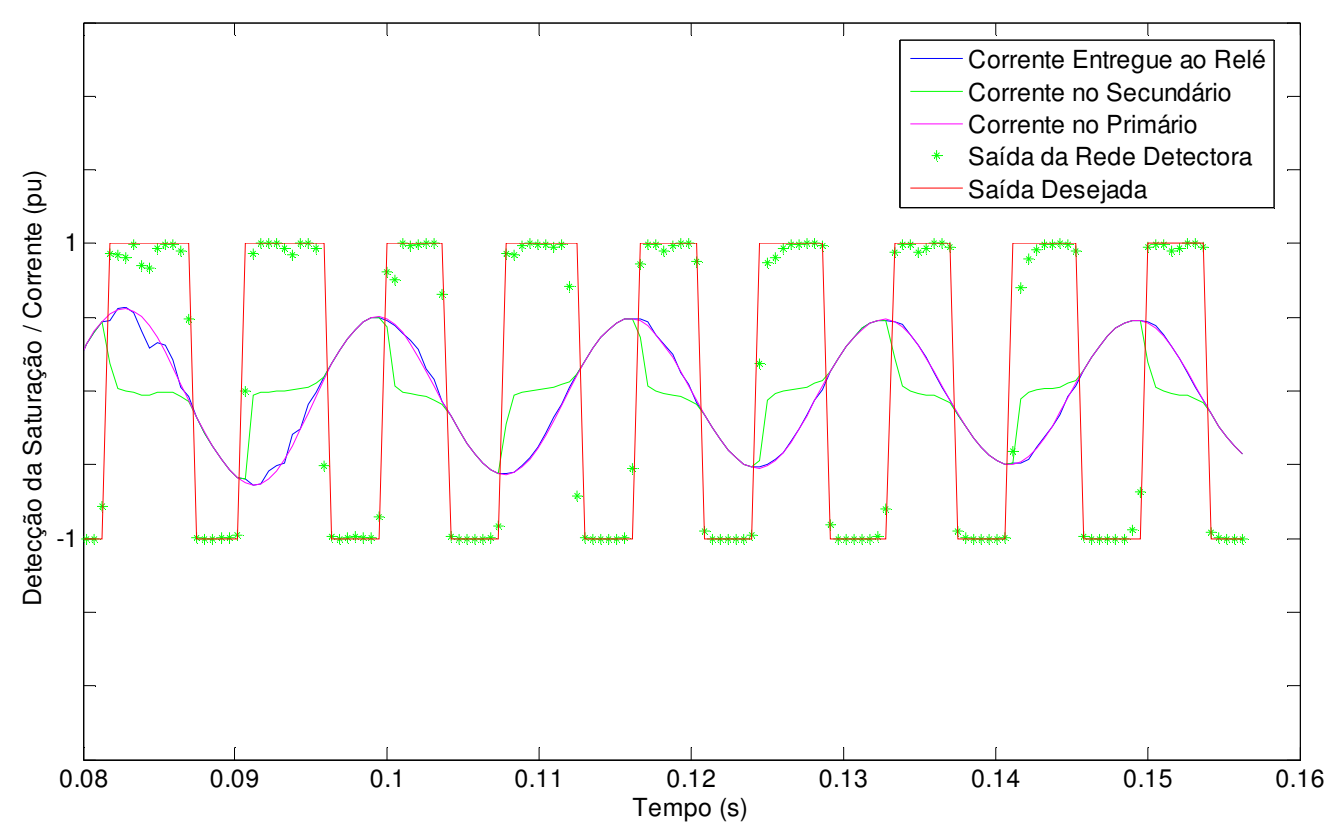

Figura 7.13 - Saída do algoritmo de detecção e correção falta externa ABT 90ํำ 
A Figura 7.14 traz o resultado do funcionamento do algoritmo, que engloba as redes detectora e corretora, para o caso de falta interna $A B C$ com ângulo de incidência de $180^{\circ}$ (caso 75 ).

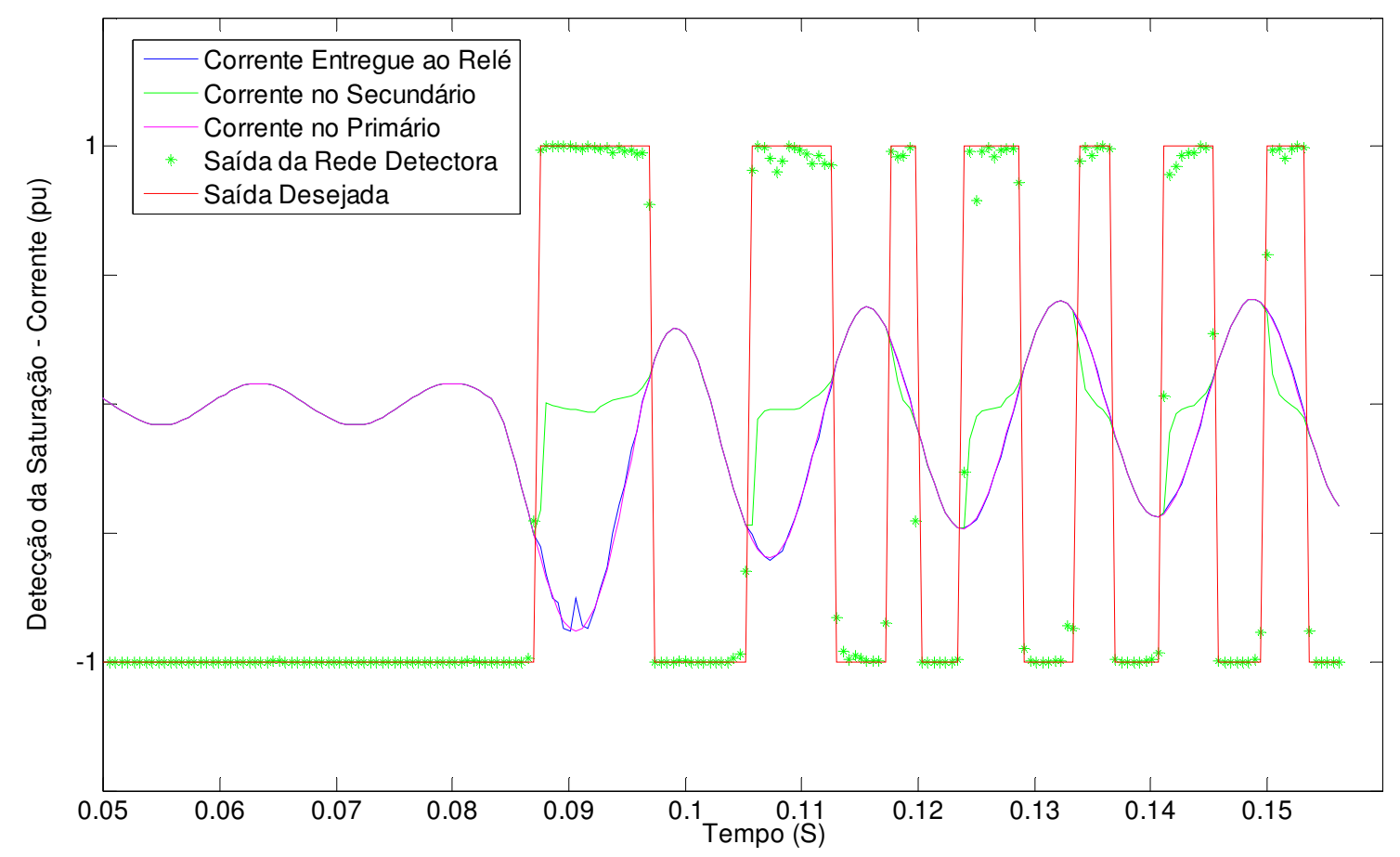

Figura 7.14 - Saída do algoritmo de detecção e correção falta interna ABC 180ํำ

Este trabalho de pesquisa propôs um esquema composto por duas RNAs dedicadas à detecção e correção da saturação dos TCs. A rede detectora apresentou uma taxa de acerto de $(99,6 \%)$ na identificação da saturação do TC. O desempenho da rede corretora foi também bastante satisfatório, com um erro médio de $0,66 \%$ e com uma variância de $0,81 \%$ para todos os casos.

Nota-se, por meio dos resultados apresentados na Tabela 7.1 que 0 emprego de redes neurais artificiais é considerado satisfatório quando aplicadas à detecção e correção da saturação de transformadores de corrente. O emprego desta técnica aumenta consideravelmente a confiabilidade e desempenho dos relés de proteção. 
Tabela 7.1 - Resultado dos testes antes e após o uso da RNA

\begin{tabular}{|c|c|c|c|c|c|c|c|c|c|c|}
\hline \multicolumn{8}{|c|}{ Dados sem correçẫo pela RNA } & \multicolumn{3}{|c|}{ Dados com correçẫo pela RNA } \\
\hline $\begin{array}{l}\text { No do } \\
\text { Caso }\end{array}$ & Tipo da Falta & $\begin{array}{l}\text { Ângulo de } \\
\text { Incidência }\end{array}$ & $\begin{array}{c}\text { Tempo de } \\
\text { Fechamento } \\
\text { da Falta }\end{array}$ & $\begin{array}{c}\text { Tempo de } \\
\text { Trip }\end{array}$ & $\begin{array}{c}\text { Trip Fase } \\
\text { A }\end{array}$ & $\begin{array}{c}\text { Trip Fase } \\
\text { B }\end{array}$ & $\begin{array}{c}\text { Trip Fase } \\
\text { C }\end{array}$ & Trip Fase A & Trip Fase B & Trip Fase C \\
\hline 57 & Falta Externa AB & $180^{\circ}$ & 0,42082 & 0,00478 & 0,42560 & 0,45440 & & Nẫo Detectou & Não Detectou & \\
\hline 58 & Falta Externa AB & $360^{\circ}$ & 0,42916 & 0,00404 & 0,46990 & 0,43320 & & Nẫo Detectou & Nẫo Detectou & \\
\hline 59 & Falta Externa $\mathrm{ABC}$ & $270^{\circ}$ & 0,42499 & 0,03331 & 0,69770 & 0,46800 & 0,45830 & Não Detectou & Não Detectou & Não Detectou \\
\hline 60 & Falta Externa ABCTerra & $360^{\circ}$ & 0,42916 & 0,00344 & 0,43420 & 0,43260 & 0,43880 & Nẫo Detectou & Não Detectou & Não Detectou \\
\hline 61 & Falta Externa ABTerra & $90^{\circ}$ & 0,41666 & 0,00344 & 0,42010 & 0,42310 & & Nẫo Detectou & Não Detectou & \\
\hline 62 & Falta Externa ABTerra & $180^{\circ}$ & 0,42082 & 0,00548 & 0,42630 & 0,43470 & & Nẫo Detectou & Não Detectou & \\
\hline 63 & Falta Externa ATerra & $90^{\circ}$ & 0,41666 & 0,02104 & 0,43770 & & & Nẫo Detectou & & \\
\hline 64 & Falta Externa ATerra & $270^{\circ}$ & 0,42499 & 0,01191 & 0,43690 & & & Nẫo Detectou & & \\
\hline 65 & Falta Externa BC & $270^{\circ}$ & 0,43054 & 0,00476 & & 0,43530 & 0,44000 & & Nẫo Detectou & Não Detectou \\
\hline 66 & Falta Externa BC & $360^{\circ}$ & 0,43471 & 0,00369 & & 0,46780 & 0,43840 & & Nẫo Detectou & Nẫo Detectou \\
\hline 67 & Falta Externa BCTerra & $90^{\circ}$ & 0,42221 & 0,00659 & & 0,45140 & 0,42880 & & Não Detectou & Não Detectou \\
\hline 68 & Falta Externa BTerra & $270^{\circ}$ & 0,43054 & 0,00316 & & 0,43370 & & & Nã̃o Detectou & \\
\hline 69 & Falta Externa BTerra & $360^{\circ}$ & 0,43471 & 0,01829 & & 0,45300 & & & Nẫo Detectou & \\
\hline 70 & Falta Externa CA & $90^{\circ}$ & 0,42777 & 0,00963 & 0,43760 & & 0,43740 & Nẫo Detectou & & Nẫo Detectou \\
\hline 71 & Falta Externa CATerra & $180^{\circ}$ & 0,43193 & 0,02167 & 0,45360 & & 0,47360 & Nẫo Detectou & & Nẫo Detectou \\
\hline 72 & Falta Externa CTerra & $270^{\circ}$ & 0,43610 & 0,00300 & & & 0,43910 & & & Não Detectou \\
\hline 73 & Falta Interna AB & $90^{\circ}$ & 0,41666 & 0,00094 & 0,41760 & 0,42230 & & 0,4267 & 0,4267 & \\
\hline 74 & Falta Interna $\mathrm{AB}$ & $270^{\circ}$ & 0,42499 & 0,00101 & 0,42600 & 0,42600 & & 0,4350 & 0,4455 & \\
\hline 75 & Falta Interna $\mathrm{ABC}$ & $180^{\circ}$ & 0,42082 & 0,00088 & 0,42190 & 0,42170 & 0,42620 & 0,4267 & 0,4251 & 0,4309 \\
\hline 76 & Falta Interna ABCTerra & $90^{\circ}$ & 0,41666 & 0,00094 & 0,41760 & 0,41860 & 0,42580 & 0,4210 & 0,4231 & 0,4303 \\
\hline 77 & Falta Interna ABTerra & $270^{\circ}$ & 0,42499 & 0,00101 & 0,42600 & 0,43310 & & 0,4293 & 0,4434 & \\
\hline 78 & Falta Interna ATerra & $180^{\circ}$ & 0,42082 & 0,00108 & 0,42190 & & & 0,4267 & & \\
\hline 79 & Falta Interna BC & $180^{\circ}$ & 0,42637 & 0,00093 & & 0,43200 & 0,42730 & & 0,4428 & 0,4314 \\
\hline 80 & Falta Interna BCTerra & $180^{\circ}$ & 0,42637 & 0,00083 & & 0,43880 & 0,42720 & & 0,4444 & 0,4309 \\
\hline 81 & Falta Interna BTerra & $180^{\circ}$ & 0,42637 & 0,01023 & & 0,43660 & & & 0,4439 & \\
\hline 82 & Falta Interna BTerra & $360^{\circ}$ & 0,43471 & 0,00089 & & 0,43560 & & & 0,4402 & \\
\hline 83 & Falta Interna CA & $270^{\circ}$ & 0,43610 & 0,00100 & 0,43710 & & 0,44160 & 0,4460 & & 0,4460 \\
\hline 84 & Falta Interna CA & $360^{\circ}$ & 0,44027 & 0,00093 & 0,44130 & & 0,44120 & 0,4455 & & 0,4455 \\
\hline 85 & Falta Interna CATerra & $90^{\circ}$ & 0,42777 & 0,00103 & 0,42940 & & 0,42880 & 0,4345 & & 0,4319 \\
\hline 86 & Falta Interna CATerra & $360^{\circ}$ & 0,44027 & 0,00093 & 0,44120 & & 0,44130 & 0,4449 & & 0,4465 \\
\hline 87 & Falta Interna CTerra & $90^{\circ}$ & 0,42777 & 0,00103 & & & 0,42880 & & & 0,4319 \\
\hline 88 & Falta Interna CTerra & $180^{\circ}$ & 0,43193 & 0,01017 & & & 0,44210 & & & 0,4496 \\
\hline
\end{tabular}

Podemos verificar através da Tabela 7.1, que os dados referentes aos casos de falta externa que estão sem a correção pela RNA, estavam causando falso trip, e após, o uso das RNAs houve a correção para 100\% dos casos de trips ocorridos indevidamente pela saturação dos TCs, justificando portanto 0 excelente desempenho das RNAs. Dos 32 casos utilizados na etapa de validação das RNAs, foram selecionados 16 tipos de falta externa e 16 tipos de falta interna, variando-se 0 tipo de falta e o seu ângulo de incidência, onde dessa maneira procurou-se ser mais criterioso, ou seja, selecionar a mesma quantidade de casos de falta interna e externa, com isso se fez uma representação melhor e eficaz dos resultados obtidos.

Foram testados no algoritmo da proteção diferencial os 32 casos sem a correção pela RNA, onde se verificou um erro de $50 \%$ nos casos para a falta externa e interna, ou seja, enviando o trip indevidamente ao disjuntor do gerador.

Após a correção pela RNA, foi verificado que para os casos de falta externa não foi detectado nenhum trip, ou seja, a correção pela RNA foi bastante satisfatória no auxílio à proteção diferencial, fazendo com que a proteção diferencial não atuasse erroneamente. 


\section{CONCLUSÕES}

Este trabalho apresentou um estudo sobre a deteç̧ão e correção da saturação de transformadores de corrente quando estes são aplicados à proteção de geradores síncronos, através das técnicas de Redes Neurais Artificiais.

O programa MATLAB que foi utilizado nesse estudo, permite a simulação de ferramentas computacionais de forma eficiente e rápida, contando ainda com vasta gama de opções de sub-rotinas especializadas.

$\mathrm{O}$ trabalho propõe um esquema composto por duas RNAs dedicadas à detecção e correção da saturação de TCs. A rede detectora apresentou uma elevada taxa de acerto $(99,6 \%)$ na identificação da saturação do TC. O desempenho da rede corretora foi também bastante satisfatório, com $0,66 \%$ de erro médio e com variância de $0,81 \%$. Pode-se verificar que a resposta do algoritmo da proteção diferencial foi satisfatória, visto que a RNA corretora conseguiu fazer a correção dos 16 tipos de faltas externas, sem envio do falso trip, auxiliando assim o desempenho da proteção diferencial.

Algumas observações sobre os resultados encontrados são necessárias, já que as figuras apresentadas nos capítulos anteriores são referentes às condições mais significativas. Tal abordagem teve a motivação de apresentar os casos mais significativos, pois nas demais situações avaliadas não foram encontrados resultados divergentes, sejam no tempo de atuação ou na tomada de decisão.

Os resultados mostram a viabilidade da aplicação de RNAs como solução ao problema de saturação dos TCs. O emprego desta técnica aumenta consideravelmente a confiabilidade e desempenho dos relés de proteção. Adicionalmente, por se tratar de uma técnica com esforço computacional médio, a sua incorporação nos relés de proteção não adicionaria grandes custos ao equipamento.

Conclui-se, através dos resultados obtidos, que a aplicação da ferramenta baseada em Redes Neurais Artificiais constitui uma nova e importante etapa na análise da proteção diferencial de geradores síncronos. Em conformidade com os resultados apresentados, pôde-se observar que a agregação das RNAs, possibilitou 
o desenvolvimento de um algoritmo capaz de auxiliar de maneira bastante satisfatória e eficaz a proteção diferencial de geradores síncronos.

\subsection{Continuidade da pesquisa}

Tendo em vista o aperfeiçoamento contínuo do algoritmo apresentado, principalmente no tocante a técnica de Redes Neurais Artificiais, propõe-se a realização de novos testes com a utilização de outros tipos de RNAs, tais como: utilização de RNAs com arquitetura Perceptron Multicamadas do tipo TDNN (Time Delay Neural Network) e algoritmo de treinamento com a regra delta generalizada (backpropagation), podemos também utilizar redes funções base radial (Radial Basis Function - RBF). Assim como na rede TDNN, as RBF são arquiteturas de RNA que são também normalmente utilizadas na aproximação de funções e classificação de padrões.

Outra proposta interessante seria a de se utilizar dados reais para a simulação no ATP, ou seja, utilizar os dados de uma oscilografia registrada em campo onde tenha ocorrido a saturação dos TCs próximos ao neutro e terminador do gerador síncrono. 


\section{REFERÊNCIAS}

ASSOCIAÇÃO BRASILEIRA DE NORMAS TÉCNICAS (1992). NBR 6856: Transformadores de corrente. Rio de Janeiro.

ANSI/IEEE Std. C57.13 (1993). ANSI/IEEE guide for requirements for instrument transformers.

ANSI/IEEE Std. C37.110 (2007). ANSI/IEEE guide for the application of current transformers used for protective relaying purposes.

ARAÚJO, C. A. S. et al. (2005). Proteção de sistemas elétricos. 2. ed. Rio de Janeiro: Editora Interciência.

BARBOSA, D., SILVA, M., BERNARDES, A., OLESKOVICZ, M, and COURY, D., "Lógica fuzzy aplicada na proteção de transformadores," in VIII Simpósio Brasileiro de Automação Inteligente, Florianópolis, 2007.

BARBOSA, D., MONARO, R. M., COURY, D. V., and OLESKOVICZ, M., "Digital frequency relaying based on the modified least mean square method," IET Generation, Transmission \& Distribution, 2008.

BARNETT, E. A. C. W.; CHADWICK, J. W. (1993). Relay performance considerations with low ratio cts and high fault currents. IEEE Transaction on Power Delivery, New York, v. 8, n. 3, p. 884-887.

BISHOP, C. (1995). Neural networks for pattern recognition. England: Oxford University Press, $504 \mathrm{p}$.

BRAGA, A. P.; LUDERMIR, T. B.; CARVALHO, A. C. P. L. F. (2000). Redes neurais artificiais: teoria e aplicações. Rio de Janeiro: Editora LTC.

CAMINHA, A. C. (1999). Introdução à proteção dos sistemas elétricos. São Paulo: Edgard Blucher; Itajubá: Escola Federal de Engenharia. Convênio Eletrobrás.

CASTRO, R. M. G.; GOMES, A. E.; FERREIRA, J. J. M. (1989). Transient behaviour of an induction generator in small hydro plants. In: ELECTROTECHNICAL CONFERENCE, 1989, Lisboa. Proceedings... Lisboa. p. 79-82.

CHEN, K. W.; GLAD, S. T. (1991). Estimation of the primary current in a saturated transformer. In: CONFERENCE ON DECISION AND CONTROL, 30., 1991, Brighton. Proceedings... Brighton: IEEE. p. 116-124.

COMPANHIA PAULISTA DE FORÇA E LUZ (2002). Apostila de proteção.

COURY, D. V.; CAMPOS, P. E. G.; TAVARES, M. C. (1998). Utilização do ATPEMTP para Estudo da Proteção Diferencial dos Transformadores de Potência. In: CONGRESSO BRASILEIRO DE AUTOMÁTICA, 12., 1998, Uberlândia. Anais... Uberlândia. 
COURY, D. V.; OLESKOVICZ, M.; GIOVANINI, R. (2007). Proteção digital de sistemas elétricos de potência: dos relés eletromecânicos aos microprocessados inteligentes. São Carlos: USP/EESC.

CROSSLEY, P.; HASIAN, S.; JENKINS, N. (2002). Evaluation of a new type of protection relay for wind farms.

CUMMINS, D. Y. J. C. e KOJOVIC, L. (2000). Simplified artificial neural network structure with the current transformer saturation detector provides a good estimate of primary currents. Power Engineering Society Summer Meeting, vol. 3.

DEMUTH, H.; BEALE, M; HAGAN, M. (2007). Neural network toolbox 5 - user's guide. Disponível em:

<http://www.mathworks.com/access/helpdesk/help/toolbox/nnet/>. Acesso em: 05 jan. 2008.

ELMAN, J. L. (1990). Finding structure in time. Cognitive Science, Amsterdam, v.14, n. 2, p.179-211.

FERNANDES, R. A. S. (2009). Identificação de fontes de correntes harmônicas por redes neurais artificiais. Dissertação (Mestrado) - Escola de Engenharia de São Carlos, Universidade de São Paulo, São Carlos.

FILHO, J. M. (2005). Manual de equipamentos elétricos. 3. ed. Rio de Janeiro: Editora LTC.

FITZGERALD, A. E.; KINGSLEY, C. Jr.; D.UMANS, S. (2006). Máquinas elétricas. 6. ed. Rio de Janeiro: McGraw-Hill Interamericana Brasil.

GIBELLI, G., BARBOSA, D., OLESKOVICZ. M., COURY, D. V., "Efeitos sobre a resposta dinâmica dos motores de indução trifásicos quando da ocorrência de afundamentos de tensão na rede de alimentação."

HAGAN, M. T.; MENHAJ, M. B. (1994). Training feedforward networks with the marquardt algorithm. IEEE Transactions on Neural Networks, v. 5, n. 6, p. 989993.

HALINKA, A.; M. SZEWCZYK, (2004), ANN based detection of electrical faults in generator-transformer units, IEE International Conference on Developments in Power System Protection, Vol. 1, 348-351, Amsterdan, Holanda, Abril 5-8

HAYKIN, S. (1994). Neural networks: a comprehensive foundation. New York: Prentice-Hall, $842 \mathrm{p}$.

HOROWITZ, S. H.; PHADKE, A. G, (1995). Power System Relaying. England: Research Studies Press Ltd., 2nd ed.

HOSEMANN, G.; STEIGERWALD, H. (1993). Modal saturation detector for digital differential protection. IEEE Transaction on Power Delivery, v. 8, n. 3, p. 933-940. 
HUNT, R., (2010) "Dimensioning CTs for small generator differential protection" Industrial and Commercial Power Systems Technical Conference (I\&CPS), 2010 IEEE.

INDIRESAM, P. V. , MURTHY, S. S. (1989). Generating electrical power form wave energy. $\mathrm{CH} 2781-3 / 89 / 0000-2121-\mathrm{IEEE}$.

JAMALI, S.; RADJI, K. M. (1997). A digital compensating technique for the saturation of protective current transformers. In: UNIVERSITIES POWER ENGINEERING CONFERENCE, 32., 1997, Manchester. Proceedings... Manchester: v. 1, p. 10-12.

JOHNS, A. T.; SALMAN, S. K.. (1995). Digital Protection for Power Systems. Stevenage: Peter Peregrinus.

KANG, A. T. J. Y. C.; PARK, J. K.; AGGARWAL, R. K. (1997). Algorithm for compensating secondary currents of current transformers. IEEE Transaction on Power Delivery, v. 12, n. 1, p. 116-124.

KASZTENNY, B.; FINNEY D. (2005). Generator protection and ct saturation Presented at the Texas A \& M Protective Relay Conference, April 5, 2005.

KINDERMANN, G. (2008). Proteção de sistemas elétricos de potência. Florianópolis: Edição do autor.

LU YUPING, LAI L. L., GUOQING, T. (2004). Neural network based generatortransformer protection. In: INTERNATIONAL CONFERENCE ON MACHINE LEARNING AND CYBERNETICS, 30., 2004, Shangai. Proceedings... Shangai, 26 -29 August.

MAO, P. L. et al. (1998). Identification of eletromagnetic transients in power transformer system using artificial neural network. In: International Conference on Power System Technology, 1998, Proceedings... p. 880-884.

MEGAHED, A. I. and O. P. MALIK, (1999). An Artificial neural network based digital differential protection scheme for synchronous generator stator winding protection, IEEE Transactions on Power Delivery, New York, v. 14, n. 1, p. 86-93.

MIKRUT, W. W.; WITEK, B. (1989). Performance of differential protection for threewinding power transformers during transient cts saturation. In: INTERNATIONAL CONFERENCE ON DEVELOPMENTS IN POWER SYSTEM PROTECTION, 4., 1989, n. 302, p. 40-44.

MONARO, R. M., SILVA, R.C.S., JUNIOR, J.C.M.V., COURY, D.V. (2010). Detecção e correção de sinais de transformadores de corrente distorcidos pela saturação através de redes neurais artificiais. In: Congresso Brasileiro de Automática, 09., 2010, Bonito. Anais...Bonito: Cigré.

PIHLER, B. G. J.; DOLINAR, D. (1997). Improved operation of power transformer protection using artificial neural network. IEEE Transaction on Power Delivery, New York, v. 12, n. 3, p. 1128-1136. 
REIMERT, D. (2006), Protective relaying for power generation systems. Boca Raton: CRC Press.

RIGOTTO, G. J. Jr., BATISTA, J. C., e ALVES, C. E. (2010). Análise de operação indevida da função de gerador por saturação de transformadores de corrente. In: SEMINÁRIO TÉCNICO DE PROTEÇÃO E CONTROLE, 10., 2010, Recife. Anais... Recife: Cigré.

SEGATTO, E. C. (2005). Relé diferencial para transformadores de potência utilizando ferramentas inteligentes. (Doutorado) - Escola de Engenharia de São Carlos, Universidade de São Paulo, São Carlos, 2005.

TAALAB, A. I.; DARWISH, H. A.; KAWADY, T. A. (1999). ANN based novel fault detector for generator windings protection. IEEE Transaction on Power Delivery, New York, v. 14, n. 3, p. 824-830.

VILLADA, F.; VALENCIA, J. A.; ORILLE, A. L. (2006). Aplicação de redes neurais na proteção diferencial de geradores síncronos. Disponível em: <http://www.scielo.cl/scielo.php>. Acesso em: 20 dez. 2008.

YU, D. et al. (2001). Correction of current transformer distorted secondary currents due to saturation using artificial neural network. IEEE Transactions on Power Delivery, New York, v. 16, n. 2, p. 189-194.

YU, D. et al. (1999). Neural network for current transformer saturation correction. In: TRANSMISSION AND DISTRIBUTION CONFERENCE, 1999, New Orleans. Proceedings... New Orleans: IEEE. v. 1, p. 441-446.

ZOCHOLL, S. E. (2004). Análise e aplicação de transformadores de corrente. Washington: Schweitzer Engineering Laboratories. 


\section{APÊNDICE A - Casos utilizados para treinamento e validação das RNAs}

\begin{tabular}{|c|c|c|}
\hline Treinamento & Tipo de Falta & Ângulo de Incidência \\
\hline Caso 1 & Falta Externa $\mathrm{AB}$ & $90^{\circ}$ \\
\hline Caso 2 & Falta Externa $\mathrm{AB}$ & $270^{\circ}$ \\
\hline Caso 3 & Falta Externa $\mathrm{ABC}$ & $90^{\circ}$ \\
\hline Caso 4 & Falta Externa ABC & $180^{\circ}$ \\
\hline Caso 5 & Falta Externa $\mathrm{ABC}$ & $360^{\circ}$ \\
\hline Caso 6 & Falta Externa ABCTerra & $90^{\circ}$ \\
\hline Caso 7 & Falta Externa ABCTerra & $180^{\circ}$ \\
\hline Caso 8 & Falta Externa ABCTerra & $270^{\circ}$ \\
\hline Caso 9 & Falta Externa ABTerra & $270^{\circ}$ \\
\hline Caso 10 & Falta Externa ABTerra & $360^{\circ}$ \\
\hline Caso 11 & Falta Externa ATerra & $180^{\circ}$ \\
\hline Caso 12 & Falta Externa ATerra & $360^{\circ}$ \\
\hline Caso 13 & Falta Externa BC & $90^{\circ}$ \\
\hline Caso 14 & Falta Externa BC & $180^{\circ}$ \\
\hline Caso 15 & Falta Externa BCTerra & $180^{\circ}$ \\
\hline Caso 16 & Falta Externa BCTerra & $270^{\circ}$ \\
\hline Caso 17 & Falta Externa BCTerra & $360^{\circ}$ \\
\hline Caso 18 & Falta Externa BTerra & $90^{\circ}$ \\
\hline Caso 19 & Falta Externa BTerra & $180^{\circ}$ \\
\hline Caso 20 & Falta Externa CA & $180^{\circ}$ \\
\hline Caso 21 & Falta Externa CA & $270^{\circ}$ \\
\hline Caso 22 & Falta Externa CA & $360^{\circ}$ \\
\hline Caso 23 & Falta Externa CATerra & $90^{\circ}$ \\
\hline Caso 24 & Falta Externa CATerra & $270^{\circ}$ \\
\hline Caso 25 & Falta Externa CATerra & $360^{\circ}$ \\
\hline Caso 26 & Falta Externa CTerra & $90^{\circ}$ \\
\hline Caso 27 & Falta Externa CTerra & $180^{\circ}$ \\
\hline Caso 28 & Falta Externa CTerra & $360^{\circ}$ \\
\hline Caso 29 & Falta Interna $\mathrm{AB}$ & $180^{\circ}$ \\
\hline Caso 30 & Falta Interna AB & $360^{\circ}$ \\
\hline Caso 31 & Falta Interna $\mathrm{ABC}$ & $90^{\circ}$ \\
\hline Caso 32 & Falta Interna $\mathrm{ABC}$ & $270^{\circ}$ \\
\hline Caso 33 & Falta Interna $\mathrm{ABC}$ & $360^{\circ}$ \\
\hline Caso 34 & Falta Interna ABCTerra & $180^{\circ}$ \\
\hline Caso 35 & Falta Interna ABCTerra & $270^{\circ}$ \\
\hline Caso 36 & Falta Interna ABCTerra & $360^{\circ}$ \\
\hline Caso 37 & Falta Interna ABTerra & $90^{\circ}$ \\
\hline Caso 38 & Falta Interna ABTerra & $180^{\circ}$ \\
\hline Caso 39 & Falta Interna ABTerra & $360^{\circ}$ \\
\hline Caso 40 & Falta Interna ATerra & $90^{\circ}$ \\
\hline Caso 41 & Falta Interna ATerra & $270^{\circ}$ \\
\hline Caso 42 & Falta Interna ATerra & $360^{\circ}$ \\
\hline Caso 43 & Falta Interna BC & $90^{\circ}$ \\
\hline Caso 44 & Falta Interna BC & $270^{\circ}$ \\
\hline Caso 45 & Falta Interna BC & $360^{\circ}$ \\
\hline Caso 46 & Falta Interna BCTerra & $90^{\circ}$ \\
\hline Caso 47 & Falta Interna BCTerra & $270^{\circ}$ \\
\hline Caso 48 & Falta Interna BCTerra & $360^{\circ}$ \\
\hline Caso 49 & Falta Interna BTerra & $90^{\circ}$ \\
\hline Caso 50 & Falta Interna BTerra & $270^{\circ}$ \\
\hline Caso 51 & Falta Interna CA & $180^{\circ}$ \\
\hline Caso 52 & Falta Interna CA & $90^{\circ}$ \\
\hline Caso 53 & Falta Interna CATerra & $180^{\circ}$ \\
\hline Caso 54 & Falta Interna CATerra & $270^{\circ}$ \\
\hline Caso 55 & Falta Interna CTerra & $270^{\circ}$ \\
\hline Caso 56 & Falta Interna CTerra & $360^{\circ}$ \\
\hline
\end{tabular}

\begin{tabular}{|l|l|c|}
\hline Validação & Tipo de Falta & Ángulo de Incidência \\
\hline Caso 57 & Falta Externa AB & $180^{\circ}$ \\
\hline Caso 58 & Falta Externa AB & $360^{\circ}$ \\
\hline Caso 59 & Falta Externa ABC & $270^{\circ}$ \\
\hline Caso 60 & Falta Externa ABCTerra & $360^{\circ}$ \\
\hline Caso 61 & Falta Externa ABTerra & $90^{\circ}$ \\
\hline Caso 62 & Falta Externa ABTerra & $180^{\circ}$ \\
\hline Caso 63 & Falta Externa ATerra & $90^{\circ}$ \\
\hline Caso 64 & Falta Externa ATerra & $270^{\circ}$ \\
\hline Caso 65 & Falta Externa BC & $270^{\circ}$ \\
\hline Caso 66 & Falta Externa BC & $360^{\circ}$ \\
\hline Caso 67 & Falta Externa BCTerra & $90^{\circ}$ \\
\hline Caso 68 & Falta Externa BTerra & $270^{\circ}$ \\
\hline Caso 69 & Falta Externa BTerra & $360^{\circ}$ \\
\hline Caso 70 & Falta Externa CA & $90^{\circ}$ \\
\hline Caso 71 & Falta Externa CATerra & $180^{\circ}$ \\
\hline Caso 72 & Falta Externa CTerra & $270^{\circ}$ \\
\hline Caso 73 & Falta Interna AB & $90^{\circ}$ \\
\hline Caso 74 & Falta Interna AB & $270^{\circ}$ \\
\hline Caso 75 & Falta Interna ABC & $180^{\circ}$ \\
\hline Caso 76 & Falta Interna ABCTerra & $90^{\circ}$ \\
\hline Caso 77 & Falta Interna ABTerra & $270^{\circ}$ \\
\hline Caso 78 & Falta Interna ATerra & $180^{\circ}$ \\
\hline Caso 79 & Falta Interna BC & $180^{\circ}$ \\
\hline Caso 80 & Falta Interna BCTerra & $180^{\circ}$ \\
\hline Caso 81 & Falta Interna BTerra & $180^{\circ}$ \\
\hline Caso 82 & Falta Interna BTerra & $360^{\circ}$ \\
\hline Caso 83 & Falta Interna CA & $270^{\circ}$ \\
\hline Caso 84 & Falta Interna CA & $360^{\circ}$ \\
\hline Caso 85 & Falta Interna CATerra & $90^{\circ}$ \\
\hline Caso 86 & Falta Interna CATerra & $360^{\circ}$ \\
\hline Caso 87 & Falta Interna CTerra & $90^{\circ}$ \\
\hline Caso 88 & Falta Interna CTerra & $180^{\circ}$ \\
\hline
\end{tabular}




\section{APÊNDICE B - Processo de treinamento da RNA detectora}

\begin{tabular}{|c|c|}
\hline \multicolumn{2}{|c|}{ NET_DET_27 1} \\
\hline Arquitetura: & 2 camadas neurais \\
\hline Algoritimo de Treinamento: & Levenberg Marquardt \\
\hline Número de Camadas: & 2 \\
\hline Número de Neurônios Por Camada: & $27 \quad 1$ \\
\hline Funçấo de Ativaçấo: & Tangente Hiperbólica \\
\hline Coeficiente: & $\beta=2$ \\
\hline Erro: & 38 \\
\hline Acerto (\%): & 99,6042 \\
\hline \multicolumn{2}{|l|}{ Progresso } \\
\hline No de Epocas & $28-1000$ \\
\hline Tempo de Treinamento: & $00: 03: 48$ \\
\hline Erro Quadrático Médio: & 0.00165 \\
\hline
\end{tabular}

\begin{tabular}{|c|c|}
\hline \multicolumn{2}{|c|}{ NET DET 261} \\
\hline Arquitetura: & 2 camadas neurais \\
\hline Algoritimo de Treinamento: & Levenberg Marquardt \\
\hline Número de Camadas: & 2 \\
\hline Número de Neurónios Por Camada & 26,1 \\
\hline Funçấo de Ativaçấ: & Tangente Hiperbólica \\
\hline Coeficiente: & $\beta=2$ \\
\hline Erro: & 34 \\
\hline Acerto (\%): & 99,6458 \\
\hline & \\
\hline Progresso & \\
\hline No de Epocas & $31-1000$ \\
\hline Tempo de Treinamento: & 00:04:10 \\
\hline Erro Quadrático Médio: & 0.000144 \\
\hline
\end{tabular}

\begin{tabular}{|l|l|}
\hline \multicolumn{2}{|c|}{ NET_DET_25 1} \\
\hline Arquitetura: & 2 camadas neurais \\
\hline Algoritimo de Treinamento: & Levenberg Marquardt \\
\hline Número de Camadas: & 2 \\
\hline Número de Neurônios Por Camada & 251 \\
\hline Funçấo de Ativaçấo: & Tangente Hiperbólica \\
\hline Coeficiente: & $6=2$ \\
\hline Erro: & 66 \\
\hline Acerto (\%): & 99,3125 \\
\hline & \\
\hline Progresso & $00: 05: 30$ \\
\hline No de Epocas: & $460 \mathrm{e}^{-06}$ \\
\hline Tempo de Treinamento: & \\
\hline Erro Quadrático Médio: &
\end{tabular}

\begin{tabular}{|c|c|}
\hline \multicolumn{2}{|c|}{ NET_DET_24_1 } \\
\hline Arquitetura: & 2 camadas neurais \\
\hline Algoritimo de Treinamento: & Levenberg Marquard \\
\hline Número de Camadas: & 2 \\
\hline Número de Neurônios Por Camada: & 241 \\
\hline Funcấo de Ativaçấo: & Tangente Hiperbólica \\
\hline Coeficiente: & $\beta=2$ \\
\hline Erro: & 41 \\
\hline Acerto $(\%)$ : & 99.5729 \\
\hline & \\
\hline Progresso & \\
\hline$N^{\circ}$ de Epocas & $29-1000$ \\
\hline Tempo de Treinamento: & $00: 03: 58$ \\
\hline Erro Quadrático Médio: & $1.17 \mathrm{e}^{-07}$ \\
\hline
\end{tabular}




\begin{tabular}{|c|c|}
\hline Arquitetura: & 2 camadas neurais \\
\hline Algoritimo de Treinamento: & Levenberg Marquardt \\
\hline Número de Camadas: & 2 \\
\hline Número de Neurônios Por Camada & 231 \\
\hline Funçẫo de Ativação: & Tangente Hiperbólica \\
\hline Coeficiente: & $\beta=2$ \\
\hline Erro: & 35 \\
\hline Acerto $(\%):$ & 99,6354 \\
\hline \multicolumn{2}{|l|}{ Progresso } \\
\hline$N^{\circ}$ de Epocas & $24-1000$ \\
\hline Tempo de Treinamento: & $00: 02: 38$ \\
\hline Erro Quadrático Médio: & 0,00228 \\
\hline
\end{tabular}

\section{NET DET 211}

\begin{tabular}{|c|c|}
\hline Arquitetura: & 2 camadas neurais \\
\hline Algoritimo de Treinamento: & Levenberg Marquardt \\
\hline Número de Camadas: & 2 \\
\hline Número de Neurônios Por Camada & 211 \\
\hline Funçấo de Ativação: & Tangente Hiperbólica \\
\hline Coeficiente: & $\beta=2$ \\
\hline Erro: & 43 \\
\hline Acerto $(\%)$ : & 99,5521 \\
\hline \multirow{2}{*}{\multicolumn{2}{|c|}{ Progresso }} \\
\hline & \\
\hline No de Épocas & $25-1000$ \\
\hline Tempo de Treinamento: & 00:02:18 \\
\hline Erro Quadrático Médio: & 0,00296 \\
\hline
\end{tabular}

\section{NET DET 22}

\begin{tabular}{|c|c|}
\hline Arquitetura: & 2 camadas neurais \\
\hline Algoritimo de Treinamento: & Levenberg Marquardt \\
\hline Número de Camadas: & 2 \\
\hline Número de Neurônios Por Camada: & 221 \\
\hline Funçấo de Ativaçấ: & Tangente Hiperbólica \\
\hline Coeficiente: & $\beta=2$ \\
\hline Erro: & 43 \\
\hline Acerto (\%): & 99,5521 \\
\hline & \\
\hline \multicolumn{2}{|l|}{ Progresso } \\
\hline No de Epocas & $45-1000$ \\
\hline Tempo de Treinamento: & $00: 04: 39$ \\
\hline Erro Quadrático Médio: & $1.36 \mathrm{e}^{-07}$ \\
\hline
\end{tabular}

\begin{tabular}{|c|c|}
\hline NET_DET_ & $\begin{array}{l}201 \\
2 \text { camadas neurais }\end{array}$ \\
\hline Algoritimo de Treinamento: & Levenberg Marquardt \\
\hline Número de Camadas: & 2 \\
\hline Número de Neurónios Por Camada: & 201 \\
\hline Funcâo de Ativacâo: & Tangente Hiperbólica \\
\hline Coeficiente: & $\beta=2$ \\
\hline Erro: & 51 \\
\hline Acerto (\%): & 99,4668 \\
\hline \multicolumn{2}{|l|}{ Progresso } \\
\hline No de Epocas & $35-1000$ \\
\hline Tempo de Treinamento: & $00: 03: 04$ \\
\hline Erro Quadrático Médio: & 0,00161 \\
\hline
\end{tabular}




\section{APÊNDICE C - Processo de treinamento da RNA corretora}

\begin{tabular}{|c|c|}
\hline \multicolumn{2}{|c|}{ NET COR 17 13 1} \\
\hline Arquitetura: & 3 camadas neurais \\
\hline Algoritmo de Treinamento: & Levenberg Marquardt \\
\hline Número de Camadas: & 3 \\
\hline Número de Neurônios Por Camada: & $17 \quad 13 \quad 1$ \\
\hline Funçấo de Ativaçấ: & Tangente Hiperbólica \\
\hline EM (Erro Médio) & 0,0087 \\
\hline EM (Erro Médio) em Amper & 3,3891 e-004 \\
\hline VAR (Variância) & 0,0319 \\
\hline VAR (Variância) em Amper & 0,8180 \\
\hline \multicolumn{2}{|l|}{ Progresso } \\
\hline No de Epocas & 1.000 \\
\hline Tempo de Treinamento: & $01: 47: 51$ \\
\hline Erro Quadrático Médio: & 0.000147 \\
\hline
\end{tabular}

\begin{tabular}{|l|l|}
\hline & NET COR 22,181 \\
\hline Arquitetura: & 3 camadas neurais \\
\hline Algoritmo de Treinamento: & Levenberg Marquardt \\
\hline Número de Camadas: & 3 \\
\hline Número de Neurônios Por Camada: & 22,18 1 \\
\hline Funçấo de Ativação: & Tangente Hiperbólica \\
\hline EM (Erro Médio) & 0.0094 \\
\hline EM (Erro Médio) em Amper & $3.8626 e^{-0.004}$ \\
\hline VAR Variância) & 0.0363 \\
\hline VAR Variância) em Amper & 0.8865 \\
\hline Progresso & 1.000 \\
\hline No de Epocas: & $03: 14: 04$ \\
\hline Tempo de Treinamento: & 0.000179 \\
\hline Erro Quadrático Médio: & \\
\hline
\end{tabular}

\begin{tabular}{|c|c|}
\hline \multicolumn{2}{|c|}{ NET COR 23161} \\
\hline Arquitetura: & 3 camadas neurais \\
\hline Algoritmo de Treinamento: & Levenberg Marquardt \\
\hline Número de Camadas: & 3 \\
\hline Número de Neurônios Por Camada: & 23161 \\
\hline Funçấo de Ativaçấo: & Tangente Hiperbólica \\
\hline EM (Erro Médio) & 0,0125 \\
\hline EM (Erro Médio) em Amper & $4,8600 e^{-004}$ \\
\hline VAR (Variância) & 0,0457 \\
\hline VAR (Variância) em Amper & 1,1729 \\
\hline \multicolumn{2}{|l|}{ Progresso } \\
\hline No de Epocas & 1.000 \\
\hline Tempo de Treinamento: & $03: 17: 19$ \\
\hline Erro Quadrático Médio: & 0.000308 \\
\hline
\end{tabular}

\begin{tabular}{|l|l|}
\hline & NET COR 20151 \\
\hline Arquitetura: & 3 camadas neurais \\
\hline Algoritmo de Treinamento: & Levenberg Marquardt \\
\hline Número de Camadas: & 3 \\
\hline Número de Neurônios Por Camada: & 20151 \\
\hline Funçâo de Ativaçấo: & Tangente Hiperbólica \\
\hline EM (Erro Médio) & 0,0133 \\
\hline EM (Erro Médio) em Amper & $5,2373 \mathrm{e}^{-004}$ \\
\hline VAR Variância) & 0,0492 \\
\hline VAR (Variância) em Amper & 1,2516 \\
\hline Progresso & 1,000 \\
\hline No de Epocas: & $02: 30: 32$ \\
\hline Tempo de Treinamento: & 0,000278 \\
\hline Erro Quadrático Médio: & \\
\hline
\end{tabular}

\begin{tabular}{|c|c|}
\hline \multicolumn{2}{|c|}{ NET COR 22 19 1} \\
\hline Arquitetura: & 3 camadas neurais \\
\hline Algoritmo de Treinamento: & Levenberg Marquardt \\
\hline Número de Camadas: & 3 \\
\hline Número de Neurônios Por Camada & 22191 \\
\hline Funçẫo de Ativaçẫo: & Tangente Hiperbólica \\
\hline EM (Erro Médio) & 0.0107 \\
\hline EM (Erro Médio) em Amper & $3.4145 e^{-0.004}$ \\
\hline VAR (Variância) & 0.0321 \\
\hline VAR Variância) em Amper & 10.095 \\
\hline \multicolumn{2}{|l|}{ Progresso } \\
\hline No de Epocas: & 11.000 \\
\hline Tempo de Treinamento: & D3:21:01 \\
\hline Erro Quadrático Médio: & 0.000208 \\
\hline
\end{tabular}

\begin{tabular}{|c|c|}
\hline \multicolumn{2}{|c|}{ NET COR $23 \quad 17 \quad 1$} \\
\hline Arquitetura: & 3 camadas neurais \\
\hline Algoritmo de Treinamento: & Levenberg_Marquardt \\
\hline Número de Camadas: & 3 \\
\hline Número de Neurônios Por Camada & $23 \quad 17 \quad 1$ \\
\hline Funcấo de Ativaçấo: & Tangente Hiperbólica \\
\hline EM (Erro Médio) & 0.0092 \\
\hline EM (Erro Médio) em Amper & $3.0851 e^{-004}$ \\
\hline VAR (Variância) & 0.0290 \\
\hline VAR Variâncial em Amper & 0.8673 \\
\hline \multicolumn{2}{|l|}{ Progresso } \\
\hline No de Epocas & 1.000 \\
\hline Tempo de Treinamento: & $03: 16: 59$ \\
\hline Erro Quadrático Médio: & $9.73 e^{-05}$ \\
\hline
\end{tabular}




\begin{tabular}{|c|c|}
\hline \multicolumn{2}{|c|}{ NET COR 23181} \\
\hline Arquitetura: & 3 camadas neurais \\
\hline Algoritmo de Treinamento: & Levenberg Marquardt \\
\hline Número de Camadas: & 3 \\
\hline Número de Neurônios Por Camada & 23181 \\
\hline Funçẫo de Ativação: & Tangente Hiperbólica \\
\hline EM (Erro Médio) & 0.0066 \\
\hline EM (Erro Médio) em Amper & $8.6079 e^{-0.005}$ \\
\hline VAR (Variância) & 0.0081 \\
\hline VAR (Variância) em Amper & 0.6223 \\
\hline \multicolumn{2}{|l|}{ Progresso } \\
\hline No de Épocas & 1.000 \\
\hline Tempo de Treinamento: & $03: 28: 32$ \\
\hline Erro Quadrático Médio: & 0.000105 \\
\hline
\end{tabular}

\begin{tabular}{|l|l|}
\hline & NET COR 23201 \\
\hline Arquitetura: & 3 camadas neurais \\
\hline Algoritmo de Treinamento: & Levenberg Marquardt \\
\hline Número de Camadas: & 3 \\
\hline Número de Neurônios Por Camada: & 23201 \\
\hline Funçáo de Ativaçấo: & Tangente Hiperbólica \\
\hline EM (Erro Médio) & 0.074 \\
\hline EM (Erro Médio) em Amper & $2.5920^{\mathrm{e}-004}$ \\
\hline VAR Variância) & 0.0244 \\
\hline VAR Nariância) em Amper & 0.6938 \\
\hline Progresso & \\
\hline No de Epocas: & 1.000 \\
\hline Tempo de Treinamento: & $9.47: 16$ \\
\hline Erro Quadrático Médio: & $9.38 \mathrm{e}^{-05}$ \\
\hline
\end{tabular}

\begin{tabular}{|c|c|}
\hline \multicolumn{2}{|c|}{ NET COR 24,181} \\
\hline Arquitetura: & 3 camadas neurais \\
\hline Algoritmo de Treinamento: & Levenberg_Marquardt \\
\hline Número de Camadas: & 3 \\
\hline Número de Neurônios Por Camada: & $24 ; 18 \_1$ \\
\hline Funçẫo de Ativaçấo: & Tangente Hiperbólica \\
\hline EM (Erro Médio) & 0,0086 \\
\hline EM (Erro Médio) em Amper & $3.4224 e^{-004}$ \\
\hline VAR (Variância) & 0.0322 \\
\hline VAR (Variância) em Amper & 0.8038 \\
\hline \multicolumn{2}{|l|}{ Progresso } \\
\hline No de Epocas & 1.000 \\
\hline Tempo de Treinamento: & $03: 46: 20$ \\
\hline Erro Quadrático Médio: & 0,000127 \\
\hline
\end{tabular}

\section{NET COR 2319}

\begin{tabular}{|c|c|}
\hline Arquitetura: & 3 camadas neurais \\
\hline Algoritmo de Treinamento: & Levenberg Marquardt \\
\hline Número de Camadas: & 3 \\
\hline Número de Neurônios Por Camada & $23 \quad 1911$ \\
\hline Funçẫo de Ativaçẫo: & Tangente Hiperbólica \\
\hline EM (Erro Médio) & 0.0091 \\
\hline EM (Erro Médio) em Amper & $3.6528^{\mathrm{e}-004}$ \\
\hline VAR (Variância) & 0.0343 \\
\hline VAR Variância) em Amper & 0.8594 \\
\hline \multicolumn{2}{|l|}{$\begin{array}{l}\text { Progresso } \\
\text { No de Enocas }\end{array}$} \\
\hline No de Épocas & 1.000 \\
\hline Tempo de Treinamento: & $03: 47: 16$ \\
\hline Erro Quadrático Médio: & $9.38 e^{-05}$ \\
\hline
\end{tabular}

\begin{tabular}{|c|c|}
\hline \multicolumn{2}{|c|}{ NET COR 24171} \\
\hline Arquitetura: & 3 camadas neurais \\
\hline Algoritmo de Treinamento: & Levenberg Marquardt \\
\hline Número de Camadas: & 3 \\
\hline Número de Neurônios Por Camada: & $24 \quad 17 \quad 1$ \\
\hline Funçấo de Ativaçẫo: & Tangente Hiperbólica \\
\hline EM (Erro Médio) & 0.0094 \\
\hline EM (Erro Médio) em Amper & $3.8433 e^{-004}$ \\
\hline VAR (Variância) & 0.0361 \\
\hline VAR (Variância) em Amper & 0.8838 \\
\hline Progresso & \\
\hline No de Epocas & 1.000 \\
\hline Tempo de Treinamento: & 03:37:07 \\
\hline Erro Quadrático Médio: & 0,000199 \\
\hline
\end{tabular}

Erro Quadrático Médio: $\quad 0,000199$

\begin{tabular}{|c|c|}
\hline \multicolumn{2}{|c|}{ NET COR 24191} \\
\hline Arquitetura: & 3 camadas neurais \\
\hline Algoritmo de Treinamento: & Levenberg Marquardt \\
\hline Número de Camadas: & 3 \\
\hline Número de Neurônios Por Camada: & $24 \quad 19 \quad 1$ \\
\hline Funçẫo de Ativacẫo: & Tangente Hiperbólica \\
\hline EM (Erro Médio) & 0,0098 \\
\hline EM (Erro Médio) em Amper & $3.9968 e^{-004}$ \\
\hline VAR (Variância) & 0.0376 \\
\hline VAR (Variância) em Amper & 0.9186 \\
\hline Progresso & \\
\hline NN de Épocas & 1.000 \\
\hline Tempo de Treinamento: & $03: 58: 15$ \\
\hline Erro Quadrático Médio: & 0,000194 \\
\hline
\end{tabular}




\begin{tabular}{|l|l|}
\hline & NET COR 24201 \\
\hline Arquitetura: & 3 camadas neurais \\
\hline Algoritmo de Treinamento: & Levenberg Marquardt \\
\hline Número de Camadas: & 3 \\
\hline Número de Neurônios Por Camada: & $2420 \quad 1$ \\
\hline Funçấo de Ativacấo: & Tangente Hiperbólica \\
\hline EM (Erro Médio) & 0,0081 \\
\hline EM (Erro Médio) em Amper & $3.3981 e^{-004}$ \\
\hline VAR Variância) & 0.0319 \\
\hline VAR Variância) em Amper & 0.07625 \\
\hline Progresso & 1,000 \\
\hline No de Épocas : & $04: 04: 12$ \\
\hline Tempo de Treinamento: & 0,000121 \\
\hline Erro Quadrático Médio: & \\
\hline
\end{tabular}

\begin{tabular}{|c|c|}
\hline \multicolumn{2}{|c|}{ NET COR 25201} \\
\hline Arquitetura: & 3 camadas neurais \\
\hline Algoritmo de Treinamento: & Levenberg_Marquardt \\
\hline Número de Camadas: & 3 \\
\hline Número de Neurônios Por Camada: & 25201 \\
\hline Funçẫo de Ativaçẫo: & Tangente Hiperbólica \\
\hline EM (Erro Médio) & 0,0094 \\
\hline EM (Erro Médio) em Amper & $3.314 \mathrm{e}^{-004}$ \\
\hline VAR Variância) & 0.0311 \\
\hline VAR Variância) em Amper & 8,8571 \\
\hline Progresso & \\
\hline$N^{\circ}$ de Epocas & 1.000 \\
\hline Tempo de Treinamento: & [04:18:58 \\
\hline Erro Quadrático Médio: & $8.23 \mathrm{e}^{-05}$ \\
\hline
\end{tabular}

\begin{tabular}{|c|c|}
\hline \multicolumn{2}{|c|}{ NET COR 32201} \\
\hline Arquitetura: & 3 camadas neurais \\
\hline Algoritmo de Treinamento: & Levenberg Marquardt \\
\hline Número de Camadas: & 3 \\
\hline Número de Neurônios Por Camada: & 32,201 \\
\hline Funçẫo de Ativaçâa: & Tangente Hiperbólica \\
\hline EM (Erro Médio) & 0.0282 \\
\hline EM (Erro Médio) em Amper & 0.0067 \\
\hline VAR (Variância) & 0.6343 \\
\hline VAR (Variância) em Amper & 2,6515 \\
\hline \multicolumn{2}{|l|}{ Progresso } \\
\hline No de Epocas & 1.000 \\
\hline Tempo de Treinamento: & $06: 36: 31$ \\
\hline Erro Quadrático Médio: & 0.00353 \\
\hline
\end{tabular}

